\author{
Universidade de São Paulo \\ Instituto de Física
}

\title{
Um Tratamento Multiescala (QM/MM) das Propriedades Espectroscópicas da Tetraciclina e seus Complexos com Mg e Eu em Água
}

\author{
Lucas Modesto da Costa
}

Orientador: Prof. Sylvio Roberto Accioly Canuto

\section{Banca Examinadora:}

Prof. Sylvio Roberto Accioly Canuto (IF/USP)

Prof. Mario José de Oliveira (IF/USP)

Prof. ${ }^{a}$ Helena Maria Petrilli (IF/USP)

Prof. Eudes Eterno Fileti (ICT/UNIFESP)

Prof. Roberto Rivelino Moreno (IF/UFBA) 
FICHA CATALOGRÁFICA

Preparada pelo Serviço de Biblioteca e Informação do Instituto de Física da Universidade de São Paulo

Costa, Lucas Modesto da

Espectroscopia de alcalinos em hélio líquido São Paulo, 2010.

Dissertação (Mestrado) - Universidade de São Paulo. Instituto de Física. Depto. de Física Geral

Orientador: Prof. Sylvio Roberto Accioly Canuto

Área de Concentração: Física

Unitermos: 1. Física atômica; 2. Espectroscopia;

3. Estrutura da matéria (Química teórica).

USP/IF/SBI-021/2010 
"Nada na vida é para ser temido, apenas compreendido."

Marie Curie 



\section{Agradecimentos}

Agradeço a minha família pelo suporte fornecido desde a infância. Mesmo sendo contra a minha mudança de Goiânia para São Paulo, acabaram apoiando minha decisão. Sou muito grato a eles, pois me forneceram um ambiente estável e seguro.

Ao Prof. Sylvio Canuto pela confiança em mim depositada, devido às discussões sobre os mais variados temas e pela paciência em me orientar.

Aos colaboradores, como a Prof. a Kaline Coutinho no suporte a simulações clássicas e do programa DICE e ao Prof. Pasantra Murkherjee (IACS, India) pelas discussões sobre o tema do trabalho.

À Viviane Morcelle por ser uma namorada compreensiva e apoiadora.

A todos os membros do grupo que me ajudaram muito na hora de realizar as simulações, comentários sobre os resultados, discussões sobre os métodos e nos momentos de descontração.

Ao Prof. Francisco Elias (UFES) por nos conceder funções de bases para o Rb antes da publicação.

Aos amigos, funcionários e demais professores que conheci na USP e que não arriscaria escrever os nomes de todos, pois sempre iria deixar de citar alguém em especial.

À CAPES e à FAPESP (Processo: 08/51807-3) pelo apoio financeiro.

Muito obrigado a todos,

Lucas Modesto da Costa. 



\section{Resumo}

O complexo formado pela molécula de tetraciclina com o íon de magnésio é capaz de impedir a replicação do material genético no ribossomo bacteriano, tornando a tetraciclina um excelente antibiótico. Outra aplicação da tetraciclina, ligada ao íon európio, consiste em estimar a concentração de colesterol no sangue a partir das mudanças do espectro de emissão. Tal técnica apresenta uma resposta imediata e confiável, comparada às técnicas atuais. Em geral, o espectro de absorção e emissão da tetraciclina é bastante sensível aos íons alojados e ao $\mathrm{pH}$ do solvente que o conjunto está imerso. Entretanto, o espectro de absorção teórico em solvente foi obtido com simples modelos contínuos que não consideram interações específicas impostas pelo ambiente no líquido, além da escassez de estudos teóricos para os complexos. Nossa proposta é obter o espectro de absorção eletrônica da tetraciclina e dos complexos formados com os íons $\mathrm{Mg}$ e Eu. Além disso, analisamos as mudanças de intensidade e deslocamentos dos máximos das bandas nos sistemas mencionados, em função do $\mathrm{pH}$ do solvente e do posicionamento do íon, estimando seu correto posicionamento. Realizamos a simulação clássica usando a técnica de Monte Carlo aplicando o potencial de Lennard-Jones mais Coulomb para cada átomo da molécula de tetraciclina e dos complexos em água. O espectro de absorção eletrônica foi obtido a partir da teoria funcional da densidade dependente do tempo considerando diversos modelos para descrição do solvente e do íon. Em geral, obtivemos uma boa descrição qualitativa dos espectros, quando comparado com os resultados experimentais. Os deslocamentos das bandas e mudanças de intensidades foram bem descritos pelos modelos que utilizaram a simulação clássica para gerar as configurações. Porém cada modelo privilegiou uma propriedade de um determinado sistema, tanto para as diferentes formas da tetraciclina quanto para a presença de íons.

Palavras-chaves: tetraciclina, magnésio-tetraciclina, európio-tetraciclina, espectro de absorção, teoria do funcional da densidade dependente do tempo, simulação por Monte Carlo 



\section{Abstract}

The complex formed by the tetracycline molecule with the magnesium ion is able to avoid the replication of the genetic material in bacterial ribosome, making tetracycline an excellent antibiotic. Another application of tetracycline attached to the europium ion, is to evaluate the concentration of cholesterol in the blood from the changes in the emission spectrum. This technique presents an immediate and reliable response compared to current techniques. In general, the absorption and emission spectrum of tetracycline is sensitive to ions coupled and the $\mathrm{pH}$ of the solvent that the complex is immersed. However, the theoretical absorption spectrum in solvent was obtained with simple continuum models that do not consider specific interactions imposed by the liquid environment, and also the lack of theoretical studies for the complexes. Our proposal is to obtain the electronic absorption spectrum of tetracycline and complexes formed with the ions $\mathrm{Mg}$ and $\mathrm{Eu}$. In addition, we analyze the changes in intensity and peak shifts of the bands in the systems mentioned as the function of $\mathrm{pH}$ of the solvent and the position of the ion, and estimating the correct position of the ion. We performed a simulation using the classical Monte Carlo technique applying the Lennard-Jones plus Coulomb potential for each atom of the molecule tetracycline and complexes in water. The electronic absorption spectrum was obtained with the time dependent density functional theory considering several models to describe the solvent and ion. In general, we obtained a good qualitative description of the spectra when compared to the experimental results. The shift of the bands and intensity changes were well described by the used models on classical simulation. However, each model favored one property of the system, both for the different forms of tetracycline and for the presence of ions.

Keywords: tetracycline, magnesium-tetracycline, europium-tetracycline, absorption spectrum, time dependent density functional theory, Monte Carlo simulation 



\section{Lista de Abreviaturas}

$\begin{array}{ll}\text { BO } & \text { Born-Oppenheimer } \\ \text { DFT } & \text { Density Functional Theory } \\ \text { DM } & \text { Dinâmica Molecular } \\ \text { ECP } & \text { Effective Core Potential } \\ \text { EuTC } & \text { (Complexo) Európio-Tetraciclina } \\ \text { H } & \text { HOMO: Highest Occupied Molecular Orbital } \\ \text { HF } & \text { Hartree-Fock } \\ \text { KS } & \text { Kohn-Sham } \\ \text { L } & \text { LUMO: Lowest Unoccupied Molecular Orbital } \\ \text { LJ } & \text { Lennard-Jones } \\ \text { MC } & \text { Monte Carlo } \\ \text { MgTC } & \text { (Complexo) Magnésio-Tetraciclina } \\ \text { MM } & \text { Mecânica Molecular } \\ \text { MQ } & \text { Mecânica Quântica }\end{array}$

OPLS-AA Optimized Potentials for Liquid Simulations All-Atom

SPC/E Extended Simple Pिoint Charge Model

TC Tetraciclina

TDDFT Time Dependent Density Functional Theory 



\section{Sumário}

Lista de Abreviaturas viii

1 Introdução 1

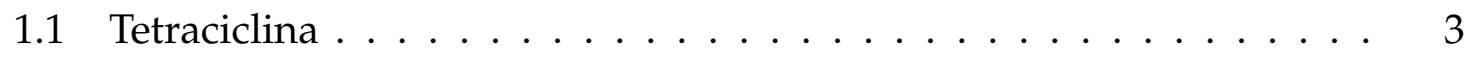

1.2 Complexos MgTC e EuTC . . . . . . . . . . . . . . . 6

1.3 Espectros de Absorção Experimentais . . . . . . . . . . . . . . 9

1.4 Motivação . . . . . . . . . . . . . . . . . . . . . 12

2 Metodologia $\quad 15$

2.1 Simulações Clássicas . . . . . . . . . . . . . . . . . . . 15

2.1.1 Monte Carlo . . . . . . . . . . . . . . . . . . 16

2.1 .2 Potencial de Interação . . . . . . . . . . . . . . . . . . . 18

2.1.3 Ferramentas para Análise de Resultados . . . . . . . . . . . . 19

2.2 Cálculos por Mecânica Quântica . . . . . . . . . . . . . . . 22

2.2.1 Teoria de Perturbação Møller-Plesset de Segunda Ordem (MP2) 24

2.2.2 Teoria do Funcional da Densidade . . . . . . . . . . . 26

2.2.3 Aproximações no Termo $E_{x c}$. . . . . . . . . . . . . . . . . . 29

2.2.4 Teoria do Funcional da Densidade Dependente do Tempo . . 31

2.2.5 Conjuntos de Funções Bases . . . . . . . . . . . . . . . 33

2.3 Tratamento do Íon e Solvente . . . . . . . . . . . . . . . . . . 36

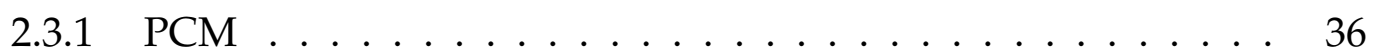

2.3.2 S-QM/MM: ASEC e Explícito . . . . . . . . . . . . 37

3 Espectro de Absorção da TC em Água 
3.1 Espectro de Absorção com PCM . . . . . . . . . . . . . . . . . . . 45

3.2 Simulação Clássica . . . . . . . . . . . . . . . . . . . 55

3.3 Espectro de Absorção com o Modelo ASEC e Solvente Parcialmente Explícito ....................... 60

4 Espectro de Absorção do Complexo MgTC em Água 73

4.1 Espectro de Absorção com PCM . . . . . . . . . . . . . . . . 78

4.2 Simulação Clássica . . . . . . . . . . . . . . . . . 83

4.3 Resultados com o Modelo ASEC . . . . . . . . . . . . . . . . 86

4.4 Resultados com o Modelo de Solvente Parcialmente Explícito . . . . 91

5 Espectro de Absorção do Complexo EuTC em Água 99

5.1 Resultados com PCM . . . . . . . . . . . . . . . . . . . . . . . 101

5.2 Simulação Clássica: Modelo ASEC e Explícito . . . . . . . . . . . . 106

6 Conclusões 115

$\begin{array}{ll}\text { Referências Bibliográficas } & 121\end{array}$ 


\section{Capítulo 1}

\section{Introdução}

A espectroscopia consiste em uma série de técnicas para caracterizar qualquer amostra a partir de sua interação com a radiação eletromagnética. A escala de energia avança sobre todo o espectro eletromagnético, sendo que cada região está associada a um tipo de propriedade específica: vibrações moleculares estão relacionadas com a região do infravermelho, transições eletrônicas estão relacionadas com a região da radiação ultravioleta e visível, sendo responsáveis pelas cores que observamos nos objetos. Considerando uma molécula como a amostra a ser analisada por técnicas espectroscópicas, mudanças em sua estrutura ou no meio que está imersa podem modificar a absorção/emissão eletrônica [1].

Essa sensibilidade das moléculas é amplamente empregada em sondas biológicas, as quais são inseridas em diferentes sistemas emitindo informações sobre a interação com o meio que estão presentes. Contudo, o simples acúmulo de informações não proporciona nenhum conhecimento, sendo necessário um estudo mais apurado da sonda a fim de interpretar as informações emitidas. A utilização de modelos teóricos simplificados é uma boa iniciativa, embora a aplicação de métodos que utilizam a mecânica quântica sejam muito mais adequado para uma descrição rigorosa dos sistemas estudados.

Com o avanço da MQ e dos computadores, a solução de problemas envolvendo 
o cálculo de propriedades de átomos e/ou moléculas evoluiu bastante nas últimas décadas [2]. Os primeiros cálculos de espectroscopia foram realizados para sistemas de poucos átomos usando métodos semi-empíricos na década de 1950, sobretudo o modelo de Hückel. Atualmente é comum a observação de sistemas compostos por dezenas ou até centenas de átomos sendo tratados através de modelos como a Teoria do Funcional da Densidade (DFT) e pós-Hartree-Fock. Tal desenvolvimento levou a uma intensa busca por mais precisão na descrição das diversas propriedades atômicas e moleculares. A inclusão do solvente em tais modelos, demonstrou-se seu refinamento bem sucedido e o qual vem sendo amplamente utilizado [3]. Contudo, aproximações são necessárias quando solvente e soluto são tratados por meio da $M Q$, devido a diversas dificuldades, o que inclui o alto custo computacional. Uma das alternativas é o método sequencial mecânica molecular/mecânica quântica (S-QM/MM) [1], no qual o cálculo de MQ é realizado numa região pequena oriunda da simulação clássica, de forma a permitir a tratamento de propriedades termodinâmicas.

Nossa proposta é estudar a sonda Tetraciclina (TC) e seus complexos com $\mathrm{Mg}^{2+}$ e $\mathrm{Eu}^{3+}$. Serão aplicadas as técnicas utilizadas e desenvolvidas por nosso grupo, a fim de obter o espectro de absorção eletrônica dos sistemas citados, considerando a água como solvente. Este é um problema complexo, pois se trata de uma molécula relativamente grande, que modifica a forma apresentando desprotonação/protonação em função da acidez do meio e possui várias posições ainda indefinidas para hospedagem dos íons.

Esta tese está dividida em 6 capítulos, contendo introdução (1), onde apresentase um panorama geral do trabalho; metodologia (2) com a descrição do procedimento usado para obter o espectro de absorção a partir das configurações. Nos capítulos seguintes apresenta-se resultados obtidos: espectro de absorção da TC em água (3) ; o complexo MgTC em água (4); o complexo EuTC em água (5). No 
capítulo final, conclusões (6), temos a discussão geral dos resultados obtidos.

\subsection{Tetraciclina}

Antibiótico é uma substância capaz de deter um elemento estranho ao organismo, matando-o ou inibindo sua reprodução. Em geral, o elemento estranho configura-se como um conjunto de bactérias ou fungos, causadores de diversos males ao indivíduo infectado. Um dos primeiros exemplos de antibiótico provém do grupo das penicilinas, utilizado desde a Grécia Antiga de forma bastante precária, a partir do bolor do pão. Em 1928, Alexander Fleming [4], ganhador do prêmio Nobel de Medicina em 1945, descobriu o comportamento do fungo por acaso. Desde a Segunda Guerra Mundial a penicilina vem sendo largamente utilizada, inaugurando assim uma revolução na busca por outros antibióticos.

Nos anos de 1950, um importante grupo de antibióticos, chamado de tetraciclinas, foi descoberto por Benjamin Minge Duggar [5] onde as moléculas deste grupo compartilham as seguintes características químicas: quatro anéis de carbono formando uma cadeia linear e diversos grupos funcionais acoplados em certas extremidades da molécula. Este novo grupo possibilitou tratar um número maior de infecções do que o grupo das penicilinas e desencadeou uma corrida por novos antibióticos [6]. Na figura 1.1 e na tabela 1.1 temos diversas moléculas pertencentes a este grupo, mudando apenas algumas terminações. Seu principal membro, a TC, é sintetizada a partir da Clorotetraciclina que por sua vez é obtida da bactéria chamada Streptomyces aureofacians $[7,8]$.

A TC atua sobre bactérias Gram-positivas e Gram-negativas, Clamídias, Riquétsias e até em alguns protozoários, sendo considerado um antibiótico de amplo espectro [4]. A lista de infecções tratadas com este antibiótico é ampla: antraz, infecções por clamídia, acne, pneumonia comunitária, cólera, sífilis, peste negra, 


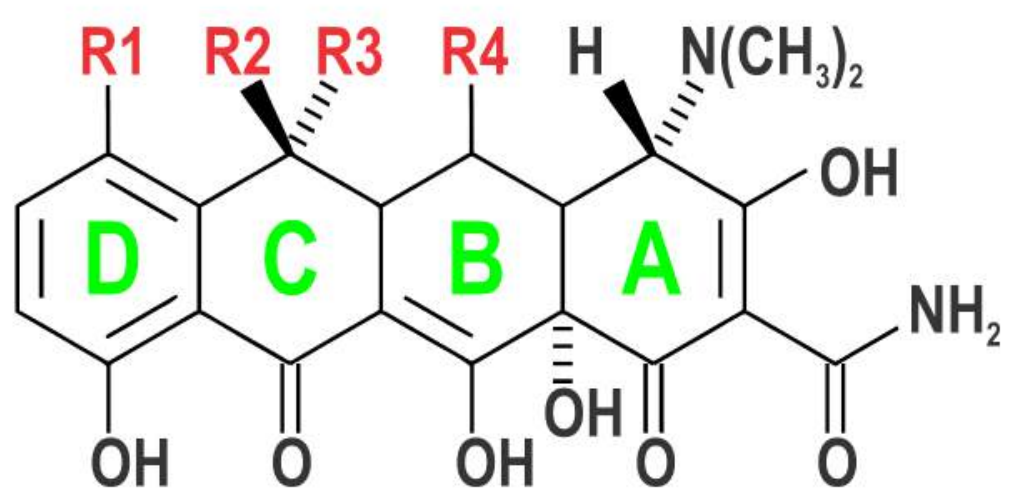

Figura 1.1: Estrutura compartilhada pelas moléculas do grupo das tetraciclinas, formada por quatro anéis de carbono onde os diferentes membros do grupo estão relacionadas às terminações $R 1, R 2$, R3 e $R 4$.

Tabela 1.1: Algumas moléculas do grupo das tetraciclinas [9], onde a diferença entre cada espécie está ligada às terminações $R 1, R 2, R 3$ e $R 4$ da figura 1.1.

\begin{tabular}{lcccc}
\hline \hline & R1 & R2 & R3 & R4 \\
\hline Tetraciclina(TC) & $\mathrm{H}$ & $\mathrm{CH}_{3}$ & $\mathrm{OH}$ & $\mathrm{H}$ \\
Oxitetraciclina & $\mathrm{H}$ & $\mathrm{CH}_{3}$ & $\mathrm{OH}$ & $\mathrm{OH}$ \\
Clorotetraciclina & $\mathrm{Cl}$ & $\mathrm{CH}_{3}$ & $\mathrm{OH}$ & $\mathrm{H}$ \\
Doxiciclina & $\mathrm{H}$ & $\mathrm{CH}_{3}$ & $\mathrm{H}$ & $\mathrm{OH}$ \\
Minociclina & $\mathrm{N}\left(\mathrm{CH}_{3}\right)_{2}$ & $\mathrm{H}$ & $\mathrm{H}$ & $\mathrm{H}$ \\
Metaciclina & $\mathrm{H}$ & $=\mathrm{CH}_{2}$ & $\mathrm{OH}$ \\
Demeclociclina & $\mathrm{Cl}$ & $\mathrm{H}$ & $\mathrm{OH}$ & $\mathrm{H}$ \\
Anidro oxitetraciclina & $\mathrm{H}$ & \multicolumn{2}{c}{$\mathrm{CH}_{3}$} & $\mathrm{OH}$ \\
Anidro tetraciclina & $\mathrm{H}$ & \multicolumn{2}{c}{$\mathrm{CH}_{3}$} & $\mathrm{H}$ \\
\hline \hline
\end{tabular}

malária, rosácea ou doenças de Lyme, etc. [10]. Dentre os perigos de sua administração está o escurecimento dos dentes de crianças, desde a gestação até a segunda dentição se estabilizar, tornando cauteloso o seu uso, como qualquer outro remédio. A TC possui várias aplicações na medicina veterinária, como o controle de infecções e aumento de peso [11]. Para tais indicações, a TC precisa de um complemento, geralmente um metal, a fim de formar um complexo. Entretanto o seu uso, 
muitas vezes descontrolado, é associado à poluição do meio ambiente, em especial no campo.

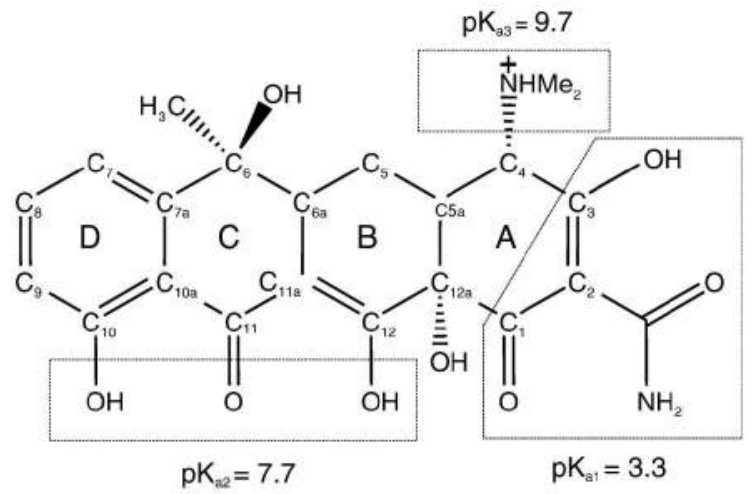

(a) Regiões de desprotonação a partir da forma catiônica da TC e valores de $\mathrm{pK}_{a}$ associados.

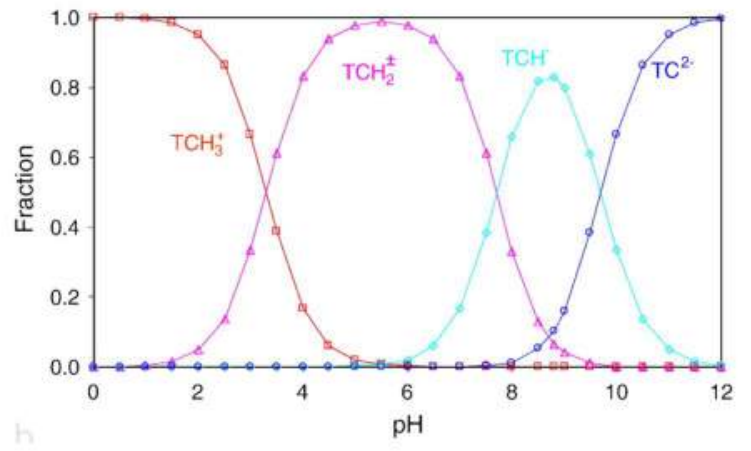

(b) Formas da TC em água em função do $\mathrm{pH}$.

Figura 1.2: A TC é sensível ao solvente e pode sofrer protonações/desprotonações de acordo com o $\mathrm{pH}$ do meio. Figuras 1.2(a) e 1.2(b) obtidas da referência [12].

A presença de diversos grupos ácidos na TC permite a mudança de sua forma em função do $\mathrm{pH}$ do solvente, como pode ser visto na figura 1.2 com os valores de $\mathrm{pK}_{a}$ e a concentração de cada forma da TC em função do $\mathrm{pH}$. Tais mudanças estão ligadas a perda ou ganho de átomos de hidrogênio, procedimentos chamados de desprotonação e protonação, respectivamente. Em ambos os casos ocorre a mudança da carga total da molécula. Para valores de $\mathrm{pH}$ muito baixos, entre 0 e 3 , prevalece a forma catiônica, totalmente protonada $\mathrm{TC}^{+}$. Na primeira desprotonação, associada ao $\mathrm{pK}_{a}=3,3$, ocorre a separação de cargas opostas em regiões diferentes da molécula e temos a forma zwiteriônica, $\mathrm{TC}^{ \pm}$. Esta forma está mais presente no $\mathrm{pH}$ próximo à 5,5. A próxima desprotonação, associada ao $\mathrm{pK}_{a}=7,7$ gera a forma ânion monovalente, $\mathrm{TC}^{-}$, que predomina no $\mathrm{pH} 9,0$. A última forma apresentada na figura 1.2 é a ânion bivalente, $\mathrm{TC}^{2-}$, que inicia no $\mathrm{pK}_{a}=9,7$. 


\subsection{Complexos MgTC e EuTC}

O íon magnésio desempenha um papel vital em vários processos de diversas espécies. Por exemplo, a fotossíntese ocorre pela presença do complexo Mgporfirina [13], da mesma forma que a obtenção de energia via o processo ATP necessita do íon $\mathrm{Mg}$ [14]. A estrutura do material genético se torna mais rígida na presença do íon, sendo que este é necessário para o processo de replicação dentro do ribossoma [15].

O mecanismo de atuação antibacteriana só ocorre quanto o íon $\mathrm{Mg}^{2+}$ se hospeda na TC, formando o complexo MgTC [16]. O primeiro passo ocorre quando o MgTC passa pela parede bacteriana se ligando ao ribossoma, precisamente na subunidade 30S. O ribossoma tem a função de sintetizar proteínas e enzimas, fundamentais para a manutenção da célula, ligando-se ao RNA para fazer a leitura sequencial e gerar a cadeia polipeptídica. Quando o complexo MgTC se acopla com a subunidade 30S, o ribossoma perde a sua função e deixa de copiar RNA, inibindo a síntese proteica $[17,18]$. Este procedimento de formação do complexo da TC, com íon de carga positiva, só é possível pela presença de diversos grupos funcionais na molécula. A TC permite o acoplamento de diversos outros íons, entre eles $\mathrm{Ca}^{2+}$, $\mathrm{Co}^{2+}, \mathrm{Fe}^{2+}, \mathrm{Fe}^{3+}, \mathrm{Al}^{3+}$ e $\mathrm{Eu}^{3+}$.

Vários lantanídeos são utilizados como sondas biológicas e o Európio não foge à regra $[19,20]$. Entretanto, o íon isolado não consegue apresentar uma emissão forte, quando comparado a outras sondas. A fim de sanar essa dificuldade é necessário que o Eu se acople a um ligante, por exemplo a molécula de TC, formando o complexo EuTC [21]. Esse aumento da emissão é bem descrito pelo efeito antena, onde a TC absorve muito mais a luz do que o Eu isolado. Após algumas transições internas e decaimentos, parte restante da energia inicial é transferida diretamente ao íon, aumentando fortemente a emissão eletrônica. O diagrama de Jablonski do 
EuTC ilustra bem o efeito antena e está mostrado na figura 1.3.

TC - Estado Excitado

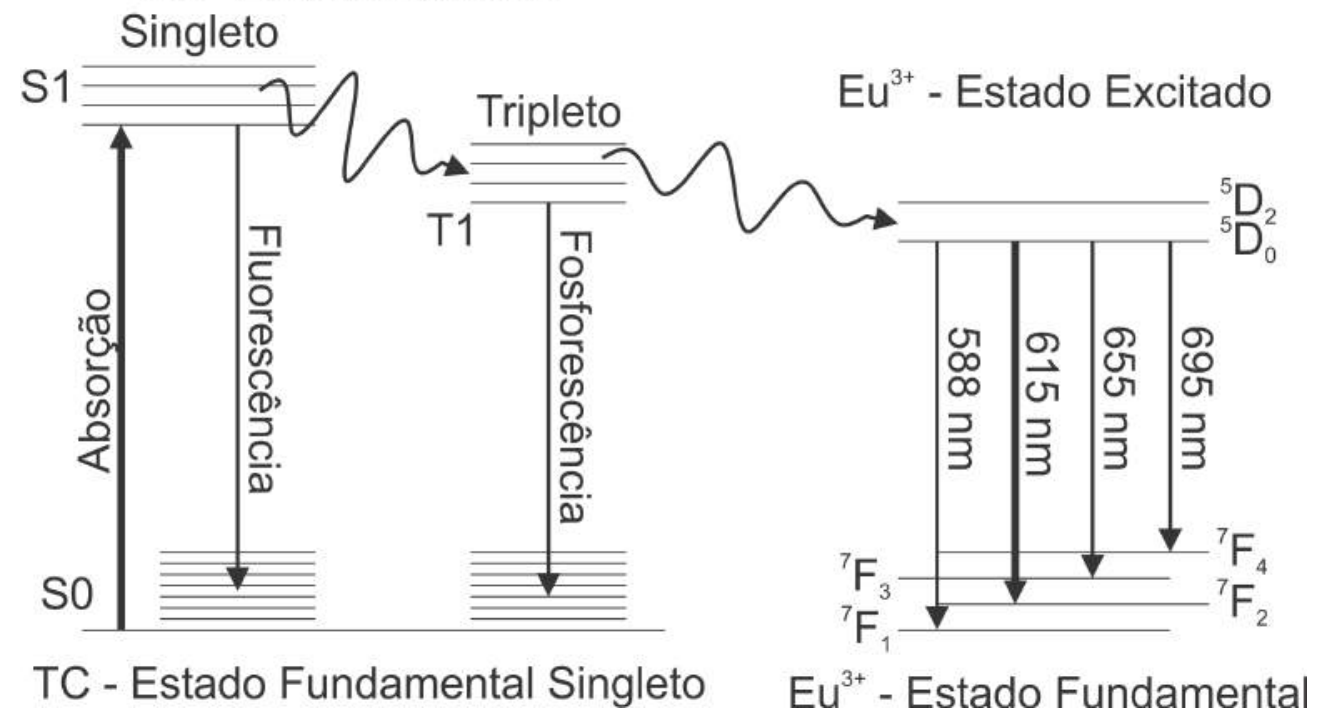

Figura 1.3: Efeito antena a partir do diagrama de Jablonski. O ligante, TC, absorve luz e transfere essa energia para os estados excitados singletos (S1). Parte desta energia retorna ao estado fundamental (S0) por um processo chamado de fluorescência enquanto que outra parte é transferida para os estados excitados tripletos (T1). Neste ponto, uma parte da energia presente em T1 decai para o estado fundamental por um processo chamado fosforescência enquanto que o restante da energia é transferido para os estados excitados quintetos do $\mathrm{Eu}^{3+}$. A emissão mais intensa é no comprimento de onda de $615 \mathrm{~nm}\left({ }^{5} \mathrm{D}_{0} \rightarrow{ }^{7} \mathrm{~F}_{2}\right)$, na cor vermelha, que decai para o estado septeto fundamental do íon.

As características que tornam o EuTC uma sonda biológica promissora são o longo tempo de decaimento, grande deslocamento Stokes e a alta intensidade da fluorescência [19,22-24]. A sonda EuTC vem sendo usada para determinar a quantidade do colesterol no sangue [25]: uma amostra do sangue é coletada do paciente, onde se adiciona uma quantidade de EuTC, na qual a intensidade da luz emitida, a partir de um aparato que excita a amostra, definirá a concentração do colesterol "ruim" (LDL). Esse procedimento oferece uma resposta imediata comparada às atuais técnicas de aferimento de colesterol em um indivíduo.

Geralmente, o íon Eu possui carga $+3 e$ e quando complexado com a molécula de TC muda os valores de $\mathrm{pK}_{a}$. Observando a tabela 1.2, a mudança da forma zwiteriônica para forma ânion monovalente da TC em água apresentava $\mathrm{pK}_{a}$ igual 
a 7,7 alterando-se para o valor 3,8 quando o Eu é complexado [26]. Essas mudanças no $\mathrm{pK}_{a}$ tornam necessário o estudo de mais uma forma da TC, a ânion trivalente $\left(\mathrm{TC}^{3-}\right)$, que tem sua incidência maior complexada ao Eu e com $\mathrm{pH}$ acima de 7,33. Nesta situação, o complexo fica com sua carga total nula.

Tabela 1.2: Novos valores do $\mathrm{pK}_{a}$ quando o Eu está complexado com a molécula TC [26].

\begin{tabular}{cc}
\hline \hline Reação & $\mathrm{pK}_{a}$ \\
\hline$\left(\mathrm{Eu}^{3+}\left(\mathrm{TC}^{ \pm}\right)\right)^{3+} \rightleftharpoons\left(\mathrm{Eu}^{3+}\left(\mathrm{TC}^{-}\right)\right)^{2+}+\mathrm{H}^{+}$ & $3,77 \pm 0,07$ \\
$\left(\mathrm{Eu}^{3+}\left(\mathrm{TC}^{-}\right)\right)^{2+} \rightleftharpoons\left(\mathrm{Eu}^{3+}\left(\mathrm{TC}^{2-}\right)\right)^{+}+\mathrm{H}^{+}$ & $5,05 \pm 0,02$ \\
$\left(\mathrm{Eu}^{3+}\left(\mathrm{TC}^{2-}\right)\right)^{+} \rightleftharpoons\left(\mathrm{Eu}^{3+} \mathrm{TC}^{3-}\right)^{0}+\mathrm{H}^{+}$ & $7,33 \pm 0,04$ \\
\hline \hline
\end{tabular}

A distribuição eletrônica de cada íon apresenta informações interessantes. O $\mathrm{Mg}$, possui 12 elétrons em sua forma neutra, mas o íon $\mathrm{Mg}^{2+}$ perde os elétrons do orbital 3s, mantendo os orbitais da camada 2 totalmente preenchidos. Já o Eu, que possui 63 elétrons, perde os elétrons do orbital 6 s e mais um elétron do $4 f$, ficando este com 6 elétrons para 7 orbitais. Ocorre uma blindagem no $\mathrm{Eu}^{3+}$, pois os elétrons envolvidos na emissão do Eu ficam localizados internamente em relação ao orbitais $5 s$ e $5 p$. O diagrama abaixo ilustra tal situação.

$$
\mathrm{Mg}^{2+}=\left\{\begin{array}{c}
1 s^{2} \\
2 s^{2} \quad 2 p^{6} \\
3 s^{0}
\end{array}\right.
$$

$$
\mathrm{Eu}^{3+}=\left\{\begin{array}{llll}
1 s^{2} & & & \\
2 s^{2} & 2 p^{6} & & \\
3 s^{2} & 3 p^{6} & 3 d^{10} & \\
4 s^{2} & 4 p^{6} & 4 d^{10} & 4 f^{6} \\
5 s^{2} & 5 p^{6} & & \\
6 s^{0} & & &
\end{array}\right.
$$




\subsection{Espectros de Absorção Experimentais}

Para validar nossos resultados faremos comparações com diversos dados experimentais obtidos ao longo de quase 60 anos por diferentes grupos de pesquisa. Tal observação começa em 1953 por Boothe et al. que encontraram os máximos em $220 \mathrm{~nm}(\log \epsilon=4,11), 268 \mathrm{~nm}(\log \epsilon=4,26)$ e $355 \mathrm{~nm}(\log \epsilon=4,12)$ para a molécula de TC em 0,1 $\mathrm{N}$ de ácido clorídrico [27]. Outro trabalho, do mesmo ano, desenvolvido por Conover et al. [28] apresenta os máximos do espectro de absorção $U V$-Vis da TC em $268 \mathrm{~nm}(\log \epsilon=4,27)$ e $363 \mathrm{~nm}(\log \epsilon=4,14)$ em solução de 0.01 $M$ de ácido clorídrico em metanol e $246 \mathrm{~nm}(\log \epsilon=4,24)$ e $372 \mathrm{~nm}(\log \epsilon=4,20$ ) em solução de 0,01 M de hidróxido de sódio em metanol. Em 1986, Takahashi e colaboradores [29] obtiveram o espectro da TC em água em duas situações: com $\mathrm{pH}$ 6,5, foram encontrados máximos em $270 \mathrm{~nm}$ e $360 \mathrm{~nm}$ enquanto no $\mathrm{pH}$ 8,5, os máximos estão localizados em $270 \mathrm{~nm}$ e $370 \mathrm{~nm}$.

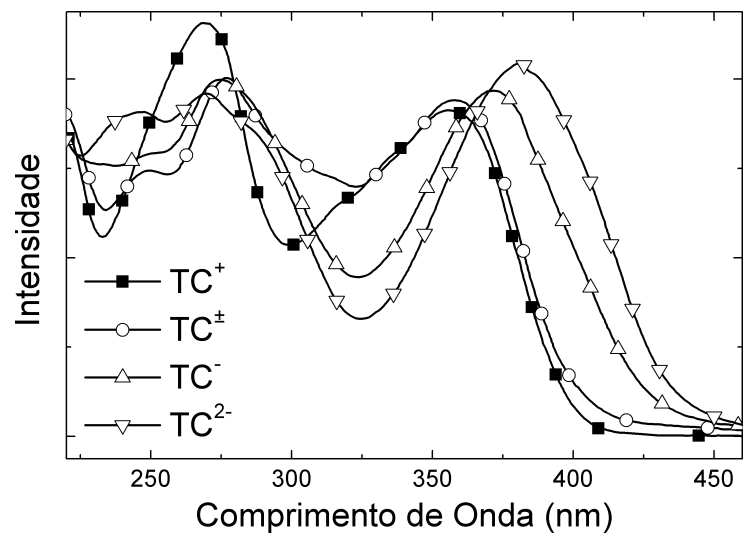

(a) Resultados por Schneider et al. [30].

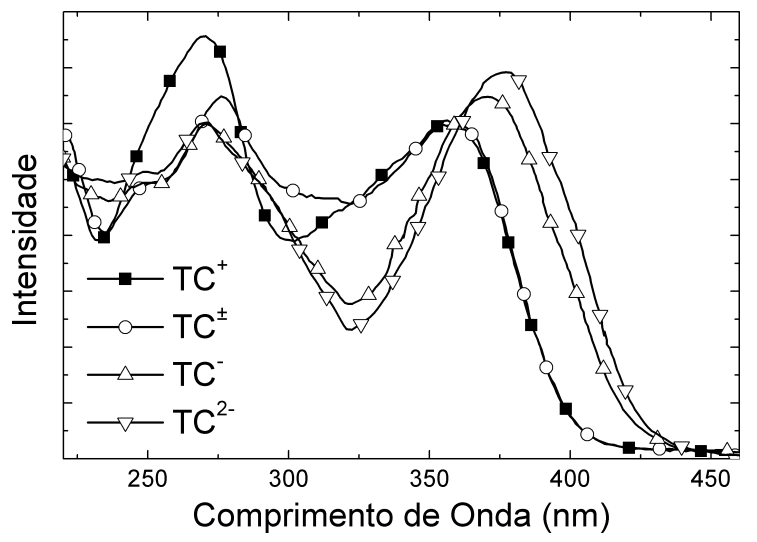

(b) Resultados por Amat et al. [31].

Figura 1.4: Espectro de absorção experimental da TC em água, considerando as diferentes formas do soluto.

Como pode ser visto nos resultados experimentais acima, mudanças no $\mathrm{pH}$ modificam o espectro de absorção causando, principalmente, deslocamentos nos máximos de absorção UV-Vis. Tais diferenças são importantes no decorrer desta 
tese, visto que trabalharemos com algumas formas da TC que são mais abundantes em determinados valores de $\mathrm{pH}$ conforme pode ser observado na figura 1.2. Schmeider e colaboradores [30] estudaram, em 2003, os efeitos da mudança do pH no espectro de absorção onde a TC foi colocada em solução aquosa usando as quatro formas citadas anteriormente, exposto na figura 1.4(a). Um estudo recente por Amat e colaboradores [31] foi efetuado com os mesmos compostos da TC e também pode ser visto na mesma figura 1.4(b). Em ambas as situações, os resultados concordam de forma muito satisfatória tanto no valor do máximo de absorção quanto na intensidade.

Ambos os casos da figura 1.4 apresentam o mesmo comportamento: a banda de absorção na região de $350 \mathrm{~nm}$ sofre deslocamentos para o vermelho com o aumento do $\mathrm{pH}$ do solvente. Estes máximos ocorrem, de acordo com Schneider e colaboradores [30], em $355 \mathrm{~nm}$ para $\mathrm{TC}^{+}, 358 \mathrm{~nm}$ para $\mathrm{TC}^{ \pm}, 372 \mathrm{~nm}$ para $\mathrm{TC}^{+}$e 381 $\mathrm{nm}$ para $\mathrm{TC}^{2+}$. Para a segunda banda, os máximos ficam em torno de $270 \mathrm{~nm}$. Amat e colaboradores [31] localizaram os máximos em $357 \mathrm{~nm}$ para $\mathrm{TC}^{+}$, $358 \mathrm{~nm}$ para $\mathrm{TC}^{ \pm}, 371 \mathrm{~nm}$ para $\mathrm{TC}^{+}$e $376 \mathrm{~nm}$ para $\mathrm{TC}^{2+}$.

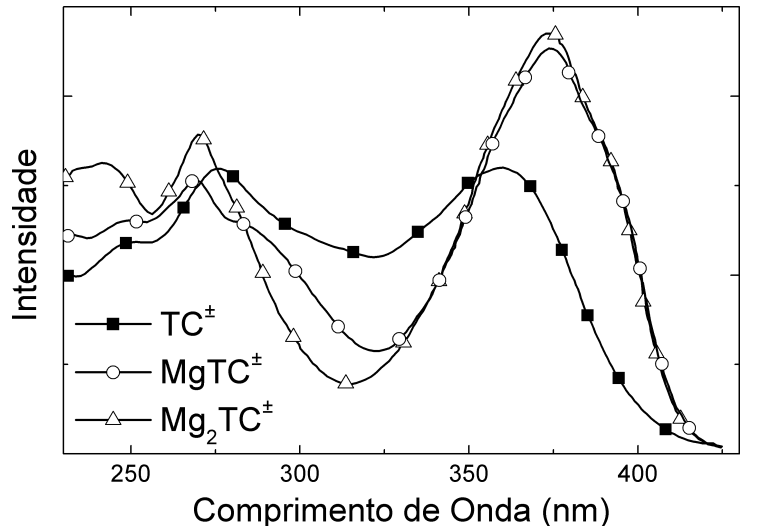

(a) Solvente com $\mathrm{pH}$ igual a 7.0, onde prevalece a forma $\mathrm{TC}^{ \pm}$ligada ao $\mathrm{Mg}^{2+}$.

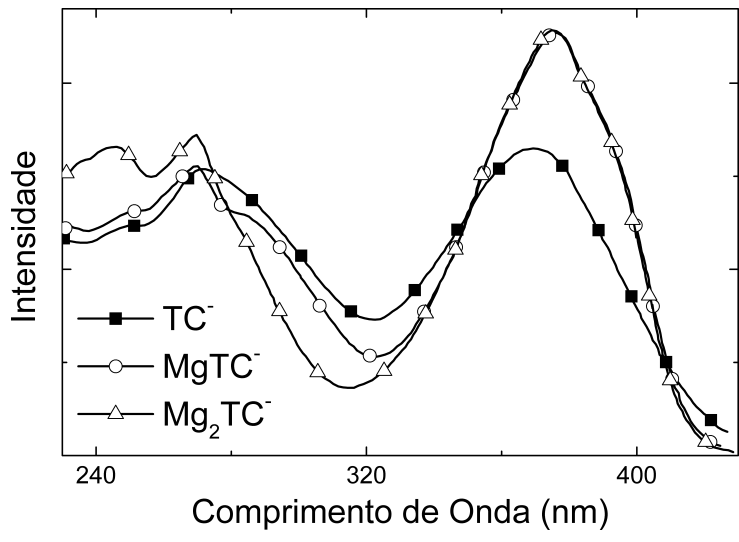

(b) Solvente com $\mathrm{pH}$ igual a 8.5 , onde prevalece a forma $\mathrm{TC}^{-}$ligada ao $\mathrm{Mg}^{2+}$.

Figura 1.5: Espectro de absorção experimental da TC livre e complexada com $\mathrm{Mg}^{2+}$ em água [30].

A presença de íons modifica de modo relevante o espectro de absorção eletrônica, 
como podemos observar no complexo MgTC, presente na figura 1.5 e na tabela 1.3. Analisando os resultados de Schneider e colaboradores [30], no pH igual a 7,0, onde está mais presente a forma $\mathrm{TC}^{ \pm}$, o íon desloca o máximo da banda do espectro experimental de 360 para $374 \mathrm{~nm}$, não havendo diferença com a presença de um ou dois íons $\mathrm{Mg}$ complexados. O mesmo comportamento foi observado para $\mathrm{pH}$ igual a 8,5, onde predomina a forma $\mathrm{TC}^{-}$. Para o máximo na região de $270 \mathrm{~nm}$, cada espectro apresenta um máximo específico, mas todos estão em torno do mesmo ponto. Para os resultados do complexo $\mathrm{Mg}_{2} \mathrm{TC}$ ocorre um aumento da intensidade da banda em $240 \mathrm{~nm}$ em ambos os casos.

Tabela 1.3: Máximos do espectro de absorção do Mg complexado à molécula TC com as posições e os valores da intensidade. Resultados obtidos por Carlotti e colaboradores [32].

\begin{tabular}{lccc}
\hline \hline Estrutura & $\mathrm{pH}$ & $\lambda_{\text {abs }} / \mathrm{nm}$ & $\epsilon^{a} / \mathrm{M}^{-1} \mathrm{~cm}^{-1}$ \\
\hline $\mathrm{TC}^{ \pm}$ & & $275 ; 355$ & $13300 ; 12700$ \\
$\mathrm{Mg}^{2+} \mathrm{TC}^{ \pm}$ & 5,0 & $240 ; 270 ; 365$ & $12900 ; 14500 ; 14600$ \\
$\left(\mathrm{Mg}^{2+}\right)_{2} \mathrm{TC}^{ \pm}$ & & $235 ; 270 ; 375$ & $18500 ; 19500 ; 19300$ \\
\hline $\mathrm{TC}^{-}$ & & $270 ; 370$ & $14000 ; 15300$ \\
$\mathrm{Mg}^{2+} \mathrm{TC}^{-}$ & 9,0 & $270 ; 375$ & $13800 ; 19300$ \\
$\left(\mathrm{Mg}^{2+}\right)_{2} \mathrm{TC}^{-}$ & $240 ; 270 ; 375$ & $25100 ; 22700 ; 27800$ \\
\hline \hline
\end{tabular}

Carlotti e colaboradores [32] sintetizaram diversos resultados dos complexos formados com as moléculas do grupo das tetraciclinas, contudo analisaremos apenas os casos para pH 5,0 e 9,0 (tabela 1.3). O surgimento de uma terceira banda na região de $240 \mathrm{~nm}$ e o deslocamento para o vermelho da banda de $370 \mathrm{~nm}$ são as principais mudanças com a presença do íon $\mathrm{Mg}$. Para a forma $\mathrm{TC}^{-}$, a presença do íon desloca a banda inicialmente em $370 \mathrm{~nm}$ para $375 \mathrm{~nm}$. Essa diferença cresce para $10 \mathrm{~nm}$ quando analisamos a forma $\mathrm{TC}^{ \pm}$.

Observamos que a presença do íon $\mathrm{Mg}$ provoca pequenas mudanças no es- 


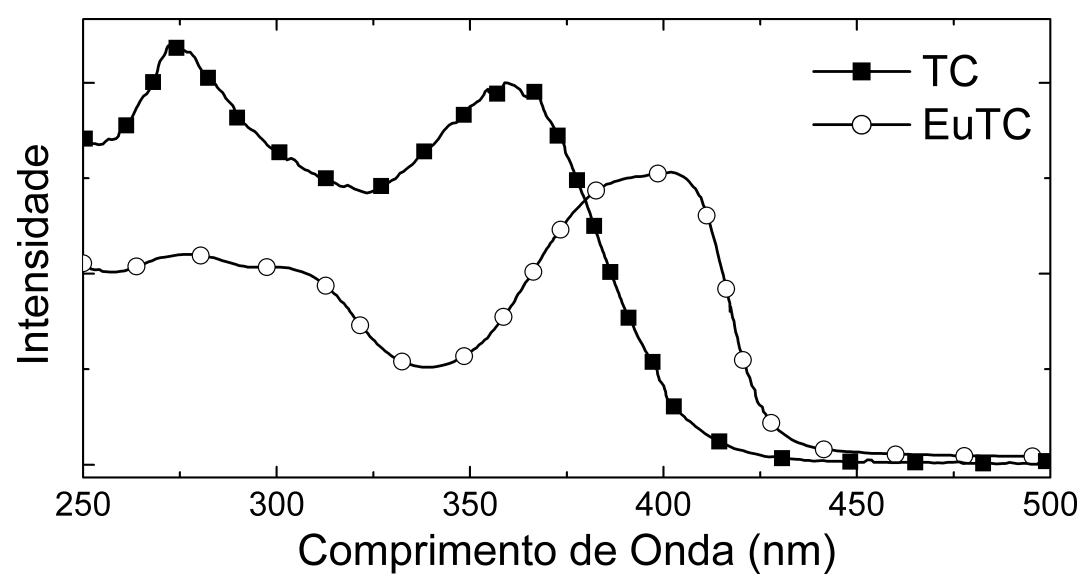

Figura 1.6: Comparativo do espectro de absorção da TC e do complexo EuTC em solução aquosa [25].

pectro de absorção eletrônica. O íon Eu provoca mudanças maiores (figura 1.6) forçando o máximo do espectro de absorção sair de $370 \mathrm{~nm}$ da TC em solução aquosa para 395 nm quando o complexo EuTC é formado na mesma solução, causando um deslocamento de $25 \mathrm{~nm}$. Outro fato interessante é que a banda na região de $270 \mathrm{~nm}$ diminuiu de intensidade, comparado à banda em $370 \mathrm{~nm}$. Este resultado foi obtido por Courrol e Liu [21,25], com interesse de criar uma sonda para estimar a quantidade de colesterol no sangue.

Todos estes resultados experimentais mostram deslocamentos nas posições dos máximos e na intensidade do espectro de absorção eletrônica. Há também mudanças nas intensidades das bandas observadas. Em todos os casos, o solvente utilizado foi a água e a mudança de pH foi forçada com a adição de cátions ou ânions na solução.

\subsection{Motivação}

O método S-QM/MM (Sequential quantum mechanics/molecular mechanics) vem sendo usado com relativo sucesso por nosso grupo de pesquisa [33-38]. Cálculos do espectro de absorção eletrônica considerando o solvente, seja na forma explícita ou 
como campo eletrostático ou a mistura das duas representações, têm apresentado tendências e valores que concordam muito bem com os resultados experimentais. O escopo deste trabalho é aplicar as técnicas utilizadas e desenvolvidas por nosso grupo, a fim de obter o espectro de absorção eletrônica da TC e dos complexos MgTC e EuTC e em todos os casos consideraremos a água como solvente. A molécula de TC possui, em sua forma neutra, a seguinte composição: $\mathrm{C}_{22} \mathrm{H}_{24} \mathrm{O}_{8} \mathrm{~N}_{2}$. Além das dificuldades impostas pelo tamanho e as várias formas da TC, devemos nos preocupar aonde os íons irão se hospedar na molécula. Os íons $\mathrm{Mg}$ e Eu possuem cargas $+2 e \mathrm{e}+3 e$, respectivamente, o que facilita o compartilhamento do conhecimento adquirido de um sistema para outro.

No caso $\mathrm{Eu}^{3+}$, os conjuntos de bases que descrevem o íon com todos os 60 elétrons apresentam dificuldades para convergir o cálculo do campo auto consistente. Um detalhamento acurado para os elétrons mais internos não é fundamental comparado aos elétrons mais externos para a realização do cálculo da absorção eletrônica, permitindo a utilização de potenciais que substituem os elétrons do caroço. Essa aproximação, que também apresenta correções relativísticas necessárias, é chamada de ECP (Effective Core Potential ou potencial efetivo de caroço), reduzindo o custo computacional sem prejudicar marcantemente a qualidade do resultado.

Para obter o espectro de absorção será necessário recorrer a cálculos de Mecânica Quântica (MQ). Neste ponto, faz-se necessário balancear o recurso computacional e a qualidade dos resultados adquiridos e para este fim vamos utilizar a DFT. De forma geral, a DFT situa-se entre os métodos semi-empíricos e os métodos pós-HF mais acurados, proibitivos para o tamanho do sistema estudado, considerando nosso aparato computacional. Estes cálculos de MQ serão aplicados em configurações do sistema soluto-solvente, provenientes de simulações clássicas a partir do método de Monte Carlo. Os espectros de absorção calculados para a TC e complexos MgTC e EuTC serão comparados com espectros de absorção experimentais a fim de avaliar 
a qualidade do procedimento S-MQ/MM, observando as posições dos máximos das bandas e os valores dos deslocamentos. Vamos considerar o solvente formado apenas por moléculas de água, pois a quantidade de cátions ou ânions, para os valores de $\mathrm{pH}$ trabalhados, são desprezíveis comparados ao número de moléculas de água em nossas simulações. 


\section{Capítulo 2}

\section{Metodologia}

Neste capítulo, apresentaremos brevemente as teorias associadas às ferramentas empregadas nesta tese para a obtenção dos resultados, tanto para a simulação clássica como para os cálculos de MQ. Diversas referências possuem os temas apresentados de forma mais aprofundada como livros [1,3,39-43] e artigos de revisão [44-47].

\subsection{Simulações Clássicas}

A qualidade do resultado de qualquer propriedade a ser calculada depende do nível de aproximação utilizado. No decorrer deste texto observamos que várias aproximações foram empregadas, as quais conduziram a uma boa descrição do sistema estudado. A primeira aproximação é desprezar, no primeiro momento, a presença dos elétrons. Assim o sistema molecular é composto apenas por sítios que representam as massas atômicas, com massas e cargas específicas. Tal etapa é nominada de simulações clássicas e tem por finalidade gerar as configurações que incluem as posições de todos os sítios, isto é, as posições dos átomos respeitando as flutuações características pelo sistema líquido.

Ao se trabalhar com simulações clássicas de moléculas, dois métodos são 
muitos utilizados: Dinâmica Molecular (DM) e Monte Carlo (MC). O método de DM consiste em resolver as equações de Newton de todos os átomos do sistema para intervalos de tempo discretizados. Usando um potencial conhecido, as forças que atuam em cada átomo são calculadas, e assim, é possível obter posições e velocidades de todos os átomos em tempos seguintes. Estudar propriedades que dependam da evolução temporal do sistema é mais factível com a DM por ser processo determinístico.

Já no método de MC, não usamos informações das velocidades de cada um dos átomos e de propriedades que dependam da evolução temporal. Em síntese, a simulação via MC é um processo no qual as propriedades de interesse são obtidas com médias de diferentes estados configuracionais acessíveis no equilíbrio termodinâmico. A ideia do MC nasceu no século XVIII, porém foi com o surgimento de grandes computadores e do interesse em obter previsões sobre fissão nuclear para fabricação da bomba atômica no período da Segunda Guerra Mundial [39], que a metodologia ganhou um grande impulso.

\subsubsection{Monte Carlo}

Na simulação $\mathrm{MC}^{1}$, as propriedades de interesse são obtidas com médias configuracionais do sistema em equilíbrio termodinâmico. Sendo um processo estocástico, a evolução temporal do sistema não é considerada, perdendo informações interessantes, como a velocidade de cada partícula em função do tempo de simulação. Como estamos interessados em obter médias configuracionais para cálculos de MQ posteriores, dados sobre as velocidades dos átomos ou moléculas não são necessários.

Inicialmente são colocados $N$ moléculas de forma aleatória numa caixa cúbica de volume não fixo, respeitando a densidade inicial. Para evitar problemas com as

\footnotetext{
${ }^{1}$ Para realização das simulações clássicas, usamos o programa DICE [48].
} 
bordas da caixa de simulação, são geradas caixas em todas as direções, todas imagens da caixa central. Caso um átomo saia da caixa central, o mesmo será substituído por um átomo da caixa imagem da face oposta e desse modo são reproduzidas as condições de contorno, nas quais será mantido o número de átomos na caixa central. Além do número de átomos, são mantidas constantes a pressão $p$ e a temperatura $T$. Ao fixar essas constantes, estamos trabalhando num ensemble $N p T$, ou ensemble isotérmico-isobárico. Neste caso, a variação da energia será dada por

$$
\Delta \mathcal{H}=\Delta U+p \Delta V
$$

onde $\Delta V$ é a variação do volume de forma que $\Delta V=V_{y^{\prime}}-V_{y}$.

Partindo de uma configuração inicial, são geradas configurações de um sistema modificando a posição de uma partícula por um movimento aleatório, tanto em módulo como em direção, de valor máximo igual a um $\delta_{m x}$. Este valor não pode ser muito grande, pois poderia causar a sobreposição de dois átomos. Em contrapartida, não pode ser demasiadamente pequeno, pois não estaríamos gerando flutuações suficientes para considerar novos estados, além de um alto grau de correlação das configurações. Normalmente, o valor de $\delta_{m x}$ é modificado automaticamente a fim de manter um valor de aceitação de novas configurações igual a 50\%.

A cada configuração estará associado um valor de energia e assim a um peso de Boltzmann, a partir do equilíbrio. Sendo um processo markoviano [49], a probabilidade de um evento ocorrer depende apenas do evento anterior. Da mecânica estatística, a probabilidade associada a um estado é

$$
P_{o}(y)=\frac{1}{Z} \exp \left[-\frac{\mathcal{H}(y)}{K_{B} T}+N \ln \left(\frac{V_{y^{\prime}}}{V_{y}}\right)\right],
$$

onde $Z$ é a função de partição e o último termo decorre do reescalonamento de todas as posições atômicas após a mudança de volume. No equilíbrio, a condição de balanço detalhado impõe que a probabilidade de mudar de configuração $\left(y \rightarrow y^{\prime}\right)$ 
não depende do tempo [49]. Aplicando-se esta condição na equação mestra, a transição será dada por

$$
\frac{w\left(y \rightarrow y^{\prime}\right)}{w\left(y^{\prime} \rightarrow y\right)}=\exp \left(-\frac{\Delta \mathcal{H}}{K_{B} T}\right)
$$

onde $\Delta \mathcal{H}$ é a diferença de energia entre as configurações $\mathcal{H}\left(y^{\prime}\right)-\mathcal{H}(y)$.

Usando o algoritmo de Metropolis, a probabilidade de uma configuração mudar de y para y' é dada por

$$
w\left(y \rightarrow y^{\prime}\right)=\left\{\begin{array}{cl}
\exp \left(-\frac{\Delta \mathcal{H}}{K_{B} T}\right) & \text { se } \quad \Delta \mathcal{H}>0 \\
1 & \text { se } \Delta \mathcal{H} \leq 0
\end{array}\right.
$$

Na prática, sempre aceitamos a nova configuração quando $\Delta \mathcal{H} \leq 0$. No outro caso, selecionamos um número aleatório $\zeta$. Se $\zeta$ for menor que $w\left(y \rightarrow y^{\prime}\right)$, a nova configuração será aceita. Assim, um passo de MC é definido como a tentativa de mudar a posição de todos os átomos do sistema².

\subsubsection{Potencial de Interação}

Um dos pontos mais importantes nas simulações clássicas é a descrição da interação entre os átomos. A escolha do campo de força, e subsequentemente um potencial, leva em conta vários fatores como as propriedades de interesse a serem obtidas, o custo computacional e o nível de aproximações. Desta forma, os potenciais podem ser construídos a partir de parâmetros experimentais ou cálculos ab initio ou ainda uma mistura dos dois. Como cálculos $a b$ initio são bastante demorados para serem repetidos em todos os ciclos de MC, o uso de potenciais parametrizados é de grande utilidade para simulações clássicas.

A interação pode conter termos de potencial de dois corpos, potencial de três corpos, e assim sucessivamente. Entretanto, a contribuição energética de potenciais

\footnotetext{
${ }^{2}$ Mais detalhes sobre o método MC e do algoritmo de Metropolis podem ser encontrados nas referências $[39,50]$.
} 
de três ou mais corpos é muito pequena comparada ao potencial de dois corpos para sistemas líquidos [50]. Para maior eficiência, o potencial é calculado até um limite de distância, chamado raio de corte $\left(r_{c u t}\right)$. Correções no valor da energia potencial podem ser adicionadas, a fim de compensar a parte eliminada da interação de dois corpos com distância acima do $r_{c u t}$.

O potencial utilizado adiciona o potencial de Coulomb ao de Lennard-Jones (LJ), processo frequentemente utilizado com êxito na descrição de diversos sistemas líquidos [51,52]. A parte atrativa a grandes distâncias do potencial de LJ é dada pelo termo $r_{i j}^{-6}$, proveniente da interação de van der Waals. A parte repulsiva do potencial é dado pelo termo $r_{i j}^{-12}$ em curtas distâncias. As interações eletrostáticas entre pares de átomos é dado pelo potencial de Coulomb. A forma do potencial é

$$
U\left(r_{i j}\right)=4 \epsilon_{i j}\left[\left(\frac{\sigma_{i j}}{r_{i j}}\right)^{12}-\left(\frac{\sigma_{i j}}{r_{i j}}\right)^{6}\right]+\frac{q_{i} q_{j}}{r_{i j}},
$$

onde $r_{i j}$ é a distância entre os átomos $i$ e $j$. Os termos $\epsilon_{i j}$ e $\sigma_{i j}$ são obtidos, neste trabalho, a partir das médias geométricas dos parâmetros de cada átomo $\epsilon_{i}, \epsilon_{j}, \sigma_{i} \mathrm{e}$ $\sigma_{j} . q_{i}$ e $q_{j}$ são as cargas em cada átomo.

Os parâmetros do potencial são, neste trabalho, baseados no campo de força OPLS (Optimized Potentials for Liquid Simulations) [53]. Este potencial é largamente utilizado com sucesso na descrição de sistemas líquidos [54-57] e gasosos, sendo que os parâmetros são focados de modo a representar corretamente propriedades experimentais do líquido. Para a água, usamos o modelo SPC/E, que possui definidas a geometria, as cargas e os parâmetros $\sigma$ e $\epsilon$.

\subsubsection{Ferramentas para Análise de Resultados}

\section{Função de Distribuição Radial}

A função de distribuição radial $(G(r))$ ou função de correlação de pares, fornece 
a distribuição média de átomos em função da distância radial $r$, a partir de uma origem pré-estabelecida. Através de $G(r)$ podemos obter, por exemplo, o fator de estrutura estático. Experimentalmente, a função $G(r)$ pode ser medida através de experimentos de difração de raios $X$ e nêutrons, e espalhamento de raios $X$. Nos sólidos tal difração permite-nos obter os picos de Bragg, devido ao arranjo regular e ordenado dos átomos. No entanto, nos fluidos a difração é difusa, mostrando a não existência de um arranjo ordenado de longo alcance.

Para obter a $G(r)$, deve-se integrar a função de distribuição radial sobre a posição de todos os átomos, exceto os dois $\vec{r}_{1}$ e $\vec{r}_{2}$, nos quais está sendo calculada a $G(r)$ [39]. Com o fator de normalização adequado, temos a seguinte expressão

$$
G\left(\vec{r}_{1}, \vec{r}_{2}\right)=\frac{N(N-1)}{\rho^{2} Z_{N V T}} \int d \vec{r}_{3} d \vec{r}_{4} d \vec{r}_{5} \ldots d \vec{r}_{N} e^{-\beta U\left(\vec{r}_{1}, \vec{r}_{2}, \vec{r}_{3} \ldots \vec{r}_{N}\right)}
$$

onde $Z_{N V T}$ é a integral configuracional no ensemble canônico. Uma forma equivalente muito usada no cálculo de $G(r)$, por simulação computacional, é tomar a média no ensemble sobre os pares

$$
G(r)=\rho^{2}\left\langle\sum_{i} \sum_{j \neq i} \delta\left(\vec{r}_{i}\right) \delta\left(\vec{r}_{j}-\vec{r}\right)\right\rangle=\frac{V}{N^{2}}\left\langle\sum_{i} \sum_{j \neq i} \delta\left(\vec{r}-\vec{r}_{i j}\right)\right\rangle .
$$

Sendo $\rho$ a densidade, o número médio de átomos do solvente a uma distância $r$ do centro de massa do soluto pode ser expressa por

$$
N(r)=4 \pi \rho \int_{0}^{r} r^{2} G(r) d r
$$

Obtendo o valor de $N(r)$ para o primeiro vale da $G(r)$ teremos o número de átomos na primeira camada de solvatação. O mesmo processo pode ser realizado para os picos subsequentes, obtendo-se as camadas de solvatação correspondentes.

Uma modificação na $g(r)$ permite alterar a origem da função para passear por todos os átomos do soluto, acumulando as médias da quantidade de solvente em função da distância. Essa função é chamada de mínima distância [58] e permite 
calcular de forma precisa o número de moléculas de solvente em torno do soluto, tornando muito útil em solutos grandes.

\section{Auto-Correlação da Energia}

A simulação clássica irá gerar um grande número de configurações, da ordem de $10^{5}$ neste trabalho. Obter a média de uma determinada propriedade com cálculos de MQ usando esse número de configurações seria um exagero computacional, pois a média sobre centenas de configurações sucessivas geradas por MC é igual à média sobre algumas configurações estatisticamente descorrelacionadas [59]. Consequentemente, é suficiente selecionar poucas configurações descorrelacionadas e realizar cálculos de MQ sobre essas configurações.

A correlação estatística das configurações do sistema foi obtida através da função de auto-correlação da energia, a qual é definida com a seguinte expressão

$$
C(i)=\frac{\left\langle\delta E_{n} \delta E_{i+n}\right\rangle}{\left\langle\delta E^{2}\right\rangle}=\frac{\sum_{n}\left(E_{n}-\langle E\rangle\right)\left(E_{n+i}-\langle E\rangle\right)}{\sum_{n}\left(E_{n}-\langle E\rangle\right)^{2}} .
$$

Realizada a simulação clássica, obtemos o valor da função de auto-correlação em função da quantidade de passos de simulação $(C(i))$. Uma forma de analisar o nível de correlação estatística das configurações geradas na simulação é usar o intervalo de correlação, que é uma propriedade da simulação, no qual se estima um valor de passos de $\mathrm{MC}$, onde as configurações estarão em média descorrelacionadas. Como $C(i)$ obedece a um decaimento exponencial, para processos markovianos [50,60], é possível ajustar os dados da correlação com uma função exponencial. Em nossos trabalhos temos usado o decaimento duplo,

$$
C(i)=a_{1} e^{-i / t_{1}}+a_{2} e^{-i / t_{2}}
$$

Somente com um número infinito de configurações teremos o valor $\operatorname{de} C(n)$ tendendo a zero, ou seja, configurações descorrelacionadas. Integrando a expressão acima 
obtém-se o intervalo de correlação

$$
\tau=\int_{0}^{\infty} C_{f}(i) d i=a_{1} t_{1}+a_{2} t_{2} .
$$

Em geral, trabalhamos com $2 \tau$. Espera-se que $C(2 \tau)$ seja menor ou igual a 0,15 , pois assim consideramos que as configurações estão descorrelacionadas.

\subsection{Cálculos por Mecânica Quântica}

Até o momento, consideramos os átomos sendo objetos pontuais carregados interagindo pelo potencial de Lennard-Jones e Coulomb. Porém, para o cálculo do espectro de absorção e outras propriedades ópticas/eletrônicas, é necessário considerar explicitamente os elétrons do sistema estudado. Para este cálculo, é preciso usar a Mecânica Quântica (MQ) aplicada nas configurações obtidas pela simulação clássica e resolver a equação de Schrödinger,

$$
\mathcal{H} \Psi(\vec{r}, \vec{R})=E \Psi(\vec{r}, \vec{R})
$$

Sabemos que existe solução analítica para a equação de Schrödinger no caso do átomo de Hidrogênio, porém para outros átomos e moléculas são necessárias algumas aproximações. O operador hamiltoniano não-relativístico, em unidades atômicas, para o sistema de $N$ átomos e $n$ elétrons é

$$
\mathcal{H}=-\sum_{i=1}^{n} \frac{1}{2} \nabla_{i}^{2}-\sum_{A=1}^{N} \frac{1}{2 M_{A}} \nabla_{A}^{2}-\sum_{i=1}^{n} \sum_{A=1}^{N} \frac{Z_{A}}{r_{i A}}+\frac{1}{2} \sum_{i, j}^{n} \frac{1}{r_{i j}}+\frac{1}{2} \sum_{A, B}^{N} \frac{Z_{A} Z_{B}}{r_{A B}}
$$

onde os índices minúsculos e maiúsculos referenciam os elétrons e os núcleos, respectivamente. Algumas aproximações são necessárias para resolver a equação de Schrödinger independente do tempo desses sistemas moleculares. Considerando a aproximação adiabática [43],

$$
\Psi(\vec{r}, \vec{R})=\psi_{i}(\vec{r} ; \vec{R}) \chi_{i}(\vec{R}),
$$


e assim, os elétrons movimentam-se sobre os núcleos fixos. Com o desacoplamento dos movimentos dos núcleos e dos elétrons, podemos tratar os espectros eletrônico e nuclear de forma separada. Esta separação é conhecida como aproximação de Born-Oppenheimer (BO) [41].

O operador hamiltoniano eletrônico é

$$
\mathcal{H}_{\text {ele }}=\left[-\frac{1}{2} \sum_{i=1}^{n} \nabla_{i}^{2}-\sum_{i=1}^{n} \sum_{A=1}^{N} \frac{Z_{A}}{r_{i A}}+\sum_{i>j}^{n} \frac{1}{r_{i j}}\right] .
$$

Para um sistema de $n$ elétrons, a função de onda eletrônica anti-simétrica de camada fechada, satisfazendo o princípio de exclusão de Pauli, é aproximada por um determinante de Slater

$$
\psi=\frac{1}{\sqrt{n !}}\left|\begin{array}{cccc}
\varphi_{1}(1) & \varphi_{1}(2) & \ldots & \varphi_{1}(n) \\
\varphi_{2}(1) & \varphi_{2}(2) & \ldots & \varphi_{2}(n) \\
\vdots & \vdots & \ddots & \vdots \\
\varphi_{n}(1) & \varphi_{n}(2) & \ldots & \varphi_{n}(n)
\end{array}\right|
$$

onde $\varphi_{n}(n)$ são os spin-orbitais. A energia eletrônica usando a aproximação de BO será dada por [40-43]:

$$
E_{\text {ele }}=\sum_{i=1}^{n}\left\langle\varphi_{i}\left|\left[\frac{-\nabla^{2}}{2}-\sum_{A=1}^{N} \frac{Z_{A}}{\left|r_{A}-r_{i}\right|}\right]\right| \varphi_{i}\right\rangle+\frac{1}{2} \sum_{i, j}^{n}\left[\left\langle\varphi_{j}\left|\mathcal{J}_{i}\right| \varphi_{j}\right\rangle-\left\langle\varphi_{j}\left|\mathcal{K}_{i}\right| \varphi_{j}\right\rangle\right],
$$

onde temos os operadores de um elétron, $\mathcal{J}$ e $\mathcal{K}$. A representação da repulsão clássica entre dois elétrons é dada pelo operador de Coulomb,

$$
\mathcal{J}_{i}\left|\varphi_{j}(2)\right\rangle=\left\langle\varphi_{i}(1)\left|\frac{1}{\left|r_{1}-r_{2}\right|}\right| \varphi_{i}(1)\right\rangle\left|\varphi_{j}(2)\right\rangle .
$$

O outro termo, que não possui análogo clássico, é o operador de troca relacionado com antissimetria da função de onda,

$$
\mathcal{K}_{i}\left|\varphi_{j}(2)\right\rangle=\left\langle\varphi_{i}(1)\left|\frac{1}{\left|r_{1}-r_{2}\right|}\right| \varphi_{j}(1)\right\rangle\left|\varphi_{i}(2)\right\rangle .
$$


Este procedimento é básico para o desenvolvimento do método Hartree-Fock (HF). A função de onda inicial consiste em diversas aproximações que serão vistas na seção 2.2.5. Sendo um processo variacional, a energia é minimizada modificando a função de onda.

No método HF, o elétron interage com o potencial gerado pelos núcleos e com o campo médio gerado pela distribuição dos outros elétrons, perdendo informações sobre a correlação eletrônica. A energia exata de um determinado problema é diferente da energia fornecida pelo método $\mathrm{HF}$, e a parte que está faltando é chamada de energia de correlação. Este termo é muito importante, quando queremos uma maior precisão em processos físicos e químicos e para obtê-lo é necessário recorrer a outros métodos, que considerem a correlação do sistema.

\subsubsection{Teoria de Perturbação Møller-Plesset de Segunda Ordem (MP2)}

Devido à falta de uma descrição da energia de correlação com o método HF, procedimentos variacionais e pertubativos devem ser empregados. Uma alternativa é a teoria de perturbação de muitos corpos com a separação de Møller-Plesset (MBPT), que se baseia na teoria de Rayleigh-Schrödinger, na qual um termo perturbativo $\lambda \mathcal{V}$ é adicionado ao hamiltoniano que permite resolver $\mathcal{H}_{0}$,

$$
\begin{aligned}
& \mathcal{H}=\mathcal{H}_{0}+\lambda \mathcal{V}, \\
& \mathcal{H}_{0} \psi_{i}=E_{i} \psi_{i}, \quad i=0,1,2, \ldots, \infty, \\
& \mathcal{H} \Psi_{i}=W_{i} \Psi_{i}, \quad i=0,1,2, \ldots, \infty
\end{aligned}
$$

considerando que $\mathcal{H}_{0}$ possui solução extada da equação de Schrödinger. Supondo a influência do termo pertubativo seja pequena, podemos expandir a função de onda $(\Psi)$ e a energia conforme

$$
\begin{aligned}
& \Psi_{n}=\Psi_{n}^{(0)}+\lambda \Psi_{n}^{(1)}+\lambda^{2} \Psi_{n}^{(2)}+\ldots+\lambda^{k} \Psi_{n}^{(k)}+\ldots \\
& W_{n}=W_{n}^{(0)}+\lambda W_{n}^{(1)}+\lambda^{2} W_{n}^{(2)}+\ldots+\lambda^{k} W_{n}^{(k)}+\ldots
\end{aligned}
$$


Para $\lambda=0$, temos as soluções do sistema não perturbado: $\Psi_{n}^{(0)}=\psi_{n}$ e $W_{n}^{(0)}=E_{n}$. As correções perturbativas de k-ésima ordem para a função de onda e para a energia do n-ésimo estado perturbado é dado por $\Psi_{n}^{(k)}$ e $W_{n}^{(k)}$, respectivamente. Trabalharemos com correções até segunda ordem (MP2).

Observando os termos de correções de primeira e segunda ordem para a energia e a função de onda

$$
\begin{gathered}
W_{n}^{(1)}=\left\langle\Psi_{n}^{(0)}|\mathcal{V}| \Psi_{n}^{(0)}\right\rangle, \\
W_{n}^{(2)}=\left\langle\Psi_{n}^{(0)}|\mathcal{V}| \Psi_{n}^{(1)}\right\rangle=\sum_{m \neq n} \frac{\left|\left\langle\Psi_{m}^{(0)}|\mathcal{V}| \Psi_{n}^{(0)}\right\rangle\right|^{2}}{W_{n}^{(0)}-W_{m}^{(0)}}, \\
\left|\Psi_{n}^{(1)}\right\rangle=\sum_{m \neq n} \frac{\left\langle\Psi_{m}^{(0)}|\mathcal{V}| \Psi_{n}^{(0)}\right\rangle}{W_{n}^{(0)}-W_{m}^{(0)}}\left|\Psi_{m}^{(0)}\right\rangle,
\end{gathered}
$$

Usando a partição de Møller-Plesset associado ao Teorema de Brillouin encontramos que a energia corrigida até a primeira ordem é a própria energia obtida pelo método Hartree-Fock $[40,43]$. Considerando que a pertubação $\mathcal{V}$ possui operadores de uma e duas partículas, a correção de segunda ordem da energia do estado fundamental exige apenas a inclusão de excitações duplas,

$$
W_{0}^{(2)}=\sum_{\substack{a<b \\ r<s}} \frac{\left|\left\langle\Psi_{0}|\mathcal{V}| \Psi_{a b}^{r s}\right\rangle\right|^{2}}{W_{0}^{(0)}-W_{\substack{a b \\ r s}}^{(0)}},
$$

onde o estado de referência de Hartree-Fock é $\Psi_{0}$ associado à energia $W_{0}$. A $\Psi_{a b}^{r s}$ é a função de onda de duas partículas excitadas para $r s$, inicialmente em $a b$. A partição de Møller-Plesset define

$$
W_{0}^{(0)}=\sum_{i} \varepsilon_{i}
$$

a soma sobre todos os orbitais moleculares ocupados no estado fundamental $\Psi_{0}$ e

$$
W_{\substack{a b \\ r s}}^{(0)}=\sum_{n} \varepsilon_{n}
$$


a mesma soma, com exceção de $\varepsilon_{a}$ e $\varepsilon_{b}$ que são substituídos por $\varepsilon_{r}$ e $\varepsilon_{s}$. Chegamos no termo de correção de segunda ordem, que se anula quando $a=b$ ou $r=s$, conhecida como forma de Brandow

$$
W_{0}^{(2)}=\frac{1}{4} \sum_{\substack{a b \\ r s}} \frac{\left|\left\langle\Psi_{0}|\mathcal{V}| \Psi_{a b}^{r s}\right\rangle\right|^{2}}{\varepsilon_{a}+\varepsilon_{b}-\varepsilon_{r}-\varepsilon_{s}} .
$$

Por não partir de um princípio variacional, a energia total obtida por este método pode ser menor do que o valor exato. Para a função de onda, este procedimento se torna complicado: é necessário incluir excitações simples, duplas, triplas e quadruplas, além de não satisfazer o teorema de Hellman-Feynman. Aplicamos aqui pertubação até segunda ordem, porém é permitido pertubações de ordem superiores. Entretanto não há garantias da convergência ao aumentar a ordem da pertubação [61]. O método MP2 escala com $N^{5}$, onde $N$ é o número de funções bases, proporcionando excelentes resultados para geometria de moléculas orgânicas. Veremos que o próximo método utilizado, DFT, possui um custo menor, $N^{4}$, sendo utilizado para obter as transições eletrônicas.

\subsubsection{Teoria do Funcional da Densidade}

Devido ao seu baixo custo computacional e boa concordância com valores experimentais, a Teoria do Funcional da Densidade (DFT, do inglês Density Functional Theory) é um dos métodos de química quântica de maior utilização atualmente. Com a DFT é possível estudar sistemas com centenas de átomos e milhares de elétrons, que são muito difíceis de tratar com métodos como o MP2.

No final da década de 1920, o modelo para o estudo de metais propunha que os elétrons de valência não estariam confinados aos átomos de origem na rede metálica. Ao definir que todo o sistema era coberto por um gás de elétrons [62], apenas uma função é capaz de dar uma ideia de distribuição dos elétrons do sistema: a função 
densidade $\rho(\mathbf{r})$. A formulação foi desenvolvida por Thomas, Fermi e Dirac em 1930 e fornecia bons resultados, apesar das limitações geradas com as aproximações. Este trabalho é considerado um pré-desenvolvimento da DFT.

Partindo do operador hamiltoniano eletrônico (ver eq. 2.15), Slater (1951) propôs uma simplificação ao método $\mathrm{HF}$, a partir de uma análise no termo de troca [63], o qual depende exclusivamente de uma densidade de carga de exchange. Hohenberg e Kohn, em 1964, formularam os teoremas fundamentais para a utilização da DFT [64]. O primeiro teorema retrata o potencial externo $v(\mathbf{r})$ como um funcional único da densidade eletrônica, $\rho(\mathbf{r})$, do estado fundamental. Nesse ponto aparece a unicidade da função de onda do estado fundamental com a densidade eletrônica, pois conhecendo $\rho(\mathbf{r})$ saberemos o potencial $v(\mathbf{r})$, e teremos acesso a todas as informações do estado fundamental do sistema.

O segundo teorema diz que a energia do estado fundamental, $E_{0}$, é mínima para a densidade exata, $\rho_{0}(\mathbf{r})$, e qualquer densidade eletrônica, $\rho^{\prime}$, diferente da exata, fornecerá um valor maior ou igual à energia exata $E_{0}$, isto é $E\left[\rho^{\prime}\right] \geq E_{o}=E\left[\rho_{0}\right]$. Este teorema nada mais é do que o teorema variacional para a energia como funcional da densidade eletrônica.

A energia, como funcional da densidade, é gerada a partir do hamiltoniano eletrônico (eq. 2.15). A proposta é escrever a energia como

$$
E_{D F T}[\rho]=T[\rho]+U_{n e}[\rho]+U_{e e}[\rho]
$$

separando em termos como energia cinética $(T[\rho])$, interação coulombiana núcleoelétron $\left(U_{n e}[\rho]\right)$ e a interação elétron-elétron $\left(U_{e e}[\rho]\right)$. Porém, é difícil escrever alguns termos da eq. 2.29 como um funcional de $\rho$. Uma forma de expressar a energia é colocar todos os termos, que não podem ser escritos como funcional de $\rho$, no termo de energia de troca e correlação $E_{x c}[\rho]$. Dessa forma, a energia é escrita como

$$
E_{D F T}[\rho]=T_{S}[\rho]+J[\rho]+U_{n e}[\rho]+E_{x c}[\rho]
$$


onde o termo de troca e correlação é

$$
E_{x c}[\rho]=\left(T[\rho]-T_{S}[\rho]\right)+\left(U_{e e}[\rho]-J[\rho]\right)
$$

Observa-se na eq. 2.31, a contribuição da correlação da energia cinética no primeiro parênteses, enquanto no segundo está presente o termo de troca e a correlação da energia potencial.

A interação coulombiana núcleo-elétron é

$$
U_{n e}[\rho]=\sum_{a} \int \frac{Z_{a} \rho(\mathbf{r})}{\left|\mathbf{R}_{a} \mathbf{r}\right|} d \mathbf{r} .
$$

Na interação elétron-elétron, o termo $U_{e e}[\rho]$ foi separado em um termo coulombiano $J[\rho]$ e outro de troca $K[\rho]$. O termo $K[\rho]$ está presente em $E_{x c}[\rho]$ e o coulombiano é

$$
J[\rho]=\frac{1}{2} \iint \frac{\rho(\mathbf{r}) \rho\left(\mathbf{r}^{\prime}\right)}{\left|\mathbf{r}-\mathbf{r}^{\prime}\right|} d \mathbf{r} d \mathbf{r}^{\prime}
$$

Uma contribuição muito importante de Kohn e Sham (KS), em 1965, é a mudança de um sistema de muitos corpos interativos em diversos sistemas de um corpo não-interativos [40,41,43], onde a densidade eletrônica será a mesma tanto no sistema interagente quanto no sistema não interagente. Usando o mesmo procedimento do método HF para obter a função de onda anti-simétrica $\phi_{i}$, chegamos nas equações de KS

$$
\mathcal{H}_{K S} \phi_{i}=\left[-\frac{1}{2} \nabla^{2}+v^{K S}[\rho]\right] \phi_{i}=\varepsilon_{i} \phi_{i}
$$

Como a expressão para a energia cinética $T_{S}$ não é escrita como dependente diretamente da densidade

$$
T_{S}[\rho]=T_{S}\left[\left\{\varphi_{i}\right\}\right]=-\frac{1}{2} \sum_{i} \int \varphi_{i}^{*} \nabla^{2} \varphi_{i} d^{3} r
$$

esta irá depender do conjunto de orbitais $\mathrm{KS}\left(\varphi_{i}\right)$, que são as soluções para o hamiltoniano $\mathcal{H}_{K S}$. O funcional da densidade eletrônica também depende do mesmo 
conjunto de orbitais $\varphi_{i}$, tal que

$$
\rho(\mathbf{r})=\sum_{i} \int \varphi_{i}^{*} \varphi_{i} d^{3} r
$$

Com a minimização da energia obtemos o potencial efetivo KS, presente também no hamiltoniano $\mathcal{H}_{K S}$, que é dado por

$$
v^{K S}[\rho]=v(\mathbf{r})+\int \frac{n\left(\mathbf{r}^{\prime}\right)}{\left|\mathbf{r}-\mathbf{r}^{\prime}\right|} d \mathbf{r}^{\prime}+\frac{\delta E_{x c}[\rho]}{\delta \rho(r)}(\mathbf{r}) .
$$

Desta forma, o próximo passo é trabalhar com o termo de troca e correlação $E_{x c}[\rho]$, tema da seção 2.2.3.

\subsubsection{Aproximações no Termo $E_{x c}$}

\section{Funcionais Não-Híbridos}

Para a aplicação da DFT, em problemas de estrutura eletrônica, ainda é necessário aproximar o funcional de troca e correlação. Aqui chegamos num ponto de grande importância para o uso da DFT, uma vez que seus resultados dependem fortemente da aproximação utilizada. A primeira a ser comentada, e também a mais simples, é a Local Density Approximation (LDA), na qual se assume que, localmente, a função densidade $(\rho(\mathbf{r}))$ é aquela de um gás de elétrons uniforme sofrendo pouca mudança próximo ao ponto $r$. A energia de troca é dada por

$$
E_{x}^{L D A}[\rho]=-C_{x} \int \rho^{4 / 3}(\mathbf{r}) d \mathbf{r} .
$$

No caso mais geral, onde as densidades de spins $\alpha$ e $\beta$ são diferentes, usa-se o LSDA (Local Spin Density Approximation) e a energia de troca é

$$
E_{x}^{L S D A}[\rho]=-2^{1 / 3} C_{x} \int\left[\rho_{\alpha}^{4 / 3}+\rho_{\beta}^{4 / 3}\right] d \mathbf{r} .
$$

Uma forma mais elaborada de se aproximar a energia de troca e correlação é chamada GGA (Generalized Gradient Approximation), na qual a distribuição nãouniforme da densidade é mais bem tratada, pois além da densidade eletrônica, os 
funcionais do tipo GGA trabalham com o gradiente da densidade. Um exemplo de funcional do tipo GGA é o PW86, introduzido por Perdew e Wang [65], que formularam o termo de troca, como

$$
\varepsilon_{x}^{P W 86}=\varepsilon_{x}^{L D A}\left[1+a x^{2}+b x^{4}+c x^{6}\right]^{1 / 15}
$$

onde $a, b$ e $c$ são constantes e $x$ é $\left(\frac{|\nabla \rho|}{\rho^{4 / 3}}\right)$. A proposta de Becker [66] (B88) consiste em adicionar um termo para correção do comportamento assimptótico da densidade eletrônica. Sua expressão é

$$
\varepsilon_{x}^{B 88}=\varepsilon_{x}^{L D A}-\beta \rho^{1 / 3} \frac{x^{2}}{1+6 \beta x \sinh ^{-1} x},
$$

onde $\beta$ é definido por um ajuste em dados atômicos e $x$ é $\left(\frac{|\nabla \rho|}{\rho^{4 / 3}}\right)$. Para a energia de correlação, existe o termo VWN [67], onde mais detalhes podem ser vistos na referência [40]. Uma modificação neste termo foi proposta por Perdew e Wang, chamado de PW91 [68]. Apesar de tratar a densidade eletrônica localmente de forma homogênea, essas aproximações funcionam muito bem para átomos, moléculas e sólidos. Outro termo de correlação, bastante conhecido na literatura e desenvolvido por Lee, Yang e Parr (LYP) $[69,70]$, possui

$$
\begin{aligned}
\varepsilon_{c}^{L Y P}= & -a \frac{\gamma}{1+f \rho^{1 / 3}}-a b \frac{\gamma e^{c \rho^{1 / 3}}}{9\left(1+d \rho^{1 / 3}\right) \rho^{8 / 3}}\left[1 8 ( 2 ^ { 2 / 3 } ) C _ { F } \left(\rho_{\alpha}^{8 / 3}+\right.\right. \\
& \left.\left.\rho_{\beta}^{8 / 3}\right)-18 \rho t_{W}+\rho_{\alpha}\left(2 t_{W}^{\alpha}+\nabla^{2} \rho_{\alpha}\right)+\rho_{\beta}\left(2 t_{W}^{\beta}+\nabla^{2} \rho_{\beta}\right)\right] \\
\gamma= & 2\left[1-\frac{\rho_{\alpha}^{2}+\rho_{\beta}^{2}}{\rho^{2}}\right] \\
t_{W}^{\sigma}= & \frac{1}{8}\left(\frac{\left|\nabla \rho_{\sigma}\right|^{2}}{\rho_{\sigma}}-\nabla^{2} \rho_{\sigma}\right),
\end{aligned}
$$

onde $a, b, c$ e $f$ são parâmetros calculados em um ajuste em um conjunto de moléculas [40]. 


\section{Funcionais Híbridos}

Funcionais híbridos são funcionais que misturam termos de diferentes aproximações, tanto para troca quanto para correlação. Definidos os termos a serem usados, o valor da contribuição de cada um será obtido por um ajuste com alguns resultados experimentais conhecidos. O funcional híbrido B3LYP usa a aproximação LYP na correlação não local. Para a correlação local é usado a aproximação VWN. A contribuição de cada termo que compõe a energia de troca é de $20 \%$ do HF e 80\% de Dirac-Slater. Para a energia de troca não local, o funcional B3LYP utiliza uma porcentagem da aproximação B88. De todos os modernos funcionais, o B3LYP é o mais famoso e sua expressão com os termos de correlação e troca é dada por

$$
E_{x c}^{B 3 L Y P}=0,2 * X_{H F}+0,8 * X_{L S D A}+0,72 * X_{N L}^{B 88}+0,19 * C_{L}^{V W N}+0,81 * C_{N L}^{L Y P} .
$$

\subsubsection{Teoria do Funcional da Densidade Dependente do Tempo}

A DFT funciona muito bem para o estudo do estado fundamental de um sistema molecular. A excitação eletrônica é um procedimento caro que requer a inclusão da correlação eletrônica. Metódos como MR-CI (Multi Reference Configutaion Interaction) e CASPT2 (Complete Active Space Pertubation Theory) são referências para a excitação eletrônica devido à alta precisão, entretanto são aplicados a simples sistemas da ordem de poucas dezenas de átomos devido ao custo computacional. Um modo barato de estudar a energia de excitação é o uso da TDDFT (Time-Dependent Density Functional Theory). O método foi proposto por Runge e Gross (RG) em 1984 [71] e é considerado uma aplicação da solução da equação de Schrödinger dependente do tempo para as equações de KS,

$$
i \frac{\partial}{\partial t} \phi_{i}(\mathbf{r}, t)=\mathcal{H}_{K S} \phi_{i}(\mathbf{r}, t)=\left[-\frac{1}{2} \nabla^{2}+v^{K S}[\rho]\right] \phi_{i}(\mathbf{r}, t) .
$$

A partir da TDDFT é possível calcular funções de resposta dependentes da frequência, como a polarizabilidade dinâmica [72] e energias de excitação que é o nosso 
interesse.

A dependência temporal é aplicada nos teoremas de Hohenberg-Kohn, e assim o potencial externo dependente do tempo $v(\mathbf{r}, t)$ continua funcional único da densidade eletrônica, $\rho(\mathbf{r}, t)$, mantendo a correspondência única entre eles. O potencial efetivo de uma partícula $v^{K S}$ (eq. 2.44) é escrito como

$$
v^{K S}[\rho(\mathbf{r}, t)]=v(\mathbf{r}, t)+\int \frac{n\left(\mathbf{r}^{\prime}, t\right)}{\left|\mathbf{r}-\mathbf{r}^{\prime}\right|} d \mathbf{r}^{\prime}+\frac{\delta A_{x c}[\rho]}{\delta \rho(r)}(\mathbf{r}, t) .
$$

O funcional de troca e correlação dependente do tempo, chamado também de ação, $A_{x c}[\rho]$ é o análogo do $E_{x c}[\rho]$ no caso estático. Da mesma forma que o $E_{x c}[\rho]$ é desconhecido na DFT, o funcional da ação também é desconhecido, ficando a cargo da aproximação utilizada,

$$
A_{x c}[\rho]=\int E_{x c}[\rho] d t
$$

O sucesso da TDDFT está associado à Teoria da Resposta Linear [73], na qual é aplicada uma perturbação na densidade eletrônica do estado fundamental. Essa perturbação está relacionada com as mudanças que ocorrem no potencial efetivo $v^{K S}[74]$. A função resposta é

$$
\chi\left(\mathbf{r}, \mathbf{r}^{\prime} ; \omega\right)=\lim _{\eta \rightarrow 0^{+}} \sum_{m}\left[\frac{\langle 0|\rho(\mathbf{r})| m\rangle\left\langle m\left|\rho\left(\mathbf{r}^{\prime}\right)\right| 0\right\rangle}{w-\left(E_{m}-E_{0}\right)+i \eta}-\frac{\left\langle 0\left|\rho\left(\mathbf{r}^{\prime}\right)\right| m\right\rangle\langle m|\rho(\mathbf{r})| 0\rangle}{w+\left(E_{m}-E_{0}\right)+i \eta}\right],
$$

onde os estados $|m\rangle$ são relacionados com a energia $E_{m}$ e $\eta$ é um valor infinitesimal positivo. A energia de excitação corresponde ao polo da equação $2.47, w+\left(E_{m}-E_{0}\right)$ enquanto que a integral da função de densidade eletrônica, numerador da equação 2.47, estão diretamente ligadas à força de oscilador da excitação para o estado $m$ : $|0\rangle \rightarrow|m\rangle$. 


\subsubsection{Conjuntos de Funções Bases}

Vários métodos de química teórica usam conjuntos de bases atômicas ou apenas bases ${ }^{3}$ para o estudo de moléculas e átomos. Essas bases são funções matemáticas que descrevem os orbitais, como aqueles usados na formulação de HF, provenientes do uso da equação de Schrödinger para resolver o problema eletrônico. Os conjuntos de bases devem apresentar resultados compatíveis com os valores experimentais, contendo uma quantidade expressiva de funções para uma melhor descrição do átomo em questão, porém o número de funções não pode ser demasiadamente grande, ao ponto de prejudicar a eficiência computacional.

Um dos primeiros conjuntos de bases utilizados foi baseado nas funções hidrogenóides, já que são as soluções analíticas para os sistemas mono-eletrônicos. Neste caso tem-se um potencial na forma $V=-Z / r$. Porém, estes tipos de bases são aplicadas apenas em átomos de 1 elétron. Outro conjuntos de bases usadas, para compensar tal falha, são as que possuem funções de Slater, que tem a forma parecida com as funções hidrogenóides. Neste caso, o potencialé $V=-\zeta n / r+[n(n-1)-l(l+1)] /\left(2 r^{2}\right)$ [40]. A expressão da função de Slater é

$$
\chi_{\zeta, n, l, m}(r, \theta, \phi)=N Y_{l m}(\theta, \phi) r^{n-1} e^{-\zeta r}
$$

onde $Y_{l m}(\theta, \phi)$ são os harmônicos esféricos e $N$ é um fator de normalização.

Um tipo de funções muito usadas nas bases, para o estudo de sistemas moleculares, são as funções do tipo gaussianas. A vantagem do uso de funções gaussianas é que o produto de duas gaussianas centradas em pontos diferentes é igual a uma gaussiana centrada em um ponto intermediário. Assim, as integrais de três e quatro centros são reduzidas para integrais de dois centros [41], facilitando muito o trabalho com esse tipo de função.

\footnotetext{
${ }^{3}$ Para facilitar a nomenclatura, vamos chamar de base um conjunto de bases.
} 
As funções gaussianas, em coordenadas esféricas, possuem a seguinte forma

$$
\chi_{\zeta, n, l, m}(r, \theta, \phi)=N Y_{l m}(\theta, \phi) r^{2 n-2-l} e^{-\zeta r^{2}}
$$

onde $Y_{l m}(\theta, \phi)$ são harmônicos esféricos e $N$ é o fator de normalização.

Em coordenadas cartesianas, uma função gaussiana tem a seguinte forma

$$
\chi_{\zeta, l_{x}, l_{y}, l_{z}}(x, y, z)=N x^{l_{x}} y^{l_{y}} z^{l_{z}} e^{-\zeta r^{2}},
$$

$\operatorname{com} l_{x}+l_{y}+l_{z}$ igual ao momento angular $l$. Um ponto interessante ocorre para funções do tipo $d$ e superiores. Usando como exemplo as funções do tipo $d$, verifica-se que com as coordenadas cartesianas são geradas 6 funções diferentes: $x^{2}, y^{2}, z^{2}, x y, z x \mathrm{e}$ $y z$ para $l_{x}+l_{y}+l_{z}=2$. Usando coordenadas esféricas, 5 funções do tipo $d$ diferentes são geradas: $Y_{2,-2}, Y_{2,-1}, Y_{2,0}, Y_{2,1}$ e $Y_{2,2}$. Uma análise mais detalhada mostra que há uma combinação linear das funções do tipo $d$ em coordenadas cartesianas que é na verdade uma função do tipo $s$ [41].

A base que descreve um átomo é formada por uma combinação linear de funções que representam os orbitais,

$$
\phi_{i}=\sum_{k=1}^{m} C_{i k} \chi_{k}
$$

e alguns parâmetros devem ser ajustados pelo método variacional. Sendo a energia eletrônica igual a

$$
\langle E\rangle=\frac{\langle\Psi|\mathcal{H}| \Psi\rangle}{\langle\Psi \mid \Psi\rangle}
$$

e dada qualquer função de onda aproximada $(\Psi)$, a energia correspondente sempre será maior ou igual à energia exata.

As bases podem ser obtidas a princípio para átomos neutros, descrevendo muito bem os orbitais ocupados. Para o estudo de propriedades, em estados excitados, é necessário a adição de funções para os orbitais virtuais. Contudo, os orbitais atômicos sofrem certas deformações, dependendo do meio que estão presentes. 
Uma tentativa de expandir a utilização de funções de base atômicas é a adição de funções complementares. Duas funções adicionais interessantes são:

- funções polarizadas - para orbitais deformados pelo meio presente, melhoram a descrição do átomo quando estiver associado a uma molécula.

- funções difusas - aumentam a quantidade de funções dos mesmos tipos dos orbitais nas bases, para uma melhor descrição à grandes distâncias.

Uma característica bem interessante nas bases é o uso de gaussianas contraídas, que é uma única função gaussiana representando um grupo de gaussianas primitivas. Dessa forma, o número de parâmetros variacionais é reduzido e assim o rendimento computacional aumenta. Uma família de bases muito conhecidas foi criada por Pople e colaboradores [75-77], com a forma da função similar as bases propostas por Slater, porém com maior eficiência pelo uso de gaussianas. Por exemplo, a base 6-31G possuem 6 funções gaussianas contraídas para descrever os orbitais do caroço, enquanto os orbitais de valência são divididos em duas partes: na parte mais interna são usadas 3 gaussianas contraídas e na parte mais externa são udadas apenas uma gaussiana contraída. A adição de funções difusas nesta base é representada pelo símbolo +, antes da letra G. Após a letra G, é possível especificar as funções polarizadas a serem adicionadas.

Os orbitais mais internos pouco contribuem para algumas propriedades químicas como excitação [40], além de sofrer pouca influência pelo meio. Outro ponto é que átomos de grande número atômico sofrem efeitos relativísticos, além de serem bastantes custosos para cálculos de MQ. Uma forma de amenizar esses problemas é usar um potencial para descrever os elétrons do caroço do átomo, chamado de ECP (Effective Core Potencial) [40]. Neste processo, apenas os elétrons de valência são tratados explicitamente aumentando o desempenho do cálculo com pouca perda de precisão. A base que descreve o íon Eu, MWB52ECP faz uso deste potencial e 
apenas um sexto dos elétrons iniciais são descritos explicitamente, apresentando bons resultados para estruturas, energia de excitação e ionização [78, 79].

\subsection{Tratamento do Íon e Solvente}

O principal resultado exposto neste texto é o espectro de absorção, que é obtido usando três diferentes modelos, a fim de incluir o efeito do solvente: PCM (Polarizable Continuum Model), ASEC (Average Solvent Electrostatic Configuration) e solvente explícito. Adicionar o solvente é um ponto extremamente importante, visto que diversas propriedades podem mudar quando o soluto está imerso em um meio. Cada modelo trata o efeito do solvente de forma diferente, sendo que o PCM recorre somente à cálculos de $\mathrm{MQ}^{4}$, enquanto no ASEC e solvente explícito há a combinação da simulação clássica e MQ, chamada de método Sequential-QM/MM. O espectro é obtido com a convolução das transições eletrônicas normalizadas, obtidas com o cálculo TDDFT. Cada transição é tratada como uma curva lorentziana de largura igual a $1600^{-1}$ ou $2000 \mathrm{~cm}^{-1}$, dependendo o modelo de solvente. A altura de cada curva é igual à força de oscilador. As características de cada modelo são especificadas nas próximas seções.

\subsubsection{PCM}

Uma forma bem simples de adicionar os efeitos do solvente é o uso dos meios contínuos dielétricos. Um dos primeiros modelos foi proposto por Kirkwood em 1934 [81] onde o soluto é tratado como um dipolo em uma cavidade esférica, dentro de uma região espacial caracterizada pela constante dielétrica do solvente. Em 1936, Onsager [82] adicionou ao dipolo da molécula um termo para representar a polarizabilidade, induzido pelo campo de reação. O dipolo do soluto, que tem valor de

\footnotetext{
${ }^{4}$ Os cálculos de MQ aqui presentes foram realizados com o programa Gaussian 09 [80].
} 
vácuo inicialmente, polariza o solvente que gera um campo de reação aumentando o dipolo do soluto. Este ciclo é repetido até a convergência da polarização e o método é chamado de campo de reação autoconsistente (SCRF).

No passado, a cavidade onde a molécula está presente era representada por uma esfera. Em 1973, Rinaldi e Rivail propuseram um envoltório mais geral, de forma elipsoidal [83]. Ainda assim, a molécula pode apresentar certa geometria onde uma descrição mais adequada da cavidade deve ser empregada. Um processo atual consiste em definir esferas em tornos dos átomos e a somatória delas formando a cavidade. O raio das esferas é igual ao raio de van der Waals do átomo, aumentando seu valor em $20 \%$ e o volume da cavidade possui o formato da molécula do soluto. Este modelo é chamado de PCM (Polarizable Continuum Model), desenvolvido por Tomasi e colaboradores $[46,84,85]$.

A vantagem do uso do PCM é que apenas um cálculo de MQ é suficiente para obter o espectro de absorção eletrônico, com resultados frequentemente em boa concordância com os experimentos. Por tratar a interação entre o soluto e solvente de forma puramente eletrostática, o PCM funciona muito bem em sistemas onde este tipo de interação é predominante, como os casos onde o soluto e o solvente possuem momento de dipolo alto. Ligações de hidrogênio, mistura de solventes, transferência de carga entre soluto e solvente são apenas algumas possíveis falhas encontradas neste modelo. Na próxima seção, apresentaremos outra forma de incluir o solvente no cálculo de absorção eletrônica.

\subsubsection{S-QM/MM: ASEC e Explícito}

O modelo S-QM/MM [52,86] permite adição do efeito do solvente de forma bastante simples, desmembrando a parte de MQ da simulação clássica. A simulação clássica adiciona propiedades termodinâmicas nas configurações, tornando representativas fiéis de um sistema líquido. Na fase de equilíbrio são geradas da ordem de 
$10^{6}$ configurações. Considerando o fato de que a simulação está convergida, as médias de diversas propriedades clássicas ou quânticas podem ser realizadas para uma pequena amostragem de configurações, da ordem de centenas delas respeitando um critério de descorrelação energética, sem a perda significativa de precisão, no lugar de tratar todas as configurações geradas na simulação. Dessa forma, realizamos o cálculo de MQ para um número limitado de configurações.

Recentemente, nosso grupo realizou diversos estudos, onde observou-se o efeito da polarização entre soluto e solvente [56,58]. Um método iterativo foi aplicado onde as cargas e a geometria do soluto são atualizadas, após um cálculo de otimização de geometria e cargas da média configuracional obtida após a simulação clássica de equilíbrio. Este procedimento [58] foi repetido até a convergência do valor do momento de dipolo da molécula do soluto. Verificou-se que grande parte da polarização eletrônica poderia ser obtida usando geometria e cargas provenientes de um cálculo tratando o solvente como um meio contínuo. Para facilitar a obtenção do espectro de absorção da TC e seus complexos, obtivemos a geometria e carga tratando o solvente com o PCM, evitando um grande número de simulações para o procedimento iterativo.

Tendo obtido a geometria da TC, falta definir as cargas dos sítios atômicos. Nesta etapa foi realizado um cálculo CHELPG (CHarges from ELetrostatic Potential using a Grid based method). Neste caso, as cargas atômicas se tornam funções do potencial eletrostático molecular (PEM) e os valores das cargas devem manter a mesma carga total do sistema original $[87,88]$. Para isso, é definida a região entre o raio de van der Waals dos átomos até 28 pm em todas as direções. Este espaço é discretizado e a cada 3.0 pm é calculado o valor da PEM. Com todos os pontos calculados, as cargas atômicas são ajustadas reproduzindo o PEM. Os valores de carga possuem baixa dependência do tipo e tamanho de base utilizada, além do método empregado [89]. 
Com as cargas e geometria da TC, incluindo parte do efeito do solvente, é possível realizar a simulação clássica. Com a simulação clássica efetuada, são selecionadas configurações estatisticamente descorrelacionadas a partir do estágio de equilíbrio, seguindo os critérios na seção 2.1.3. A primeira aproximação para o cálculo do espectro de absorção consiste em tratar todo o solvente como cargas pontuais. Basicamente, calculamos apenas uma configuração média do solvente ao invés de calcular cada configuração descorrelacionada energeticamente e depois realizar a média. Esse modelo é chamado de ASEC (Average Solvent Electrostatic Configuration) [90].

No modelo ASEC, toda a interação da TC com o solvente e com o íon é de forma eletrostática. Aproveitando o fato de que o soluto é tratado de forma rígida, todas as configurações selecionadas são alinhadas usando o solvente como referência gerando uma configuração fictícia onde há apenas uma molécula de soluto explícita e o solvente e íon como cargas pontuais normalizadas. Por se tratar de cargas pontuais, é possível que haja a sobreposição de solvente, mas o efeito é apenas do acúmulo de carga em determinada posição do espaço. Ao final, temos apenas uma configuração média do solvente. Essa configuração é submetida ao cálculo específico de MQ para obter as transições eletrônicas, sendo o espectro a convolução delas. Nesta tese foi usado a TDDFT para obter as tais transições eletrônicas.

O próximo passo é tratar o solvente na forma explícita a fim de tornar o cálculo mais realista, na tentativa de aprimorar os resultados de absorção. Devido aos custos computacionais, apenas as moléculas do solvente mais próximas da TC e o íon foram tratados de forma explícita, enquanto que o restante do solvente foi tratado como cargas pontuais. A quantidade de solvente explícito escolhida é plausível para nosso poder computacional e inclui praticamente todas as ligações de hidrogênio que o soluto mantém com o solvente. Além do mais, a interação eletrostática, que interage a longas distâncias, é conservada pelo solvente mais afastado. Este modelo 
é chamado de solvente parcialmente explícito ou simplesmente modelo explícito.

Diferente do método ASEC, não é possível obter uma configuração média com o modelo explícito devido à flutuação da posição do solvente. São necessárias várias configurações descorrelacionadas energeticamente, com a função de onda incluindo o soluto, o íon e parte do solvente próximo. Assim, o espectro obtido com o modelo explícito é muito mais custoso computacionalmente que os modelos ASEC e PCM, da ordem do número de configurações selecionadas. Entretanto, este método permite melhorar a descrição do solvente, tanto para a função de onda quanto para a quantidade explícita de átomos. 


\section{Capítulo 3}

\section{Espectro de Absorção da TC em Água}

A molécula de TC possui quatro anéis de carbono, sendo que o primeiro anel D é um anel aromático. Ligado a esses anéis existem alguns grupos ácidos, como hidroxilas, carbonilas e em especial os grupos ligado ao anel A: amida (denotado por am) ligada ao átomo de carbono $\mathrm{C}_{2}$ e o grupo dimetilamina (denotado por $\mathrm{dm}$ ) ligado ao $\mathrm{C}_{4}$. A presença destes grupos ácidos faz a TC sofrer processos de protonação e desprotonação, mudando a forma da molécula em função do $\mathrm{pH}$ do solvente. Na figura 3.1, apresentamos as diversas formas da TC estudadas e a nomenclatura utilizada para descrever todos os átomos da molécula.

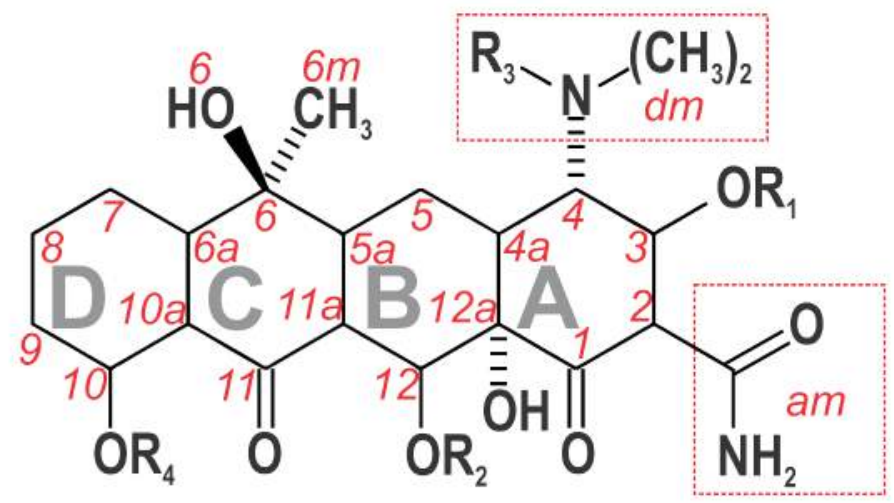

\begin{tabular}{l|l|l|l|l} 
& $\mathbf{R}_{1}$ & $\mathbf{R}_{2}$ & $\mathbf{R}_{3}$ & $\mathbf{R}_{4}$ \\
\hline $\mathbf{T C}^{\mathbf{N}}$ & $\mathrm{H}$ & $\mathrm{H}$ & - & $\mathrm{H}$ \\
\hline $\mathbf{T C}^{+}$ & $\mathrm{H}$ & $\mathrm{H}$ & $\mathrm{H}$ & $\mathrm{H}$ \\
\hline $\mathbf{T C}^{ \pm}$ & - & $\mathrm{H}$ & $\mathrm{H}$ & $\mathrm{H}$ \\
\hline $\mathbf{T C}^{-}$ & - & - & $\mathrm{H}$ & $\mathrm{H}$ \\
\hline $\mathbf{T C}^{2-}$ & - & - & - & $\mathrm{H}$ \\
\hline $\mathbf{T C}^{3-}$ & - & - & - & - \\
\hline
\end{tabular}

Figura 3.1: Estrutura da molécula de TC descrevendo as cinco formas estudadas (Neutra $\mathrm{TC}^{\mathrm{N}}$, catiônica $\mathrm{TC}^{+}$, zwiteriônica $\mathrm{TC}^{ \pm}$, ânion monovalente $\mathrm{TC}^{-}$, ânion bivalente $\mathrm{TC}^{2-}$ e ânion trivalente $\mathrm{TC}^{3-}$ ) e a nomenclatura usada para diferenciar cada átomo e grupo atômico. 


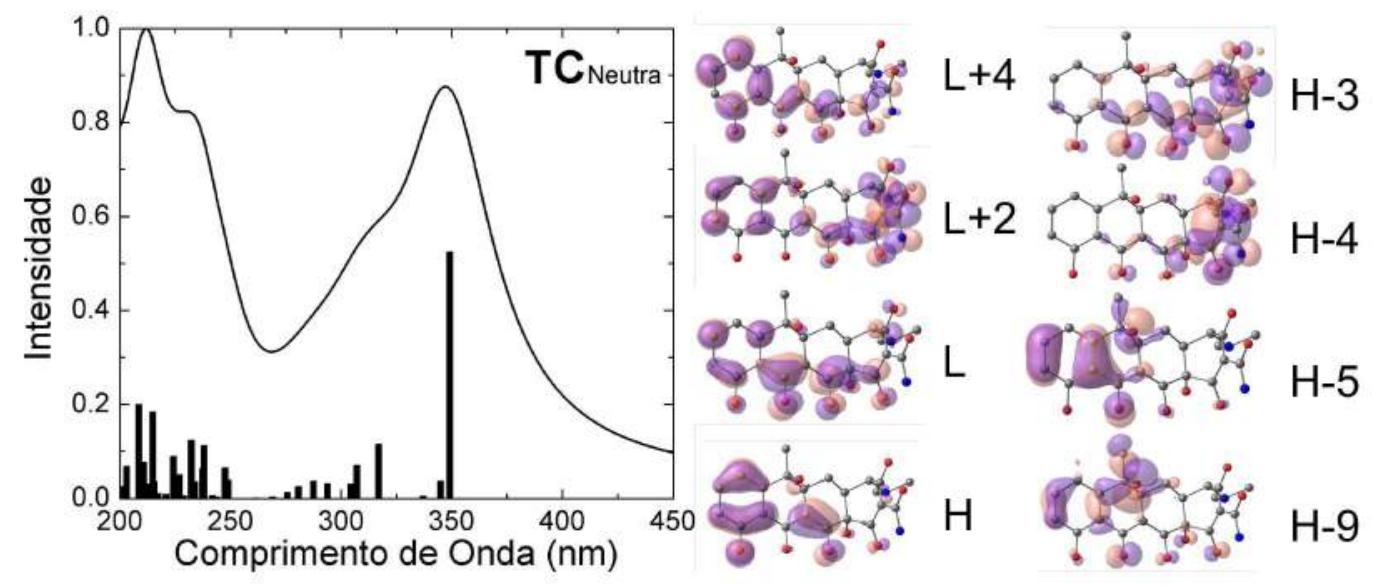

Figura 3.2: Espectro de absorção eletrônica da TC na forma neutra e os orbitais envolvidos nas transições mais intensas. A linha contínua é a convolução das transições por soma de lorentzianas e as barras são as transições com o valor multiplicado por 2 para facilitar a leitura.

Tabela 3.1: Comparativo entre os máximos do espectro de absorção eletrônica teórica com as contribuições de cada orbital envolvido nas transições da TC neutra. $\mathrm{O}$ * indica a posição do ombro e entre parênteses está a intensidade normalizada.

\begin{tabular}{ccccc}
\hline \hline $\begin{array}{c}\text { Máximo } \\
\text { Teór. }(\mathrm{nm})\end{array}$ & Ordem & $\begin{array}{c}\text { Energia } \\
(\mathrm{eV} / \mathrm{nm})\end{array}$ & $\begin{array}{c}\text { Força do } \\
\text { Oscilador }\end{array}$ & Composição \\
\hline $347,1(0,88)$ & 1 & $3,55 / 348,9$ & 0,2627 & $\mathrm{H} \rightarrow \mathrm{L}(85 \%)$ \\
\hline$* 230,0(0,82)$ & 29 & $5,77 / 214,8$ & 0,0922 & $\mathrm{H}-4 \rightarrow \mathrm{L}+2(34 \%)$ \\
& & & & $\mathrm{H}-3 \rightarrow \mathrm{L}+2(19 \%)$ \\
\hline $211,8(1,00)$ & 34 & $5,95 / 208,5$ & 0,1001 & $\mathrm{H} \rightarrow \mathrm{L}+4(36 \%)$ \\
& & & & $\mathrm{H}-5 \rightarrow \mathrm{L}+2(21 \%)$ \\
\hline \hline
\end{tabular}

A primeira análise do espectro de absorção foi realizada para a molécula de TC em vácuo, chamada também de forma neutra $\left(\mathrm{TC}^{N}\right)$. Tal condição não foi ainda reportada na literatura, e devido a ausência de qualquer solvente, espera-se que não ocorra a separação de cargas na TC. Além de ausência de regiões carregadas na molécula, a carga total deve apresentar valor nulo. A geometria foi otimizada com um cálculo MP2/6-31G(d) a partir de uma estrutura experimental retirando o átomo de hidrogênio ligado ao nitrogênio do grupo n-dimetil $\left(\mathrm{N}_{d m}\right)$. Dentre as várias ge- 
ometrias possíveis, por rotações de grupos ácidos, foi selecionada aquela geometria que apresentou a menor energia. O espectro de absorção foi obtido usando TDDFT com um cálculo B3LYP/6-31G(d), onde a sua forma, orbitais envolvidos e os dados das transições mais intensas são reportados na figura 3.2 e tabela 3.1.

O espectro de absorção eletrônica da $\mathrm{TC}^{N}$ na região do $u v$ - vis possui a forma de duas bandas, formato que será constante nos espectros de absorção estudados nesta tese com transições mais intensas do tipo $\pi \rightarrow \pi^{*}$. A primeira banda possui o máximo em 347,1 nm e é formada por diversas transições sendo a primeira a mais intensa: nela há leve transferência de carga dos anéis DCB para os grupos ácidos do anel A. A segunda banda possui o máximo em 212,8 nm, com um ombro em 230,0 $\mathrm{nm}$. Essa banda é formada por diversas transições de intensidades médias, quando comparadas à primeira transição, que envolvem transferência de cargas entre os extremos da molécula de TC.

O próximo passo é verificar como solvente modifica o espectro de absorção da TC. Na água, a TC deixa de existir na forma neutra e permanece em uma das seguintes formas em função do $\mathrm{pH}$ do meio: $\mathrm{TC}^{+}, \mathrm{TC}^{ \pm}, \mathrm{TC}^{-}, \mathrm{TC}^{2-} \mathrm{e} \mathrm{TC}^{3-}$, chamadas de cátion, zwiteriônica, ânion monovalente, ânion divalente e ânion trivalente, respectivamente. O primeiro efeito da solvatação da TC é o aumento do momento de dipolo, quando comparamos uma molécula isolada e em solvente: o solvente polariza a molécula, evidenciando ainda mais o contraste da distribuição de cargas da TC. A forma $\mathrm{TC}^{N}$ em vácuo apresenta o dipolo igual a 5,5 D, enquanto que na forma $\mathrm{TC}^{ \pm}$em solvente há um aumento de mais de três vezes, passando para 18,0 D. Todos esses cálculos foram obtidos com MP2/6-31G(d) e o solvente na forma $\mathrm{TC}^{ \pm}$ foi tratado como PCM.

Todas as estruturas da molécula de TC tiveram sua geometria otimizada a partir de resultados experimentais [91], usando um cálculo DFT com o funcional híbrido B3LYP e conjunto de bases 6-31G(d), sendo que a água foi aproximada pelo 
PCM. Após a obtenção da nova geometria, foi realizado um cálculo para refinar a estrutura, com o método MP2 e mantendo a mesma base. A otimização da geometria em meio, através do uso do PCM, é importante para obter a estrutura da molécula na forma mais próxima da encontrada em água.

Tabela 3.2: Comparativo entre os dados experimentais [92], [91] e teóricos dos valores de distância e ângulos interatômicos da TC ${ }^{ \pm}$. A geometria otimizada foi obtida no nível MP2 e base 6-31G(d).

\begin{tabular}{cccc|cccc}
\hline \hline Coorde- & \multicolumn{2}{c}{ Experimento } & Forma & Coorde- & \multicolumn{2}{c}{ Experimento } & Forma \\
nada & Ref. [92] & Ref. [91] & TC $^{ \pm}$ & nada & Ref. [92] & Ref. [91] & TC $^{ \pm}$ \\
\hline $\mathrm{C}_{7}-\mathrm{C}_{8}$ & $1,388(7)$ & 1,397 & 1,402 & $\mathrm{O}_{1}-\mathrm{C}_{1}-\mathrm{C}_{2}$ & $125,7(5)$ & 126,3 & 127,0 \\
$\mathrm{C}_{10}-\mathrm{O}_{10}$ & $1,341(7)$ & 1,355 & 1,358 & $\mathrm{C}_{7}-\mathrm{C}_{8}-\mathrm{C}_{9}$ & $121,4(5)$ & 120,9 & 120,9 \\
$\mathrm{C}_{6}-\mathrm{O}_{6}$ & $1,455(7)$ & 1,450 & 1,444 & $\mathrm{O}_{a m}-\mathrm{C}_{a m}-\mathrm{C}_{2}$ & $123,1(5)$ & 123,3 & 123,8 \\
$\mathrm{C}_{4}-\mathrm{C}_{4 a}$ & $1,546(6)$ & 1,544 & 1,530 & $\mathrm{C}_{5 a}-\mathrm{C}_{6}-\mathrm{O}_{6}$ & $108,2(4)$ & 107,4 & 104,9 \\
$\mathrm{C}_{a m}-\mathrm{N}_{a m}$ & $1,349(7)$ & 1,341 & 1,372 & $\mathrm{C}_{a m}-\mathrm{C}_{2}-\mathrm{C}_{1}$ & $121,2(5)$ & 120,9 & 122,2 \\
$\mathrm{C}_{a m}-\mathrm{O}_{a m}$ & $1,254(7)$ & 1,255 & 1,243 & $\mathrm{C}_{12 a}-\mathrm{C}_{12}-\mathrm{C}_{11 a}$ & $124,5(5)$ & 124,1 & 123,8 \\
$\mathrm{~N}_{d m}-\mathrm{C}_{d m 2}$ & $1,496(6)$ & 1,499 & 1,494 & $\mathrm{C}_{4}-\mathrm{C}_{4 a}-\mathrm{C}_{5}$ & $109,5(4)$ & 115,1 & 111,1 \\
$\mathrm{C}_{1}-\mathrm{C}_{2}$ & $1,418(8)$ & 1,430 & 1,431 & $\mathrm{C}_{10}-\mathrm{C}_{10 a}-\mathrm{C}_{6 a}$ & $120,0(5)$ & 119,2 & 119,9 \\
$\mathrm{C}_{1}-\mathrm{O}_{1}$ & $1,243(7)$ & 1,233 & 1,257 & $\mathrm{C}_{4 a}-\mathrm{C}_{12 a}-\mathrm{C}_{1}$ & $112,2(5)$ & 111,9 & 109,6 \\
$\mathrm{C}_{4}-\mathrm{N}_{d m}$ & $1,514(6)$ & 1,506 & 1,507 & $\mathrm{C}_{11}-\mathrm{C}_{11 a}-\mathrm{C}_{12}-\mathrm{C}_{12 a}$ & 179,2 & 179,7 & $-178,2$ \\
$\mathrm{C}_{3}-\mathrm{O}_{3}$ & $1,245(7)$ & 1,241 & 1,254 & $\mathrm{C}_{1}-\mathrm{C}_{2}-\mathrm{C}_{3}-\mathrm{C}_{4}$ & 35,0 & 33,0 & 25,6 \\
$\mathrm{C}_{2}-\mathrm{C}_{a m}$ & $1,469(8)$ & 1,471 & 1,484 & $\mathrm{C}_{5}-\mathrm{C}_{5 a}-\mathrm{C}_{6}-\mathrm{C}_{6 a}$ & $-178,6$ & $-178,7$ & 175,2 \\
$\mathrm{C}_{11}-\mathrm{O}_{11}$ & $1,282(7)$ & 1,278 & 1,273 & $\mathrm{C}_{6}-\mathrm{C}_{6 a}-\mathrm{C}_{7}-\mathrm{C}_{8}$ & $-176,4$ & $-177,3$ & $-176,5$ \\
$\mathrm{C}_{11}-\mathrm{C}_{11 a}$ & $1,429(8)$ & 1,443 & 1,445 & $\mathrm{C}_{4}-\mathrm{C}_{4 a}-\mathrm{C}_{12 a}-\mathrm{C}_{1}$ & 48,2 & 49,3 & 51,9 \\
$\mathrm{C}_{11 a}-\mathrm{C}_{12}$ & $1,358(8)$ & 1,364 & 1,370 & $\mathrm{C}_{5}-\mathrm{C}_{5 a}-\mathrm{C}_{11 a}-\mathrm{C}_{12}$ & $-18,4$ & $-17,7$ & $-13,8$ \\
$\mathrm{C}_{12}-\mathrm{O}_{12}$ & $1,338(6)$ & 1,334 & 1,340 & & & & \\
\hline \hline
\end{tabular}

As estruturas otimizadas foram submetidas a um cálculo de frequência vibracional onde todas as frequências obtidas foram positivas, indicando que a geometria realmente apresenta um mínimo conformacional. As bandas de maior intensidade 
são encontradas geralmente na região de $3500 \mathrm{~cm}^{-1}$ para todas as estruturas estudadas, em concordância com o estudo de Leypold e colaboradores [93], além de outros picos característicos no espectro. Na tabela 3.2 temos o comparativo da estrutura da TC obtida experimentalmente por técnicas de raios $\mathrm{X}$ em períodos diferentes, em 1977 [92] e 2013 [91], comparando com os valores obtidos para a otimização da geometria na forma zwiteriônica, $\mathrm{TC}^{ \pm}$. Como pode ser visto nos dados da tabela 3.2, a geometria obtida está em muito boa concordância com os dados experimentais.

As posições das desprotonações/protonações foram, no início deste trabalho, uma etapa de grande dificuldade, pois estávamos limitados a poucos artigos que informavam a energia total de diferentes formas numa tentativa de definir qual a forma da TC mais estável em água [94-97]. Recentemente, Amat e colaboradores [31] trataram a TC em diferentes valores de $\mathrm{pH}$, partindo da forma catiônica e realizando as desprotonações de diferentes hidrogênios mantendo a TC em um agregado de moléculas de água. Aplicando essa metodologia foi possível estimar o valor de $\mathrm{pK}_{a}$, que está em excelente concordância com os dados experimentais, além das posições corretas dos sítios onde ocorrem as desprotonações envolvendo os átomos de hidrogênio de cada forma da TC.

\subsection{Espectro de Absorção com PCM}

Uma primeira aproximação para o solvente, ou meio, consiste em adicionar um termo no hamiltoniano para representar o potencial externo. Este termo considera que átomos estão em uma cavidade esférica envolvida pela constante dielétrica do meio. O dipolo da molécula interage com o dipolo na cavidade, que por sua vez, também modifica o dipolo da molécula, tornando um processo autoconsistente. No modelo utilizado, PCM [45,46], o raio da cavidade é $20 \%$ maior que o raio de van der Waals de cada átomo e ocorre a sobreposição de várias cavidades em uma molécula, 
formando um volume englobando a TC.

Estudar a molécula de TC em água é uma boa iniciativa para verificar se a metodologia aplicada é adequada, pois este procedimento servirá de base para descrever os sistemas da TC complexados com íons positivos. Além do mais, existem resultados experimentais (ver seção 1.3) do espectro de absorção da TC em água variando o $\mathrm{pH}$, que serve de base para comparar os métodos aplicados.

A molécula de TC com a geometria otimizada foi submetida a um cálculo TDDFT com o funcional híbrido B3LYP, a base 6-31G(d) e o solvente sendo a água na aproximação PCM. A partir deste cálculo obtivemos o espectro de absorção eletrônico normalizado ${ }^{1}$, a patir da convolução das várias transições isoladas na forma de lorentzianas com a largura de cada linha espectral igual a $2000 \mathrm{~cm}^{-1}$. Nas figuras 3.3, 3.4 3.5, 3.6, 3.7 e nas tabelas 3.3, 3.4 3.5, 3.6, 3.7 temos a comparação entre os espectros de absorção teóricos e experimentais. Os dados experimentais [30] são representados por uma linha tracejada, porém a estrutura $\mathrm{TC}^{3-}$ não possui resultados experimentais para comparação. A linha contínua na cor preta representa a convolução normalizada usando o PCM, e na cor vermelha a convolução das transições na ausência de solvente, mas mantendo a mesma geometria. As barras verticais simbolizam as transições isoladas, com a altura igual ao dobro da força de oscilador. Podemos observar, nas figuras citadas, que há uma boa concordância dos dados teóricos e experimentais em várias situações. Em geral, as transições mais intensas são do tipo $\pi \rightarrow \pi^{*}$ e podem envolver o fenômeno de transferência de carga.

No primeiro caso analisado, $\mathrm{TC}^{+}$, temos o espectro de absorção formado por duas bandas, da mesma forma que é apresentada pelo resultado experimental, porém bastante deslocado. Conforme a figura 3.3 e a tabela 3.3, o máximo teórico

\footnotetext{
${ }^{1}$ Para evitar o sobrecarregamento de informações, omitimos os valores presentes no eixo vertical nos gráficos do espectro de absorção. Estes gráficos estão normalizados sendo a origem de valor zero e o máximo de valor um.
} 

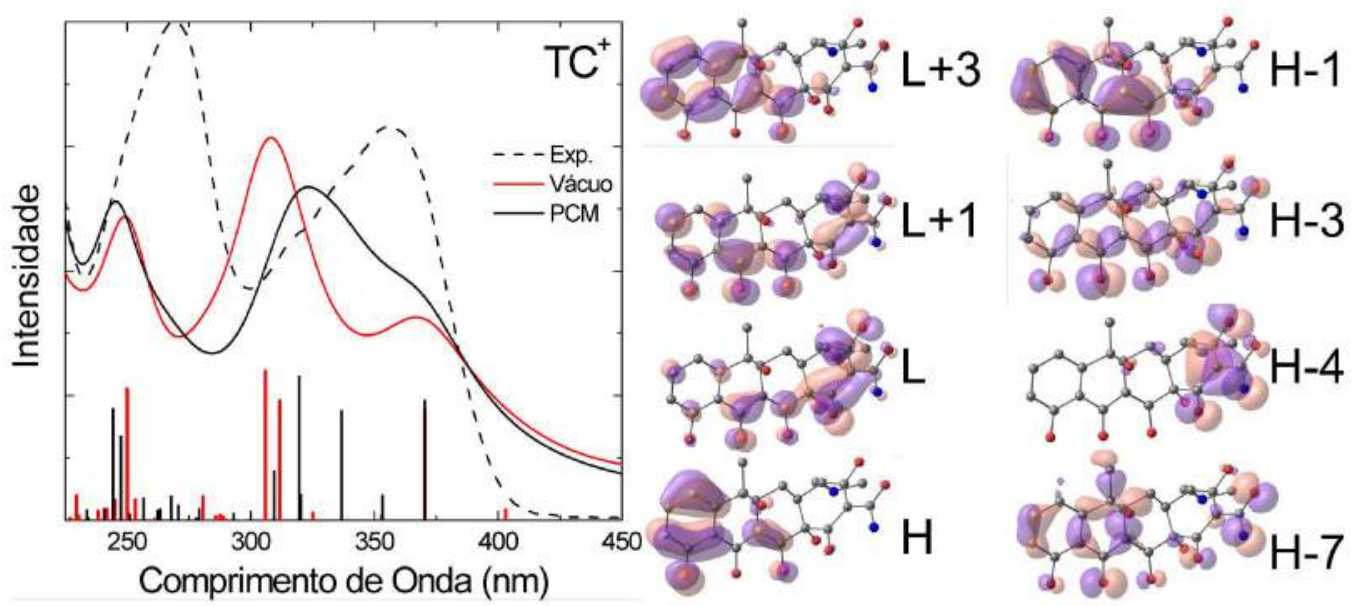

Figura 3.3: Espectro de absorção eletrônica da forma $\mathrm{TC}^{+}$usando o $\mathrm{PCM}$ para descrever o solvente (linha preta), comparado com o espectro experimental [30] (linha tracejada) e a ausência de solvente (linha vermelha), além dos orbitais envolvidos nas transições mais intensas.

Tabela 3.3: Comparativo entre os máximos do espectro de absorção eletrônica experimental [30] e teórica com as contribuições de cada orbital envolvido nas transições da forma $\mathrm{TC}^{+}$usando o PCM.

\begin{tabular}{|c|c|c|c|c|c|}
\hline \multicolumn{2}{|c|}{ Máximo } & \multirow{2}{*}{ Ordem } & \multirow{2}{*}{$\begin{array}{l}\text { Energia } \\
(\mathrm{eV} / \mathrm{nm})\end{array}$} & \multirow{2}{*}{$\begin{array}{l}\text { Força do } \\
\text { Oscilador }\end{array}$} & \multirow{2}{*}{ Composição } \\
\hline Exp. (nm) & Teór. (nm) & & & & \\
\hline \multirow[t]{4}{*}{355,4} & $323,2(0,67)$ & 1 & $3,35 / 370,3$ & 0,1206 & $\mathrm{H} \rightarrow \mathrm{L}(78 \%)$ \\
\hline & & 3 & $3,68 / 336,7$ & 0,1103 & $\mathrm{H} \rightarrow \mathrm{L}+1(65 \%)$ \\
\hline & & 5 & $3,88 / 319,6$ & 0,1449 & $\mathrm{H}-1 \rightarrow \mathrm{L}+1(48 \%)$ \\
\hline & & & & & $\mathrm{H}-3 \rightarrow \mathrm{L}+1(21 \%)$ \\
\hline \multirow[t]{3}{*}{268,7} & $245,4(0,64)$ & 16 & $5,01 / 247,5$ & 0,0850 & $\mathrm{H}-4 \rightarrow \mathrm{L}+1(34 \%)$ \\
\hline & & 17 & $5,07 / 244,4$ & 0,1122 & $\mathrm{H}-7 \rightarrow \mathrm{L}+1(31 \%)$ \\
\hline & & & & & $\mathrm{H}-4 \rightarrow \mathrm{L}+1(24 \%)$ \\
\hline
\end{tabular}

e experimental da primeira banda estão distantes de $-32,2 \mathrm{~nm}$. Na banda de maior energia, a diferença é igual a $-23,3 \mathrm{~nm}$. A primeira banda é formada por diversas transições onde as mais intensas envolvem transferência de carga dos anéis DCB para o anel A, enquanto nas transições abaixo de 250,0 nm ocorrem transferências de carga na direção contrária. Com relação à intensidade, o experimento indica 

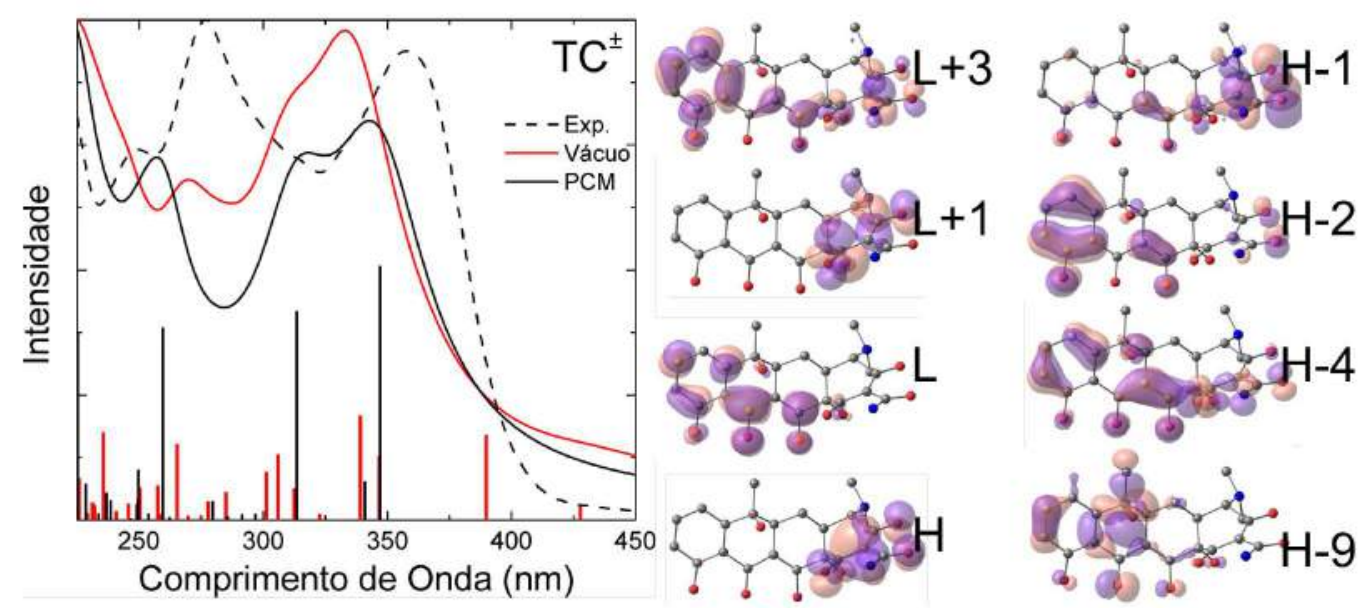

Figura 3.4: Espectro de absorção eletrônica da forma $\mathrm{TC}^{ \pm}$usando o $\mathrm{PCM}$ para descrever o solvente (linha preta), comparado com o espectro experimental [30] (linha tracejada) e a ausência de solvente (linha vermelha), além dos orbitais envolvidos nas transições mais intensas.

Tabela 3.4: Comparativo entre os máximos do espectro de absorção eletrônica experimental [30] e teórica com as contribuições de cada orbital envolvido nas transições da forma $\mathrm{TC}^{ \pm}$usando o PCM.

\begin{tabular}{cccccc}
\hline \hline \multicolumn{2}{c}{ Máximo } & Ordem & $\begin{array}{c}\text { Energia } \\
(\mathrm{eV} / \mathrm{nm})\end{array}$ & $\begin{array}{c}\text { Força do } \\
\text { Oscilador }\end{array}$ & Composição \\
\hline Exp. (nm) & Teór. (nm) & & $3,57 / 347,0$ & 0,2540 & $\mathrm{H}-1 \rightarrow \mathrm{L}(60 \%)$ \\
& $342,7(0,80)$ & 2 & & & $\mathrm{H}-2 \rightarrow \mathrm{L}(33 \%)$ \\
& & & & & \\
& $318,1(0,73)$ & 5 & $3,95 / 313,5$ & 0,2090 & $\mathrm{H}-4 \rightarrow \mathrm{L}(77 \%)$ \\
\hline 276,3 & $257,0(0,73)$ & 12 & $4,78 / 259,6$ & 0,1925 & $\mathrm{H} \rightarrow \mathrm{L}+1(57 \%)$ \\
& & 14 & $4,97 / 249,6$ & 0,0501 & $\mathrm{H}-9 \rightarrow \mathrm{L}(75 \%)$ \\
\hline & $222,4(1,00)$ & $5,51 / 225,2$ & 0,1873 & $\mathrm{H} \rightarrow \mathrm{L}+3(39 \%)$ \\
& & 26 & $5,68 / 218,3$ & 0,0656 & $\mathrm{H}-4 \rightarrow \mathrm{L}+2(85 \%)$ \\
& & $5,78 / 214,6$ & 0,0796 & $\mathrm{H}-3 \rightarrow \mathrm{L}+4(38 \%)$ \\
\hline \hline
\end{tabular}

que a primeira banda possui uma intensidade menor que a segunda, enquanto que nossos resultados indicam que ambas possuem praticamente a mesma intensidade. A adição de solvente melhora o perfil do espectro de absorção, com deslocamentos das transições para altas energias e mudança da intensidade. 
No segundo caso, a forma $\mathrm{TC}^{ \pm}$, temos novamente um deslocamento entre as posições das bandas do espectro de absorção teórico e experimental, conforme a figura 3.4 e a tabela 3.4. Esta diferença é igual a $-15,0 \mathrm{~nm}$ na primeira banda e $-19,3$ nm na segunda banda. Observa-se que a primeira banda teórica é formada por diversas transições que acabam alargando a banda, que basicamente apresenta uma transferência de carga do anel A para os anéis DCB. A descrição da intensidade pela teoria não é próxima ao resultado experimental, pois a segunda banda convoluída apresenta menor intensidade com largura pequena. Nessa banda, um pico bastante intenso é visto em 259,6 nm envolvendo redistribuição de carga no anel A. Para energia mais alta, ocorre transferência do anel A para os anéis DCB em 225,2 nm. O efeito do solvente na $\mathrm{TC}^{ \pm}$é deslocar as transições para maiores valores de energia, porém ocorre a mudança de intensidade das transições, da mesma forma que foi observada no caso $\mathrm{TC}^{+}$. Tal resultado não é observado ao considerar apenas a convolução das transições.

No terceiro caso, a forma $\mathrm{TC}^{-}$na figura 3.5 e tabela 3.5, o espectro de absorção teórico apresenta boa concordância qualitativa com o experimental e a diferença dos máximo experimental e teórico é igual-27,9 $\mathrm{nm}$ para a banda de menor energia e-14,9 nm para a banda intermediária com uma boa descrição das intensidades. A banda teórica em 343,8 nm mostra uma redistribuição de carga com pequena transferência dos anéis CB para os anéis D e A. Na banda de 260,6 nm temos diversas transições envolvendo diferentes regiões da TC, onde a mais intensa desloca a carga do anel A para o anel D. Essa banda experimental apresenta um ombro, em 250,5 nm que acreditamos ser representado por um pico teórico em 232,1 nm. Ficou bem evidente neste caso que o efeito do solvente é aumentar a energia da transição, deslocando todo o espectro em até $17,0 \mathrm{~nm}$.

No quarto caso, a forma $\mathrm{TC}^{2-}$, novamente temos a forma de duas bandas deslocadas do resultado experimental, figura 3.6 e tabela 3.6. A primeira banda, de 

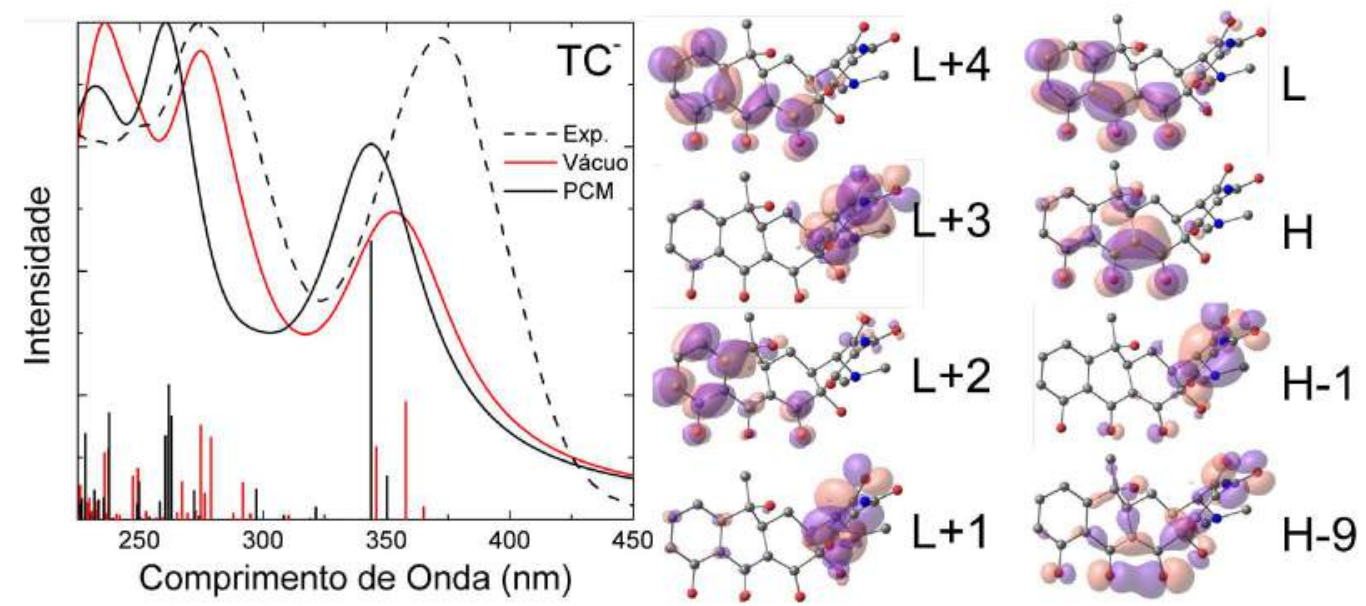

Figura 3.5: Espectro de absorção eletrônica da forma $\mathrm{TC}^{-}$usando o PCM para descrever o solvente (linha preta), comparado com o espectro experimental [30] (linha tracejada) e a ausência de solvente (linha vermelha), além dos orbitais envolvidos nas transições mais intensas.

Tabela 3.5: Comparativo entre os máximos do espectro de absorção eletrônica experimental [30] e teórica com as contribuições de cada orbital envolvido nas transições da forma $\mathrm{TC}^{-}$usando o PCM.

\begin{tabular}{|c|c|c|c|c|c|}
\hline \multicolumn{2}{|c|}{ Máximo } & \multirow{2}{*}{ Ordem } & \multirow{2}{*}{$\begin{array}{l}\text { Energia } \\
(\mathrm{eV} / \mathrm{nm})\end{array}$} & \multirow{2}{*}{$\begin{array}{l}\text { Força do } \\
\text { Oscilador }\end{array}$} & \multirow{2}{*}{ Composição } \\
\hline Exp. (nm) & Teór. (nm) & & & & \\
\hline 371,7 & $343,8(0,76)$ & 2 & $3,61 / 343,9$ & 0,2804 & $\mathrm{H} \rightarrow \mathrm{L}(82 \%)$ \\
\hline \multirow[t]{4}{*}{275,5} & $260,6(1,00)$ & 11 & $4,71 / 263,0$ & 0,1046 & $\mathrm{H} \rightarrow \mathrm{L}+2(66 \%)$ \\
\hline & & 12 & $4,73 / 261,9$ & 0,1360 & $\mathrm{H}-9 \rightarrow \mathrm{L}(31 \%)$ \\
\hline & & & & & $\mathrm{H}-1 \rightarrow \mathrm{L}+1(28 \%)$ \\
\hline & & 13 & $4,76 / 260,5$ & 0,0846 & $\mathrm{H}-1 \rightarrow \mathrm{L}+1(36 \%)$ \\
\hline \multirow[t]{2}{*}{$* 250,5$} & $232,1(0,87)$ & 20 & $5,22 / 237,7$ & 0,1077 & $\mathrm{H}-1 \rightarrow \mathrm{L}+3(65 \%)$ \\
\hline & & 25 & $5,44 / 227,9$ & 0,0867 & $\mathrm{H} \rightarrow \mathrm{L}+4(35 \%)$ \\
\hline
\end{tabular}

menor energia é deslocada de $-35,9 \mathrm{~nm}$ do resultado experimental, apresentando transições que envolvem transferência de carga dos anéis CB para o anel D. A segunda banda possui o máximo em $243,7 \mathrm{~nm}$ com um ombro localizado em 275,0 $\mathrm{nm}$, sendo este observado também no resultado experimental à direita da banda com máximo em 270,2 nm. Nesse ombro há uma transferência de carga dos anéis CB para 

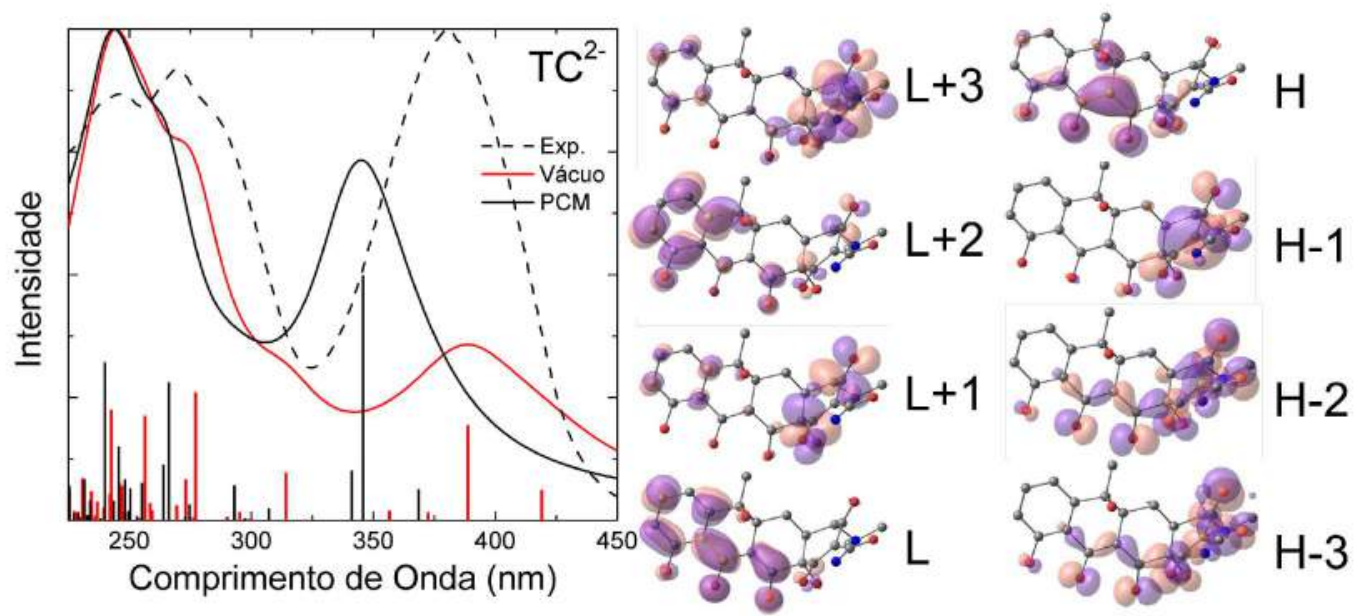

Figura 3.6: Espectro de absorção eletrônica da forma $\mathrm{TC}^{2-}$ usando o $\mathrm{PCM}$ para descrever o solvente (linha preta), comparado com o espectro experimental [30] (linha tracejada) e a ausência de solvente (linha vermelha), além dos orbitais envolvidos nas transições mais intensas.

Tabela 3.6: Comparativo entre os máximos do espectro de absorção eletrônica experimental [30] e teórica com as contribuições de cada orbital envolvido nas transições da forma $\mathrm{TC}^{2-}$ usando o PCM.

\begin{tabular}{|c|c|c|c|c|c|}
\hline \multicolumn{2}{|c|}{ Máximo } & \multirow{2}{*}{ Ordem } & \multirow{2}{*}{$\begin{array}{l}\text { Energia } \\
(\mathrm{eV} / \mathrm{nm})\end{array}$} & \multirow{2}{*}{$\begin{array}{c}\text { Força } \\
\text { Oscilador }\end{array}$} & \multirow{2}{*}{ Composição } \\
\hline Exp. (nm) & Teór. (nm) & & & & \\
\hline \multirow[t]{2}{*}{381,0} & $345,1(0,73)$ & 2 & $3,59 / 345,8$ & 0,2489 & $\mathrm{H} \rightarrow \mathrm{L}(77 \%)$ \\
\hline & & 3 & $3,63 / 341,1$ & 0,0506 & $\mathrm{H}-1 \rightarrow \mathrm{L}(79 \%)$ \\
\hline \multirow[t]{7}{*}{270,2} & $243,7(1,00)$ & 12 & $4,66 / 266,2$ & 0,1405 & $\mathrm{H} \rightarrow \mathrm{L}+2(40 \%)$ \\
\hline & & & & & $\mathrm{H}-1 \rightarrow \mathrm{L}+1(31 \%)$ \\
\hline & & 13 & $4,70 / 263,9$ & 0,0563 & $\mathrm{H} \rightarrow \mathrm{L}+2(41 \%)$ \\
\hline & & & & & $\mathrm{H}-1 \rightarrow \mathrm{L}+1(26 \%)$ \\
\hline & & 20 & $5,05 / 245,7$ & 0,0750 & $\mathrm{H}-2 \rightarrow \mathrm{L}+2(26 \%)$ \\
\hline & & 22 & $5,17 / 239,9$ & 0,1604 & $\mathrm{H}-1 \rightarrow \mathrm{L}+3(58 \%)$ \\
\hline & & & & & $\mathrm{H} \rightarrow \mathrm{L}+3(22 \%)$ \\
\hline
\end{tabular}

o anel D e no máximo da banda temos diversas transições sendo que as de maiores intensidades envolvem transferência de carga do anel A para o anel D. O resulado experimental mostra mais uma banda com máximo em $247,6 \mathrm{~nm}$, provavelmente 
descrita pela segunda banda do espectro teórico. O efeito do solvente é deslocar as transições para mais altas energias, além de melhorar bastante o perfil do espectro convoluído.

No quinto e último caso com o $\mathrm{PCM}$, a forma $\mathrm{TC}^{3-}$ está descrita na figura 3.7 e na tabela 3.7. Não foi possível encontrar dados experimentais para comparação do espectro de absorção, entretanto a forma do espectro segue a tendência dos outros casos já estudados: duas bandas bem definidas. A primeira banda, com máximo em $374,3 \mathrm{~nm}$, é formada por uma transição $\mathrm{H} \rightarrow \mathrm{L}$ de alta intensidade com transferência de carga dos anéis DC para os anéis BA. Na segunda banda, em $245,3 \mathrm{~nm}$, diversas transições contribuem para a largura da linha sendo que as mais intensas envolvem redistribuição de carga e uma leve transferência dos anéis DCB para o anel A. Novamente, o efeito de incluir o solvente é aumentar a energia de excitação da $\mathrm{TC}^{3-}$, além de mudanças na intensidade das transições.

Em todos os casos estudados o espectro de absorção mostrou bandas com máximos afastados dos valores experimentais, com diferenças chegando até $36 \mathrm{~nm}$. O passo seguinte é tentar melhorar essa descrição, verificando o efeito da base para descrever a excitação, adicionando funções difusas, polarizadas ou simplesmente aumentando a quantidade de funções bases para descrever a molécula de $\mathrm{TC}^{-}$, figura 3.8. Observamos que há poucas mudanças no espectro entre as várias bases testadas, indicando um deslocamento de 6,7 $\mathrm{nm}$ para a primeira banda partindo da base $6-31 G(d)$ com 526 funções para a base $6-311++G(d, p)$ com 865 funções. $\quad O$ mesmo deslocamento é visto na segunda banda, mas abaixo de $250 \mathrm{~nm}$ as bases com funções difusas apresentam baixa intensidade. A maior base leva um tempo computacional 5 vezes maior que a base menor, inviabilizando o uso de tais bases no decorrer deste trabalho. Em todos os cálculos foi usado o mesmo funcional B3LYP e o solvente foi tratado como PCM.

Não foi possível observar um padrão para o efeito de transferência de carga. 


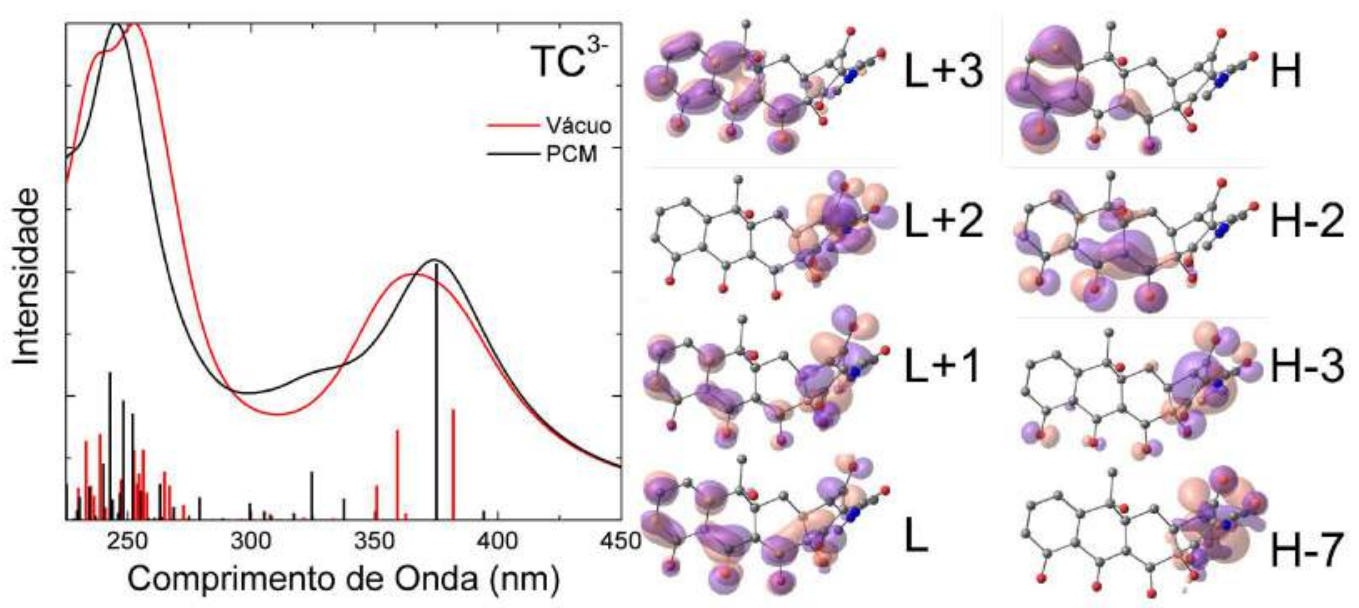

Figura 3.7: Espectro de absorção eletrônica da forma $\mathrm{TC}^{3-}$ usando o PCM para descrever o solvente (linha preta), comparado com o espectro experimental [30] (linha tracejada) e a ausência de solvente (linha vermelha), além dos orbitais envolvidos nas transições mais intensas.

Tabela 3.7: Comparativo entre os máximos do espectro de absorção eletrônica experimental e teórica com as contribuições de cada orbital envolvido nas transições da forma $\mathrm{TC}^{3-}$ usando o PCM.

\begin{tabular}{ccccc}
\hline $\begin{array}{c}\text { Máximo } \\
\text { Térico }(\mathrm{nm})\end{array}$ & Ordem & $\begin{array}{c}\text { Energia } \\
(\mathrm{eV} / \mathrm{nm})\end{array}$ & $\begin{array}{c}\text { Força do } \\
\text { Oscilador }\end{array}$ & Composição \\
\hline $374,3(0,52)$ & 2 & $3,31 / 375,1$ & 0,2579 & $\mathrm{H} \rightarrow \mathrm{L}(80 \%)$ \\
\hline $245,3(1,00)$ & 20 & $4,92 / 252,0$ & 0,1072 & $\mathrm{H}-3 \rightarrow \mathrm{L}+1(25 \%)$ \\
& & & & $\mathrm{H}-7 \rightarrow \mathrm{L}(24 \%)$ \\
& 21 & $4,99 / 248,3$ & 0,1203 & $\mathrm{H}-2 \rightarrow \mathrm{L}+3(39 \%)$ \\
& 25 & $5,10 / 242,9$ & 0,1490 & $\mathrm{H}-3 \rightarrow \mathrm{L}+2(59 \%)$ \\
& 26 & $5,16 / 240,1$ & 0,0566 & $\mathrm{H}-2 \rightarrow \mathrm{L}+3(22 \%)$ \\
\hline \hline
\end{tabular}

Para a primeira banda, temos aparentemente uma redistribuição de carga nas formas $\mathrm{TC}^{-} \mathrm{e} \mathrm{TC}^{2-}$, enquanto claramente há transferência de carga dos anéis DCB para o

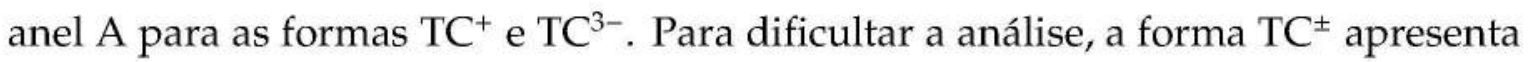
um deslocamento de carga na direção contrária, do anel A para os anéis DCB. Nas outras bandas do espectro a análise se torna mais complexa. Em todos os casos, o efeito do solvente é deslocar as transições para menores comprimentos de onda, 


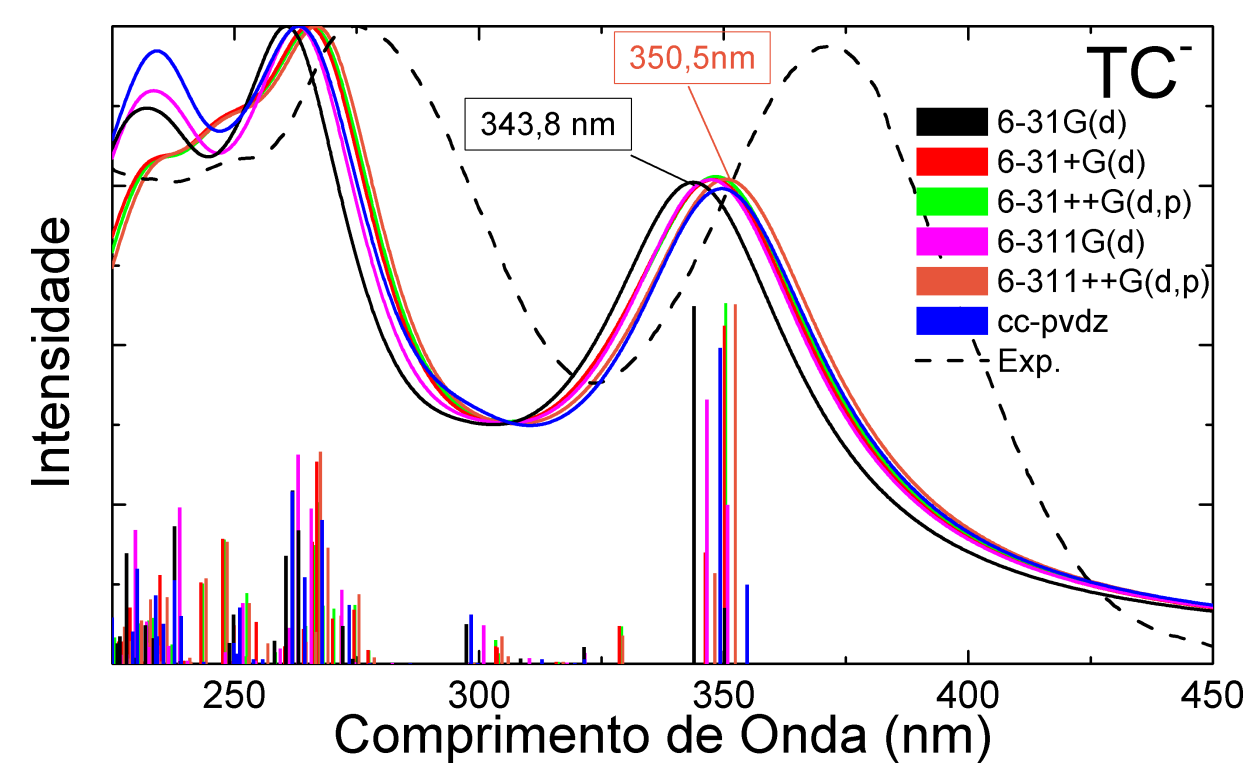

Figura 3.8: Espectro de absorção eletrônica para a forma $\mathrm{TC}^{-}$com diferentes bases, usando o funcional B3LYP e o solvente tratado com PCM. A melhor descrição eletrônica da TC ${ }^{-}$não resultou numa melhora significativa do espectro, quando comparado com o resultado experimental [30].

aumentando a energia de excitação, além de mudança da intensidade de algumas transições.

Aplicando o PCM obtivemos uma boa descrição qualitativa do espectro de absorção eletrônica das cinco formas estudadas. Em geral, as bandas teóricas apresentaram um deslocamento entre $36 \mathrm{~nm}$ e $15 \mathrm{~nm}$ com as bandas experimentais, mas a forma e, em alguns casos, a intensidade mostraram semelhanças com os dados experimentais. Analisando apenas as posições do máximo da primeira banda em função das diferentes formas da TC, resumida na tabela 3.15, o PCM não consegue descrever corretamente os deslocamento experimentais. A partir deste ponto, vamos buscar alternativas para melhorar a descrição dos espectros, além das posições dos máximos e as intensidades das bandas do espectro. 


\subsection{Simulação Clássica}

Uma forma mais realista de tratar o solvente é tratá-lo explicitamente. Além do mais, vamos considerar as flutuações das posições da moléculas impostas pelo sistema líquido e as condições termodinâmicas. Neste ponto vamos usar a simulação de MC para gerar configurações com a TC em água. Todas as moléculas nessa simulação são tratadas como rígidas, isso significa que movimentos internos da molécula não serão permitidos tanto para a TC quanto para a água. O campo de força utilizado será a OPLS-AA para a TC e SPC/E para a água.

Vamos desprezar os valores originais de cargas oriundas do campo de força OPLS-AA. Os novos valores de cargas forma obtidos por um cálculo de MQ usando o método MP2 e a base 6-31G(d) em solvente PCM com o esquema CHELPG, procedimento com vários casos de sucesso em nosso grupo [34,36,37,56,98-100]. No CHELPG, as cargas atômicas são ajustadas para reproduzir o potencial eletrostático molecular, a partir de uma grade onde temos o valor do potencial em cada ponto do espaço em torno dos átomos. O ajuste de cargas deve manter a mesma carga total do sistema [88]. Este procedimento inclui o efeito de polarização do solvente sobre o soluto.

Tais simulações foram realizadas no ensemble NPT, mantendo o número de átomos, pressão e temperatura constantes. O número de moléculas de água é igual a 1500, quantidade suficiente para gerar uma caixa de simulação de volume igual a $44 \mathrm{~nm}^{3}$, capaz de envolver toda a TC. A densidade das simulações clássicas atingiu o valor médio de $1.025 \mathrm{~g} / \mathrm{cm}^{3}$. A temperatura usada foi de $25^{\circ} \mathrm{C}$, a mesma dos experimentos realizados. A figura 3.9 mostra a função de distribuição de mínima distância das várias formas da TC em água, que converge para o valor 1 para grandes distâncias [58]. Em cada caso, a tabela interna à figura indica a quantidade de moléculas de água incluindo a primeira e a segunda camada de solvatação, indicando também 
a quantidade de moléculas até o máximo destas camadas. O aumento da primeira camada de solvatação em função da carga negativa da molécula TC está diretamente ligado ao número de ligações de hidrogênio realizadas pela TC, tema dos próximos parágrafos.

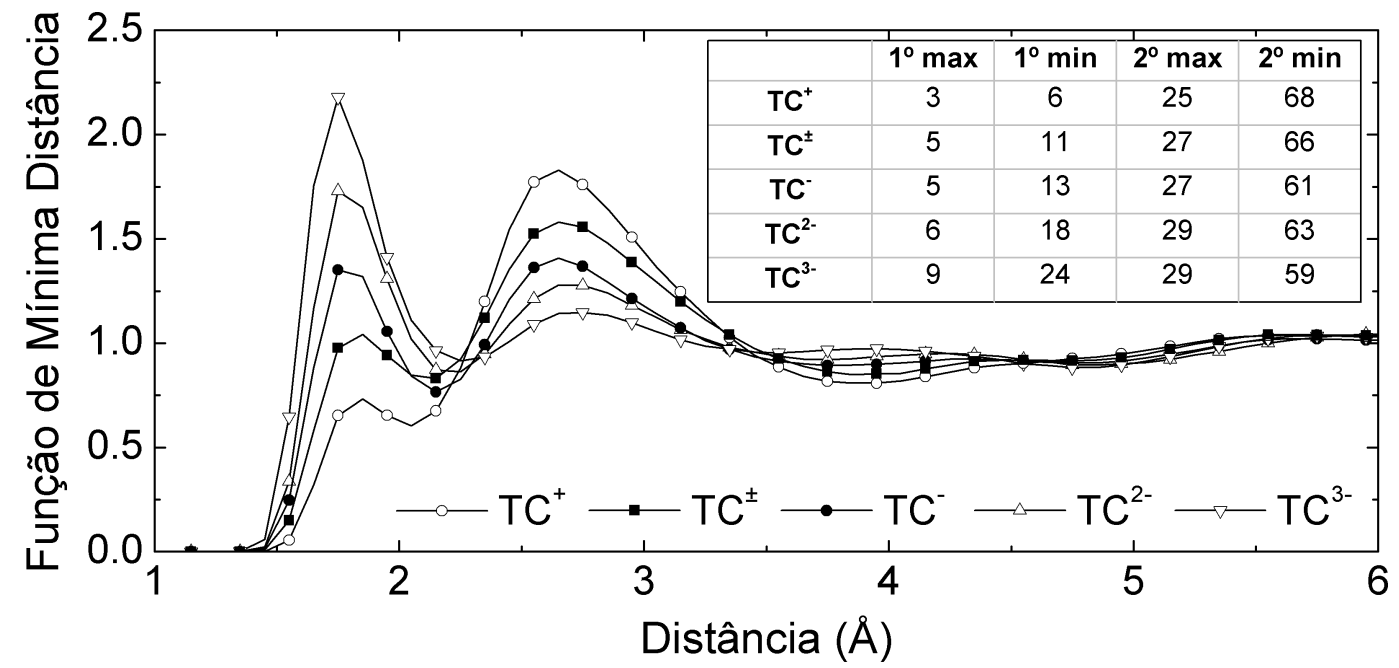

Figura 3.9: Função de mínima distância entre o soluto e as moléculas de água para as 5 formas da TC estudadas. A tabela interna mostra a quantidade de moléculas de água nas duas primeiras camadas de solvatação.

Por possuir diversos grupos ácidos, várias ligações de hidrogênio são observadas durante a simulação clássica. Além de ser energeticamente favorável, outros critérios foram adotados para considerar uma ligação de hidrogênio: distância entre os átomos $\mathrm{X}^{2}-\mathrm{O}_{\text {água }}$ menor ou igual a $3.6 \AA ̊$ e ângulo X-O água $-\mathrm{H}_{\text {água/TC }}$ menor ou igual a $35.0^{\circ}$. Aceitador, em nossos sistemas estudados, são os átomos $X$ na iminência de receber um hidrogênio de uma molécula da água próxima. Doador é considerado a ligação do átomo X com um hidrogênio da molécula TC próxima de um oxigênio da água $\left(\mathrm{O}_{\text {água }}\right)$, indicando que o hidrogênio tem potencial para sair da TC para o solvente.

Claramente, a TC deixa de ser doadora para se tornar aceitadora quando a carga da molécula se torna negativa, conforme pode ser visto nas tabelas 3.8 e 3.9.

\footnotetext{
${ }^{2} \mathrm{X}$, em nossas simulações, pode ser qualquer oxigênio $(\mathrm{O})$ ou nitrogênio $(\mathrm{N})$ da TC.
} 
Tabela 3.8: Ligações de hidrogênio onde as diferentes formas da TC atuam como aceitador de hidrogênios do solvente.

\begin{tabular}{c|cccccccccc|c}
\hline \hline & $\mathrm{O}_{1}$ & $\mathrm{O}_{3}$ & $\mathrm{O}_{6}$ & $\mathrm{O}_{10}$ & $\mathrm{O}_{11}$ & $\mathrm{O}_{12}$ & $\mathrm{O}_{12 a}$ & $\mathrm{O}_{a m}$ & $\mathrm{~N}_{a m}$ & $\mathrm{~N}_{d m}$ & Aceitadores \\
\hline $\mathrm{TC}^{+}$ & 0,42 & 0,05 & 0,60 & 0,57 & 0,04 & 0,05 & 0,02 & 0,54 & 0,00 & 0,00 & 2,29 \\
$\mathrm{TC}^{ \pm}$ & 0,72 & 0,44 & 0,46 & 0,35 & 0,09 & 0,09 & 0,14 & 0,94 & 0,26 & 0,00 & 3,49 \\
$\mathrm{TC}^{-}$ & 0,68 & 1,03 & 0,84 & 0,92 & 0,53 & 0,64 & 0,35 & 0,96 & 0,27 & 0,00 & 6,22 \\
$\mathrm{TC}^{2-}$ & 1,13 & 1,45 & 0,69 & 0,82 & 0,52 & 0,57 & 0,58 & 1,25 & 0,41 & 0,27 & 7,69 \\
$\mathrm{TC}^{3-}$ & 1,02 & 1,00 & 1,00 & 2,76 & 1,11 & 0,78 & 0,66 & 1,45 & 0,31 & 0,13 & 10,22 \\
\hline \hline
\end{tabular}

Tabela 3.9: Ligações de hidrogênio onde as diferentes formas da TC atuam como doador de hidrogênios para o solvente. Inclui também a soma das médias das ligações de hidrogênio.

\begin{tabular}{c|ccccccc|c|c}
\hline \hline & $\mathrm{O}_{3}$ & $\mathrm{O}_{6}$ & $\mathrm{O}_{10}$ & $\mathrm{O}_{12}$ & $\mathrm{O}_{12 a}$ & $\mathrm{~N}_{a m}$ & $\mathrm{~N}_{d m}$ & Doadores & Total geral \\
\hline $\mathrm{TC}^{+}$ & 0,00 & 0,99 & 0,00 & 0,00 & 0,91 & 1,02 & 0,10 & 3,02 & 5,31 \\
$\mathrm{TC}^{ \pm}$ & - & 0,97 & 0,01 & 0,01 & 0,77 & 0,83 & 0,68 & 3,27 & 6,76 \\
$\mathrm{TC}^{-}$ & - & 0,02 & 0,01 & - & 0,16 & 0,59 & 0,03 & 0,81 & 7,03 \\
$\mathrm{TC}^{2-}$ & - & 0,11 & 0,02 & - & 0,11 & 0,26 & - & 0,50 & 8,19 \\
$\mathrm{TC}^{3-}$ & - & 0,04 & - & - & 0,07 & 0,46 & - & 0,57 & 10,79 \\
\hline \hline
\end{tabular}

Este comportamento é esperado com perda de hidrogênios devido às desprotonações sofridas pelas diferentes formas estudadas, ao alterar a acidez do solvente, permitindo a aproximação de mais moléculas de água no soluto. Pela disposição dos átomos na TC, algumas ligações de hidrogênio acabam sendo blindadas, como $\mathrm{N}_{d m}$ aceitador. Outras, possuem alta incidência na condição de aceitador e doador: $\mathrm{O}_{6}, \mathrm{~N}_{a m}$ e $\mathrm{O}_{12 a}$. $\mathrm{O}$ átomo $\mathrm{O}_{10}$ faz uma ligação de hidrogênio interna com o $\mathrm{O}_{11}$, da mesma forma que ocorre com o átomo $\mathrm{O}_{12} \mathrm{e}_{3}$, e por isso apresenta baixos valores médios atuando como doador. O número médio de ligações de hidrogênio varia de 5 a 11, valores que estão dentro do primeiro pico da função de mínima distância, figura 3.9. 
Uma esfera dentro de um cubo possui, no máximo, $52 \%$ do volume do cubo. Sendo que a nossa caixa de simulação tem a forma de um cubo, praticamente metade do solvente forma um envoltório esférico em torno do soluto, tal que a densidade seja isotrópica. Sabemos que numa distância muito grande, a interação de dois corpos é praticamente nula e qualquer propriedade calculada no soluto com referência deve convergir a partir de certa distância. Assim, vamos tratar o solvente até um raio de corte, igual à metade da caixa de simulação, gerando configurações com a TC e mais 750 moléculas de água próximas ao soluto, que representa metade do solvente da caixa de simulação.

Uma análise importante para uma boa descrição estatística do líquido é o comportamento da função de auto-correlação de energia. Como vamos tratar várias configurações geométricas que contém as posições de diversos átomos, devemos levar em conta apenas as configurações estatisticamente relevantes. Na figura 3.10 temos a função de auto-correlação da energia, que relaciona o grau da correlação de duas configurações separadas por um número de ciclos de MC. Vamos tratar configurações separadas por 5.000 ciclos de MC, pois o valor está abaixo de $15 \%$ na maioria dos casos. Na parte de equilíbrio foram efetuados 500.000 ciclos de MC resultando em 100 configurações estatisticamente descorrelacionadas. Com essas configurações, duas abordagens foram utilizadas para tratar o solvente e obter o espectro de absorção: ASEC e solvente parcialmente explícito.

No modelo ASEC trabalhamos com apenas um cálculo TDDFT numa configuração fictícia, usando o funcional B3LYP e a base 6-31G(d). Aproveitando o fato da TC ser mantida rígida internamente, alinhamos todas as configurações energeticamente descorrelacionadas pela molécula de TC e realizamos a convolução de 100 configurações do solvente, que não é tratado explicitamente e sim como carga pontual. Portanto, o cálculo submetido à MQ possui a TC explícita e 225000 cargas pontuais, e a distribuição de cargas em torno do solvente forma um campo eletros- 


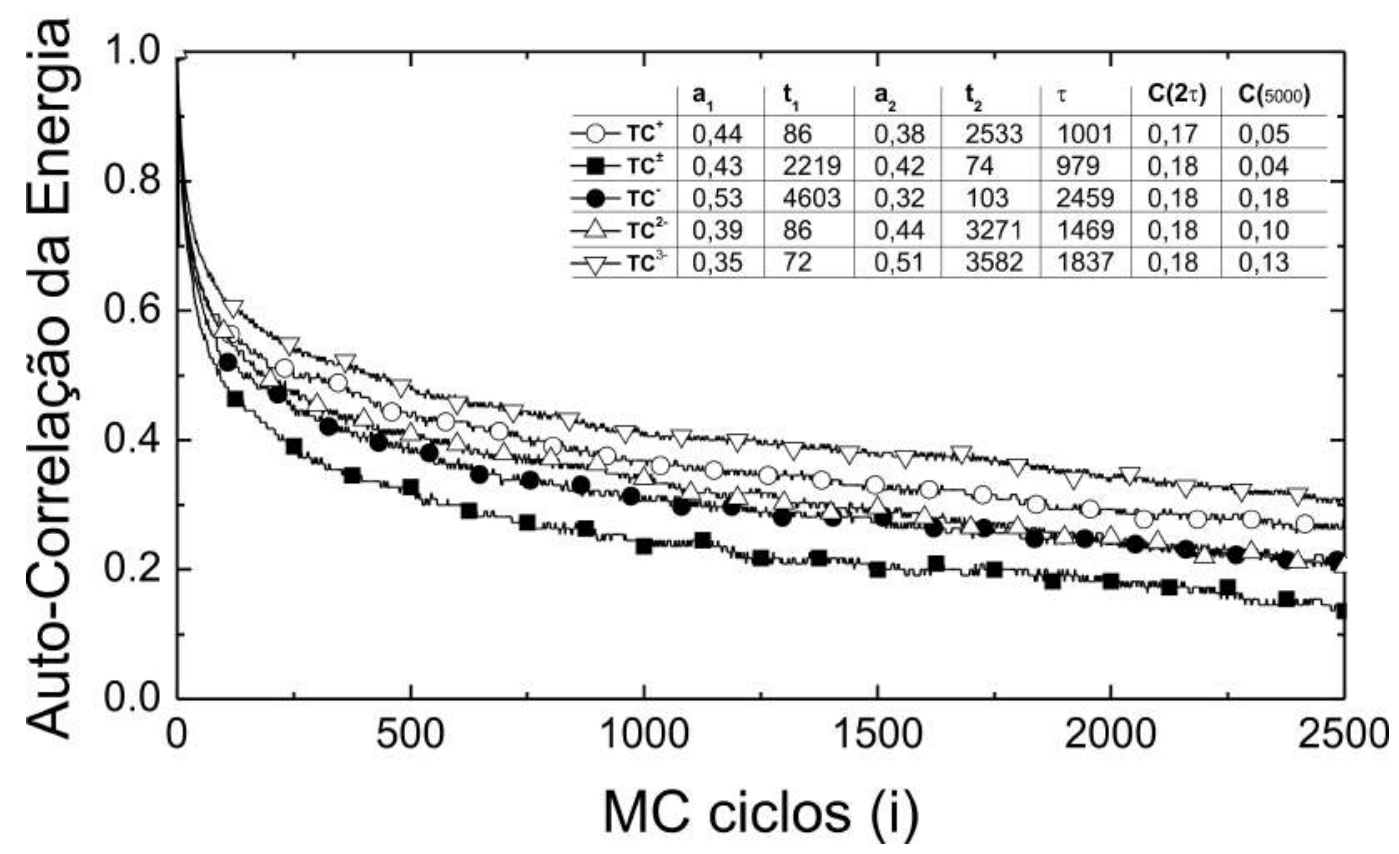

Figura 3.10: Função de auto-correlação da energia para as 5 formas da TC estudadas. A tabela interna mostra os valores dos coeficientes para o ajuste da função de auto-correlação (ver seção 2.1.3) e na última coluna temos o valor da correlação para duas configurações separadas por 5000 ciclos de MC.

tático médio. A convolução do espectro é realizada considerando cada transição como uma função lorentziana de largura $2000 \mathrm{~cm}^{-1}$.

No modelo de solvente parcialmente explícito ${ }^{3}$, o espectro de absorção é calculado com TDDFT para 100 configurações estatisticamente descorrelacionadas, formadas pela a molécula de TC mais 9 moléculas de águas mais próximas na forma explícita e 741 moléculas de água como cargas pontuais. O número de águas explícitas está relacionado ao número de ligações de hidrogênio e as 741 moléculas de águas como cargas pontuais formam uma superfície em torno do soluto. Acreditamos que esta descrição é mais sofisticada e detalhada do que usando o modelo ASEC, mas possui um preço elevado: enquanto no modelo ASEC apenas uma configuração é submetida ao calculo de MQ, com o modelo explícito são necessários

\footnotetext{
${ }^{3}$ Para simplificação, vamos considerar modelo explícito ou solvente explícito como modelo de solvente parcialmente explícito.
} 
100 configurações com a adição da descrição eletrônica do solvente. Para aumentar a eficiência, usamos a base 6-31G(d) para descrever os átomos da TC e a base 6$31 G$ para descrever os átomos das águas explícitas. Para a convolução do espectro, adotamos a largura de cada transição igual a $1600 \mathrm{~cm}^{-1}$.

\subsection{Espectro de Absorção com o Modelo ASEC e Sol- vente Parcialmente Explícito}

Até o momento, descrevemos a simulação clássica usada para obter as configurações da molécula de TC em água. Agora vamos obter o espectro de absorção usando o modelo ASEC e o modelo de solvente parcialmente explícito e comparar com o espectro obtido com o PCM e com o resultado experimental. Os orbitais envolvidos nos três modelos apresentam a mesma forma, e vamos considerar apenas os orbitais com o modelo explícito de uma configuração relevante, com dados expostos nas tabelas 3.10, 3.11, 3.12, 3.13 e 3.14 em conjunto com o espectro obtido. No espectro de absorção, figuras 3.11, 3.12, 3.13, 3.14 e 3.15, a linha contínua é a convolução das transições pelo modelo explícito, a linha pontilhada é a convolução das transições obtidas com o modelo ASEC e a linha tracejada é o resultado experimental [30]. Todos esses espectros são normalizados para facilitar a comparação. As linhas verticais são as transições dadas pelo modelo explicito mais intensas, com intensidade dada pelo dobro da força de oscilador e separadas pelo tipo de transição.

O primeiro caso tratado é a forma catiônica da $\mathrm{TC}, \mathrm{TC}^{+}$, com o espectro na figura 3.11 e dados comparativos na tabela 3.10. Os três modelos para descrever o solvente apresentam a forma do espectro bastante semelhante, sendo que a diferença entre os máximos das bandas também é pequena. A primeira banda é formada exclusivamente por três tipos de transições: $\mathrm{H} \rightarrow \mathrm{L}, \mathrm{H} \rightarrow \mathrm{L}+1$ e $\mathrm{H}-1 \rightarrow \mathrm{L}+1$. Estas 

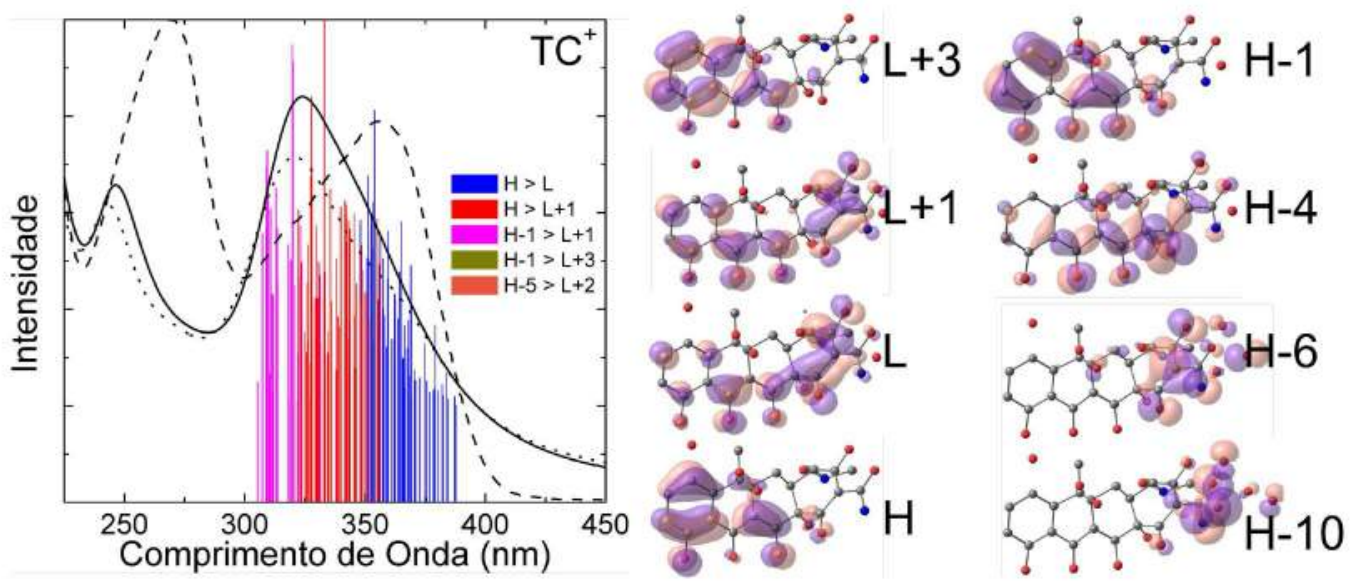

Figura 3.11: Espectro de absorção eletrônica da forma $\mathrm{TC}^{+}$comparando os modelos explícitos, ASEC e o resultado experimental [30] e os orbitais envolvidos nas transições mais intensas de uma configuração representativa com o modelo explícito.

Tabela 3.10: Comparativo entre os máximos do espectro de absorção experimental [30] e teórico com as contribuições de cada orbital envolvido de uma configuração relevante da forma $\mathrm{TC}^{+}$usando o modelo explícito.

\begin{tabular}{|c|c|c|c|c|c|}
\hline \multicolumn{2}{|c|}{ Máximo } & \multirow{2}{*}{ Ordem } & \multirow{2}{*}{$\begin{array}{l}\text { Energia } \\
(\mathrm{eV} / \mathrm{nm})\end{array}$} & \multirow{2}{*}{$\begin{array}{l}\text { Força do } \\
\text { Oscilador }\end{array}$} & \multirow{2}{*}{ Composição } \\
\hline Exp. (nm) & Teór. (nm) & & & & \\
\hline \multirow[t]{8}{*}{355,4} & $324,0(0,84)$ & 1 & $3,37 / 367,6$ & 0,0697 & $\mathrm{H} \rightarrow \mathrm{L}(67 \%)$ \\
\hline & & 2 & $3,58 / 346,6$ & 0,0928 & $\mathrm{H}-1 \rightarrow \mathrm{L}(39 \%)$ \\
\hline & & & & & $\mathrm{H} \rightarrow \mathrm{L}+1(30 \%)$ \\
\hline & & & & & $\mathrm{H} \rightarrow \mathrm{L}(23 \%)$ \\
\hline & & 3 & $3,76 / 329,7$ & 0,1432 & $\mathrm{H} \rightarrow \mathrm{L}+1(59 \%)$ \\
\hline & & & & & $\mathrm{H}-1 \rightarrow \mathrm{L}(22 \%)$ \\
\hline & & 4 & $3,83 / 323,8$ & 0,0709 & $\mathrm{H}-1 \rightarrow \mathrm{L}+1(25 \%)$ \\
\hline & & & & & $\mathrm{H}-4 \rightarrow \mathrm{L}(22 \%)$ \\
\hline \multirow[t]{2}{*}{268,7} & $246,4(0,66)$ & 25 & $5,13 / 241,7$ & 0,1004 & $\mathrm{H}-10 \rightarrow \mathrm{L}(25 \%)$ \\
\hline & & & & & $\mathrm{H}-6 \rightarrow \mathrm{L}+1(22 \%)$ \\
\hline
\end{tabular}

três transições envolvem transferência de carga do anel D para o anel A, sendo que tais transições contribuem para a largura da banda. O máximo da banda no PCM, 
ficou em 323,2 nm, enquanto que no modelo ASEC é igual a 320,6 nm e no modelo explícito ficou igual a 324,0 nm: uma diferença de 3,4 nm entre os três modelos. Ainda assim, a distância para a primeira banda experimental é da ordem de $30 \mathrm{~nm}$. Outra falha é na descrição da largura da segunda banda, muito pequena de acordo com os métodos teóricos. Os valores dos máximos da segunda banda se mantêm próximos, mas é difícil estipular a transferência da carga nas transições que formam a segunda banda, pois nesta região as transições envolvem várias contribuições de diferentes orbitais.

No segundo caso, $\mathrm{TC}^{ \pm}$, o espectro de absorção com o modelo ASEC e explícito, figura 3.12 e tabela 3.11, apresentam formas diferentes do PCM. O máximo da primeira banda obtido pelo modelo ASEC está em 317,2 nm e no modelo explícito está em 318,4 nm, enquanto que o valor apresentado pelo PCM foi igual a 342,7 $\mathrm{nm}$, resultando numa diferença de até $25,5 \mathrm{~nm}$. Com isso, a separação entre a banda experimental e os dois modelos, ASEC e explícito, se tornou ainda maior quando comparada ao PCM, chegando a 40,5 nm. Olhando para essa primeira banda, observamos que há mudança da intensidade: na figura 3.12, existe um ombro na região de $350 \mathrm{~nm}$, enquanto na figura 3.4, este ombro está no outro lado da banda, em $310 \mathrm{~nm}$. Para a formação dessa banda, constatamos a grande mistura entre as transições $\mathrm{H} \rightarrow \mathrm{L}, \mathrm{H}-2 \rightarrow \mathrm{L}$ e $\mathrm{H}-1 \rightarrow \mathrm{L}$, que nos dois últimos casos há transferência de carga do anel A para os anéis DCB. A transição H $\rightarrow$ L apresenta apenas remanejamento de carga nos anéis DCB. Com o modelo explícito, a segunda banda fica mais evidente do que no PCM, formada basicamente pela transição $\mathrm{H}-1 \rightarrow$ $\mathrm{L}+1$, envolvendo um reajuste de cargas no anel A. O máximo dessa banda apresenta pequena diferença entre os modelos de solvente usados, partindo de 250,9 nm no modelo ASEC para 255,5 nm no modelo explícito, distantes de 25,4 nm e 20,8 nm do pico experimental, respectivamente.

No terceiro caso, $\mathrm{TC}^{-}$, o espectro de absorção apresenta a forma próxima 

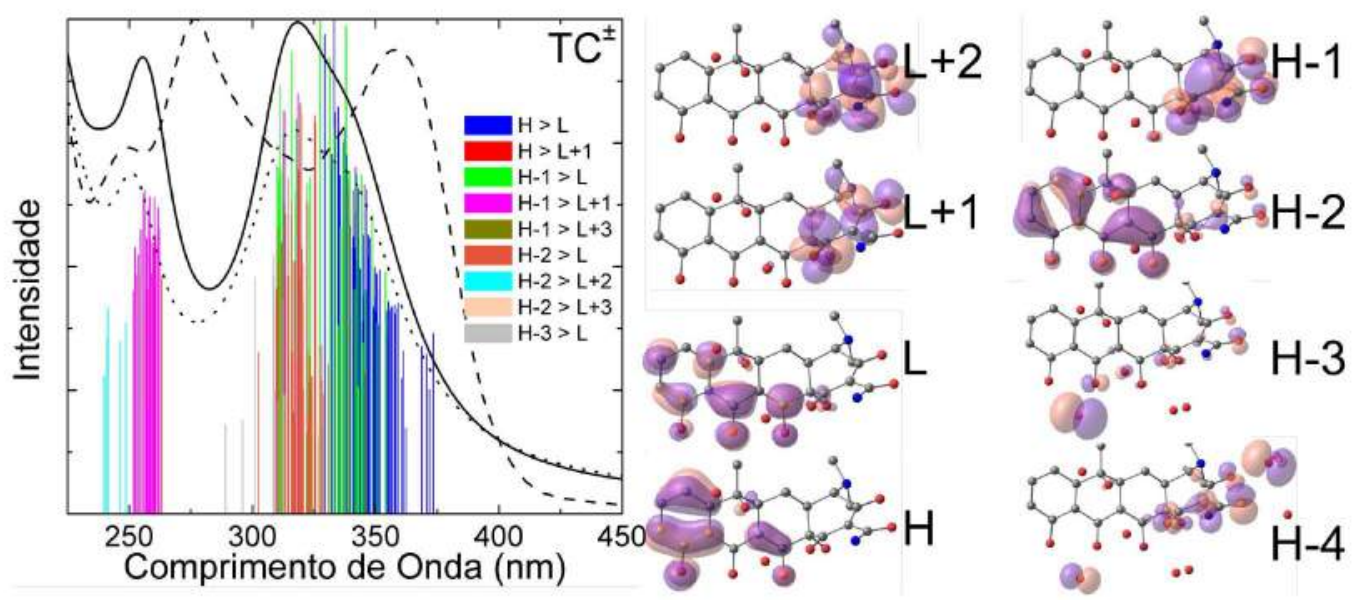

Figura 3.12: Espectro de absorção eletrônica da forma $\mathrm{TC}^{ \pm}$comparando os modelos explícitos, ASEC e o resultado experimental [30] e os orbitais envolvidos nas transições mais intensas de uma configuração representativa com o modelo explícito.

Tabela 3.11: Comparativo entre os máximos do espectro de absorção experimental [30] e teórico com as contribuições de cada orbital envolvido de uma configuração relevante da forma $\mathrm{TC}^{ \pm}$usando o modelo explícito ( $\mathrm{L}+15$ semelhante ao $\mathrm{L}+4)$.

\begin{tabular}{|c|c|c|c|c|c|}
\hline \multicolumn{2}{|c|}{ Máximo } & \multirow{2}{*}{ Ordem } & \multirow{2}{*}{$\begin{array}{l}\text { Energia } \\
(\mathrm{eV} / \mathrm{nm})\end{array}$} & \multirow{2}{*}{$\begin{array}{l}\text { Força do } \\
\text { Oscilador }\end{array}$} & \multirow{2}{*}{ Composição } \\
\hline Exp. (nm) & Teór. (nm) & & & & \\
\hline \multirow[t]{5}{*}{357,7} & $318,4(0,99)$ & 1 & $3,54 / 350,5$ & 0,1618 & $\mathrm{H} \rightarrow \mathrm{L}(93 \%)$ \\
\hline & & 3 & $3,86 / 320,9$ & 0,1247 & $\mathrm{H}-2 \rightarrow \mathrm{L}(47 \%)$ \\
\hline & & & & & $\mathrm{H}-3 \rightarrow \mathrm{L}(25 \%)$ \\
\hline & & 4 & $3,91 / 317,0$ & 0,1581 & $\mathrm{H}-2 \rightarrow \mathrm{L}(41 \%)$ \\
\hline & & & & & $\mathrm{H}-3 \rightarrow \mathrm{L}(39 \%)$ \\
\hline \multirow[t]{6}{*}{276,3} & $255,5(0,92)$ & 15 & $4,78 / 259,4$ & 0,1621 & $\mathrm{H}-1 \rightarrow \mathrm{L}+1(53 \%)$ \\
\hline & & & & & $\mathrm{H}-4 \rightarrow \mathrm{L}+1(28 \%)$ \\
\hline & $220,3(1,00)$ & 27 & $5,32 / 232,9$ & 0,0704 & $\mathrm{H}-15 \rightarrow \mathrm{L}+1(37 \%)$ \\
\hline & & & & & $\mathrm{H}-1 \rightarrow \mathrm{L}+2(29 \%)$ \\
\hline & & 33 & $5,57 / 222,6$ & 0,0999 & $\mathrm{H}-15 \rightarrow \mathrm{L}+1(36 \%)$ \\
\hline & & & & & $\mathrm{H}-1 \rightarrow \mathrm{L}+2(26 \%)$ \\
\hline
\end{tabular}


ao experimento, conforme figura 3.13 e tabela 3.12. Essa forma é semelhante a apresentada pelo PCM, figura 3.5. A primeira banda possui o máximo em 334,6
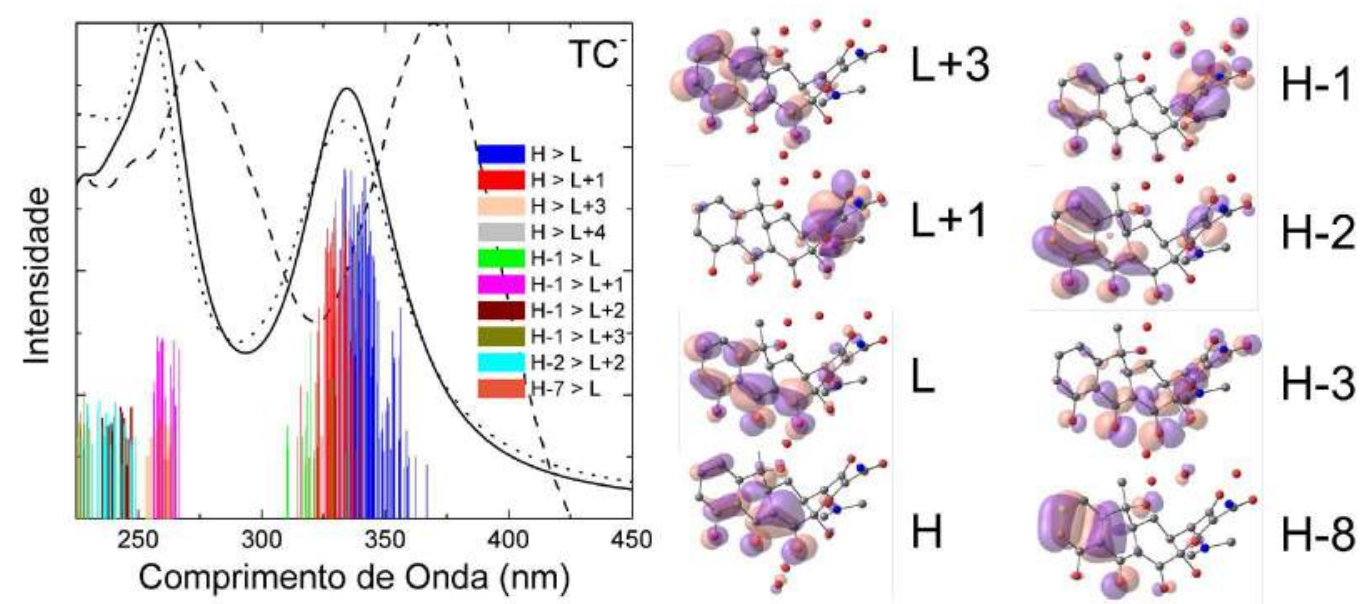

Figura 3.13: Espectro de absorção eletrônica da forma $\mathrm{TC}^{-}$comparando os modelos explícitos, ASEC e o resultado experimental [30] e os orbitais envolvidos nas transições mais intensas de uma configuração representativa com o modelo explícito.

Tabela 3.12: Comparativo entre os máximos do espectro de absorção experimental [30] e teórico com as contribuições de cada orbital envolvido de uma configuração relevante da forma $\mathrm{TC}^{-}$usando o modelo explícito $(\mathrm{L}+2$ semelhante ao $\mathrm{L}+1)$.

\begin{tabular}{|c|c|c|c|c|c|}
\hline \multicolumn{2}{|c|}{ Máximo } & \multirow{2}{*}{ Ordem } & \multirow{2}{*}{$\begin{array}{l}\text { Energia } \\
(\mathrm{eV} / \mathrm{nm})\end{array}$} & \multirow{2}{*}{$\begin{array}{l}\text { Força do } \\
\text { Oscilador }\end{array}$} & \multirow{2}{*}{ Composição } \\
\hline Exp. (nm) & Teór. (nm) & & & & \\
\hline \multirow[t]{3}{*}{371,7} & $334,6(0,87)$ & 1 & $3,66 / 338,3$ & 0,2662 & $\mathrm{H} \rightarrow \mathrm{L}(73 \%)$ \\
\hline & & 2 & $3,69 / 336,3$ & 0,0687 & $\mathrm{H}-3 \rightarrow \mathrm{L}(59 \%)$ \\
\hline & & & & & $\mathrm{H} \rightarrow \mathrm{L}(20 \%)$ \\
\hline \multirow[t]{4}{*}{275,5} & $258,4(1,00)$ & 11 & $4,61 / 269,1$ & 0,0666 & $\mathrm{H}-1 \rightarrow \mathrm{L}+1(35 \%)$ \\
\hline & & 18 & $4,83 / 256,7$ & 0,0995 & $\mathrm{H}-8 \rightarrow \mathrm{L}(54 \%)$ \\
\hline & & & & & $\mathrm{H} \rightarrow \mathrm{L}+3(38 \%)$ \\
\hline & & 21 & $4,99 / 248,7$ & 0,0619 & $\mathrm{H}-1 \rightarrow \mathrm{L}+2(47 \%)$ \\
\hline \multirow[t]{2}{*}{$* 250,5$} & $229,0(0,69)$ & 36 & $5,50 / 225,3$ & 0,0745 & $\mathrm{H}-2 \rightarrow \mathrm{L}+3(37 \%)$ \\
\hline & & & & & $\mathrm{H}-1 \rightarrow \mathrm{L}+3(25 \%)$ \\
\hline
\end{tabular}


nm pelo modelo explícito, $333,8 \mathrm{~nm}$ pelo modelo ASEC e $343,8 \mathrm{~nm}$ pelo PCM, portanto uma diferença de no máximo 10,0 nm entre os modelos. Comparado ao máximo da primeira banda experimental, a diferença que era $-27,9 \mathrm{~nm}$ para o PCM, agora é $-37,1 \mathrm{~nm}$. Essa primeira banda é formada especialmente pelas transições $\mathrm{H}$ $\rightarrow \mathrm{L}$ e $\mathrm{H} \rightarrow \mathrm{L}+1$, indicando uma transferência de carga dos anéis DCB para o anel A. A segunda banda, com máximo em $255,5 \mathrm{~nm}$ pelo modelo explícito e 255,0 nm pelo modelo ASEC, é dominado por transições que envolvem apenas redistribuição de carga, no anel A ou nos anéis DCB. Esta banda está afastada 20,0 nm da banda experimental, enquanto que o PCM mostra uma menor diferença, igual a 14,9 nm.

O próximo sistema analisado pelos modelos ASEC e explícito foi $\mathrm{TC}^{2-}$, conforme a figura 3.14 e tabela 3.13. A forma do espectro em ambos os modelos ficou qualitativamente próxima ao espectro experimental. A primeira banda é larga e apresenta três transições, $\mathrm{H} \rightarrow \mathrm{L}, \mathrm{H}-1 \rightarrow \mathrm{L}, \mathrm{H} \rightarrow \mathrm{L}+1$. Nos outros casos encontramos que as transições $\mathrm{H}-1 \rightarrow \mathrm{L}$ apresenta energia mais alta que a transições $\mathrm{H} \rightarrow \mathrm{L}+1$, mas o solvente explícito interage com o soluto mudando a ordem dos orbitais. $\mathrm{O}$ efeito continua o mesmo na primeira banda, com transferência de carga sutil para grandes comprimentos de onda enquanto que em baixos comprimentos de onda fica evidente a saída de carga dos anéis DCB para o anel A. O máximo dessa banda é localizado em 338,0 nm para o modelo explícito e 334,7 para o modelo ASEC, distantes de aproximadamente $40 \mathrm{~nm}$ da banda experimental. A segunda banda apresenta alta intensidade pela grande quantidade de transições em sua região, visto que suas transições isoladas possuem intensidade menor que transições da primeira banda. Por esse mesmo motivo, vários fluxos de cargas são observados dentro dessa banda. O máximo dessa banda está localizado em 256,0 nm pelo modelo explícito e 248,6 nm pelo modelo ASEC, enquanto que o máximo da banda experimental está localizado em $270,2 \mathrm{~nm}$.

Com a forma $\mathrm{TC}^{3-}$ em água usando o modelo ASEC e explícito, figura 3.15 e 


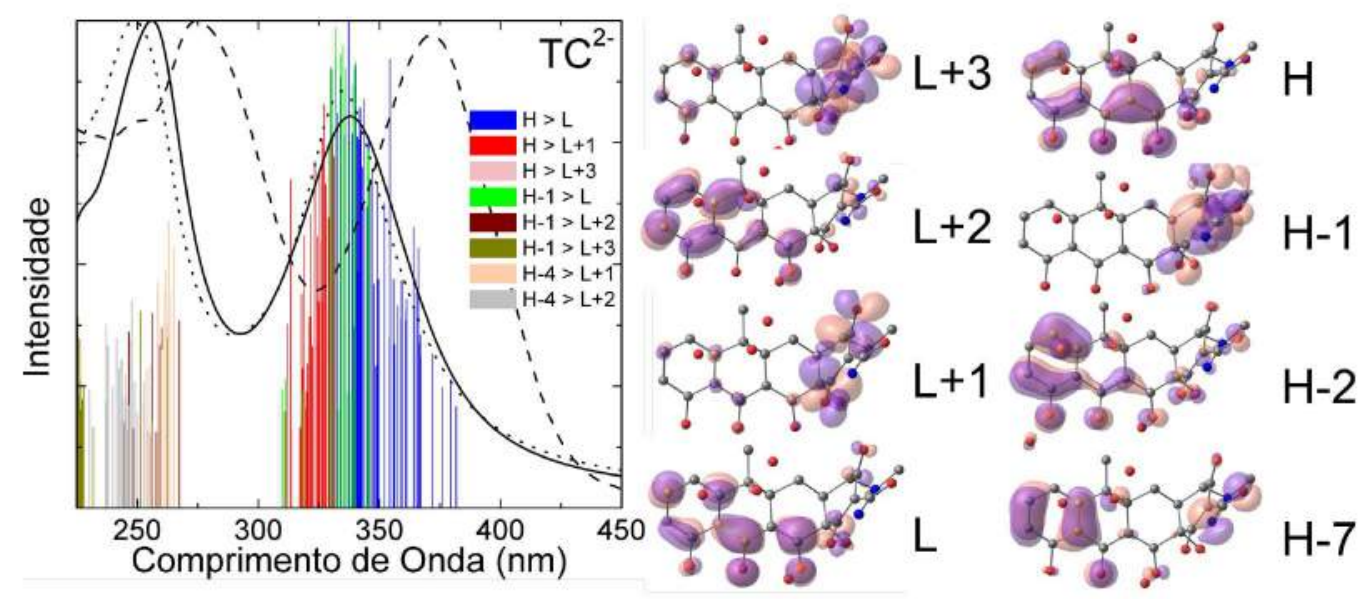

Figura 3.14: Espectro de absorção eletrônica da forma $\mathrm{TC}^{2-}$ comparando os modelos explícitos, ASEC e o resultado experimental [30] e os orbitais envolvidos nas transições mais intensas de uma configuração representativa com o modelo explícito (H-3 semelhante ao H-1).

Tabela 3.13: Comparativo entre os máximos do espectro de absorção experimental [30] e teórico com as contribuições de cada orbital envolvido de uma configuração relevante da forma $\mathrm{TC}^{2-}$ usando o modelo explícito.

\begin{tabular}{|c|c|c|c|c|c|}
\hline \multicolumn{2}{|c|}{ Máximo } & \multirow{2}{*}{ Ordem } & \multirow{2}{*}{$\begin{array}{l}\text { Energia } \\
(\mathrm{eV} / \mathrm{nm})\end{array}$} & \multirow{2}{*}{$\begin{array}{c}\text { Força } \\
\text { Oscilador }\end{array}$} & \multirow{2}{*}{ Composição } \\
\hline Exp. (nm) & Teór. (nm) & & & & \\
\hline 381,0 & $338,0(0,80)$ & 2 & $3,74 / 331,8$ & 0,3080 & $\mathrm{H} \rightarrow \mathrm{L}(83 \%)$ \\
\hline \multirow[t]{6}{*}{270,2} & $256,0(1,00)$ & 12 & $4,69 / 264,3$ & 0,1730 & $\mathrm{H}-1 \rightarrow \mathrm{L}+1(41 \%)$ \\
\hline & & & & & $\mathrm{H}-3 \rightarrow \mathrm{L}+1(26 \%)$ \\
\hline & & 15 & $4,81 / 257,5$ & 0,0682 & $\mathrm{H}-7 \rightarrow \mathrm{L}(45 \%)$ \\
\hline & & 30 & $5,35 / 231,7$ & 0,0550 & $\mathrm{H}-1 \rightarrow \mathrm{L}+3(51 \%)$ \\
\hline & & & & & $\mathrm{H}-1 \rightarrow \mathrm{L}+2(24 \%)$ \\
\hline & & 31 & $5,41 / 229,1$ & 0,0769 & $\mathrm{H}-2 \rightarrow \mathrm{L}+2(60 \%)$ \\
\hline
\end{tabular}

tabela 3.14, o espectro segue a mesma aparência apresentada no PCM. A primeira banda é bem larga e formada por diversas transições, todas envolvendo transferência de carga dos anéis DCB para o anel A, conforme os orbitais plotados de uma configuração relevante. O mesmo comportamento da carga ocorre na segunda banda, mais intensa pela quantidade de transições do que a intensidade de cada 

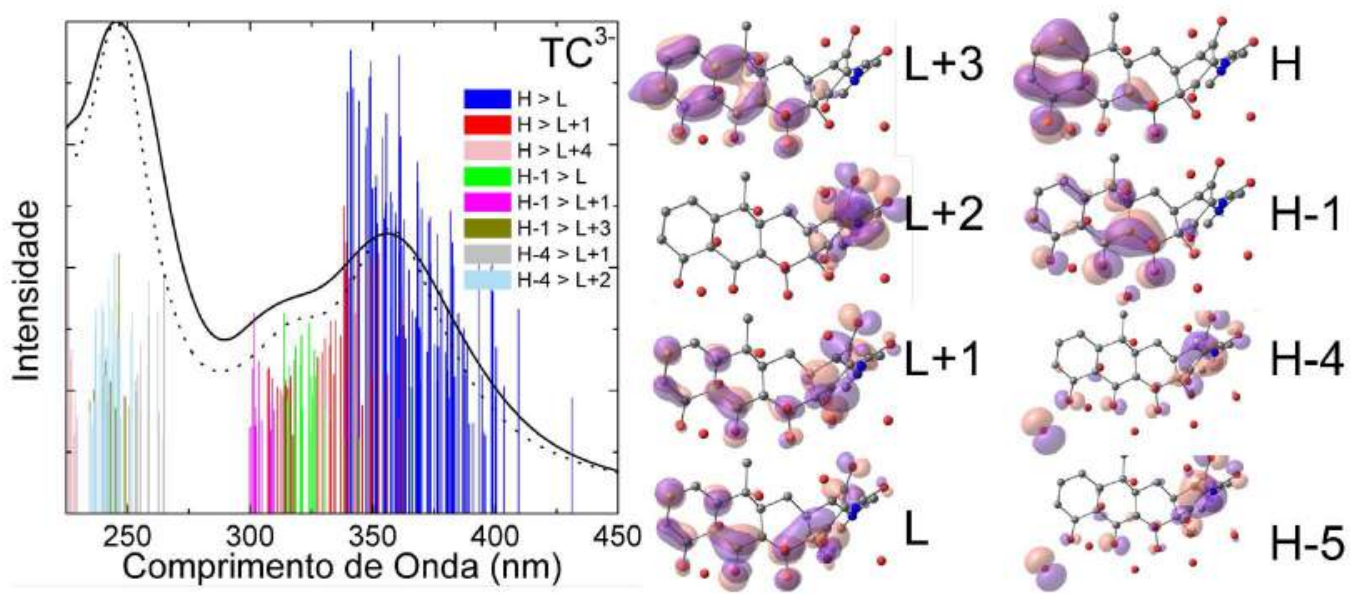

Figura 3.15: Espectro de absorção eletrônica da forma $\mathrm{TC}^{3-}$ comparando os modelos explícitos, ASEC e o resultado experimental [30] e os orbitais envolvidos nas transições mais intensas de uma configuração representativa com o modelo explícito.

Tabela 3.14: Comparativo entre os máximos do espectro de absorção experimental [30] e teórico com as contribuições de cada orbital envolvido de uma configuração relevante da forma $\mathrm{TC}^{3-}$ usando o modelo explícito.

\begin{tabular}{ccccc}
\hline \hline $\begin{array}{c}\text { Máximo } \\
\text { Teórico }(\mathrm{nm})\end{array}$ & Ordem & $\begin{array}{c}\text { Energia } \\
(\mathrm{eV} / \mathrm{nm})\end{array}$ & $\begin{array}{c}\text { Força do } \\
\text { Oscilador }\end{array}$ & Composição \\
\hline $356,0(0,57)$ & 2 & $3,47 / 357,7$ & 0,2109 & $\mathrm{H} \rightarrow \mathrm{L}(88 \%)$ \\
& 5 & $3,92 / 316,5$ & 0,0928 & $\mathrm{H} \rightarrow \mathrm{L}+1(64 \%)$ \\
& & & & $\mathrm{H}-1 \rightarrow \mathrm{L}(27 \%)$ \\
\hline $245,5(1,00)$ & 22 & $4,88 / 254,3$ & 0,0869 & $\mathrm{H}-5 \rightarrow \mathrm{L}+1(64 \%)$ \\
& 26 & $5,07 / 244,7$ & 0,0621 & $\mathrm{H}-1 \rightarrow \mathrm{L}+3(51 \%)$ \\
& 27 & $5,13 / 241,7$ & 0,1540 & $\mathrm{H}-5 \rightarrow \mathrm{L}+2(47 \%)$ \\
& & & & $\mathrm{H}-4 \rightarrow \mathrm{L}+2(36 \%)$ \\
\hline \hline
\end{tabular}

uma isolada. O máximo da primeira banda está localizado em $356,0 \mathrm{~nm}$ para o modelo explícito e $357,0 \mathrm{~nm}$ para o modelo ASEC, ambos distantes menos que 20 
nm do resultado obtido com PCM, igual a 374,3 nm. A segunda banda apresenta o máximo próximo para os três modelos, em torno de $245 \mathrm{~nm}$.

Poderíamos supor que o número de moléculas de água explícita não fosse suficiente para descrever corretamente o espectro de absorção, gerando a grande diferença entre os máximos dos modelos teóricos e experimental. Afinal, as transições são em sua grande maioria do tipo $\pi-\pi^{*}$ e é esperado que a energia de transição diminua ao usar o solvente explícito. Além do mais, o valor da energia para este tipo de transição pode depender do número de moléculas explícitas do solvente. $\mathrm{Na}$ figura 3.16 incrementamos o número de moléculas explícitas do solvente, de 9 até 44 moléculas de água, para 10 configurações submetidas aos cálculos de TDDFT e observamos a mudança no espectro convoluído, usando o funcional híbrido B3LYP com a base 6-31G $(d)$ para os átomos da TC e a base 6-31G para os átomos das moléculas de água na forma explícitas.

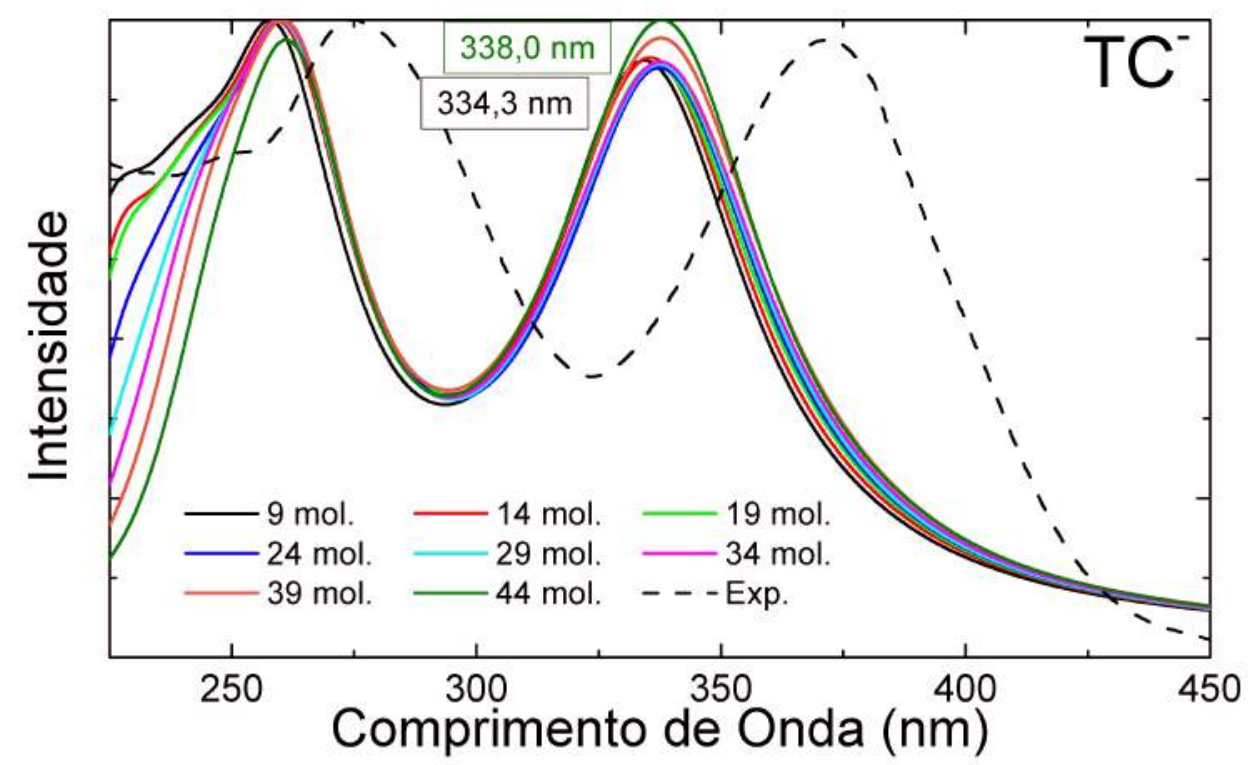

Figura 3.16: Espectro de absorção eletrônica da $\mathrm{TC}^{-}$incrementando o número de moléculas de águas explícitas. Convolução realizada com apenas 10 configurações.

A figura 3.16 mostra um pequeno deslocamento na posição das bandas, onde o máximo da primeira banda do espectro com 9 águas está localizado em 334,3 
nm enquanto para o espectro com 44 águas o mesmo máximo está localizado em $338,0 \mathrm{~nm}$, apresentando uma diferença de 3,7 nm. O deslocamento do máximo da segunda banda também é pequeno, entretanto o ombro localizado à direita desta banda desaparece manifestando o mesmo efeito ao adicionar as funções difusas no PCM, figura 3.8. Com o maior número de moléculas explícitas de solvente, aumenta o número de transições em baixas energias, sendo necessário incrementar o número total de transições para uma melhor descrição na região abaixo de 250 nm. O baixo valor do deslocamento indica que somente as pontes de hidrogênio são suficientes para uma boa descrição do espectro de absorção, não sendo necessário estender o número de moléculas explícitas do solvente até a primeira camada de solvatação. Outra questão é o custo computacional, pois o sistema com 44 moléculas de água aumenta o tempo de execução em 5 vezes para cada configuração quando comparado ao sistema com 9 moléculas de água.

Outros métodos para obter o espectro de absorção foram empregados em etapas iniciais desta tese. Semi-empíricos como Zindo fornecido por Zerner [101] e suas modificações $[80,102]$ apresentaram bandas com energia muito alta resultando em um espectro muito diferente do experimento. Métodos mais acurados como CIS e CIS(D) também apresentaram excitações com altas energias, sendo que o espectro é comprometido pelo reduzido número de transições usadas devido ao alto custo computacional. Diferentes funcionais da DFT foram exaustivamente testados, sendo o funcional O3LYP que mais deslocou o espectro inteiro da direção desejada, mas ainda ficando longe do resultado experimental. Já o CAM-B3LYP, indicado para sistemas com transferência de carga, apresentou altas energias para a excitação.

No geral, obtivemos uma boa descrição qualitativa do espectro de absorção, mas a diferença das posições das bandas experimentais e teóricas não foi solucionada, se tornando ainda maior ao usar os modelos ASEC e explícito quando 
comparada com o PCM. Comparando o modelo ASEC com o explícito, temos pequenos deslocamentos do máximo, mas a forma das bandas são semelhantes. Assim, tratar parte do solvente na forma explícita pouco interfere no espectro e a maior contribuição se deve à parte eletrostática, formada pelo envoltório de cargas pontuais nos dois modelos. Devemos lembrar que o PCM trata a interação com o solvente de forma eletrostática usando um modelo contínuo e polarizável.

Tabela 3.15: Comparativo entre o máximo da primeira banda do espectro de absorção eletrônica experimental e teórica obtido a partir das diferentes formas da TC. Os valores de deslocamento estão em nm.

\begin{tabular}{ccccc}
\hline \hline & $\mathrm{TC}^{+} \rightarrow \mathrm{TC}^{ \pm}$ & $\mathrm{TC}^{ \pm} \rightarrow \mathrm{TC}^{-}$ & $\mathrm{TC}^{-} \rightarrow \mathrm{TC}^{2-}$ & $\mathrm{TC}^{2-} \rightarrow \mathrm{TC}^{3-}$ \\
\hline Experimento [30] & 2,3 & 14,0 & 9,3 & \\
PCM & 19,5 & 1,1 & 1,2 & 29,2 \\
Modelo ASEC & $-3,4$ & 16,6 & 0,8 & 22,3 \\
Explícito & $-5,6$ & 16,2 & 3,4 & 18,0 \\
\hline \hline
\end{tabular}

Olhando apenas para o deslocamento da primeira banda entre as diferentes formas da TC, tabela 3.15, observamos que apenas a mudança da forma $\mathrm{TC}^{ \pm}$para a forma $\mathrm{TC}^{-}$foi bem descrita com os modelos ASEC e explícito. Devemos lembrar que a diferença entre o modelo ASEC e explícito é a adição da estrutura eletrônica do solvente em torno do soluto que parece pouco interferir no espectro. Dessa forma, as mudanças vistas tanto experimentalmente quanto nos modelos teóricos estão relacionadas ao efeito de desprotonações/protonação e as mudanças na geometria da TC, sempre em função do $\mathrm{pH}$ do solvente.

Ficou evidente que a molécula de TC apresenta duas regiões cromóforas, uma em torno do anel A e outra nos anéis DCB. Mas transições com transferência total de carga entre essas duas regiões apresentam baixa frequência, as vezes associada a força do oscilador fraca. Foi observado o efeito de transferência de carga para as transições mais intensas da primeira banda, com origem nos anéis DCB e destino 
no anel $\mathrm{A}$, de modo intenso para as formas $\mathrm{TC}^{+}$e $\mathrm{TC}^{3-}$, sendo bastante sutil para a forma $\mathrm{TC}^{-}$. Com a forma $\mathrm{TC}^{ \pm}$, o sentido da transferência da carga se inverte. Para a $\mathrm{TC}^{2-}$, observamos apenas a redistribuição de carga nestas transições. Mesma dinâmica foi obtida com PCM para as diferentes formas da TC estudadas. 


\section{Capítulo 4}

\section{Espectro de Absorção do Complexo MgTC em Água}

Como já explicado na introdução, o complexo MgTC é importante na inibição da síntese proteica, se acoplando ao ribossoma e impossibilitando a cópia do material genético bacteriano. A descrição deste complexo fornecerá um domínio do tratamento de sistemas íons-ligante, acarretando em uma maior facilidade ao estudar o complexo EuTC. O Mg neutro possui $12 \mathrm{e}^{-}$, mas perde dois elétrons, ficando preenchido completamente até a segunda camada, conforme o diagrama abaixo.

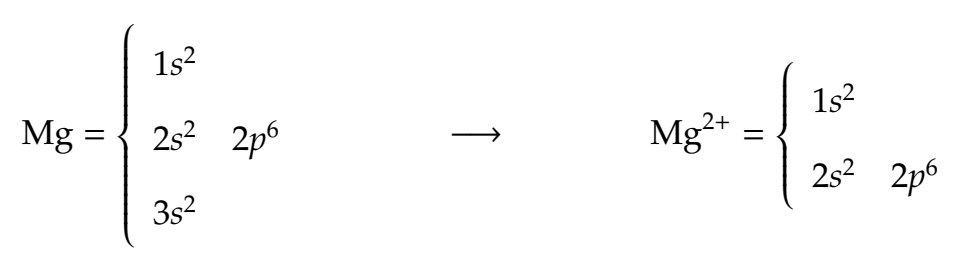

Devido à presença de vários grupos ácidos localizados nas extremidades da TC é possível que exista mais de uma posição onde o íon pode-se hospedar: os oxigênios e nitrogênios da TC apresentam carga negativa atraindo o íon $\mathrm{Mg}^{2+}$. Assim, a correta posição do íon se torna um desafio para os cálculos de absorção. Experimentalmente, diversas concentrações de íons e TC são possíveis, mas vamos limitar o nossos estudos para os dois complexos: MgTC e $\mathrm{Mg}_{2} \mathrm{TC}$. Para este estudo, trabalharemos 


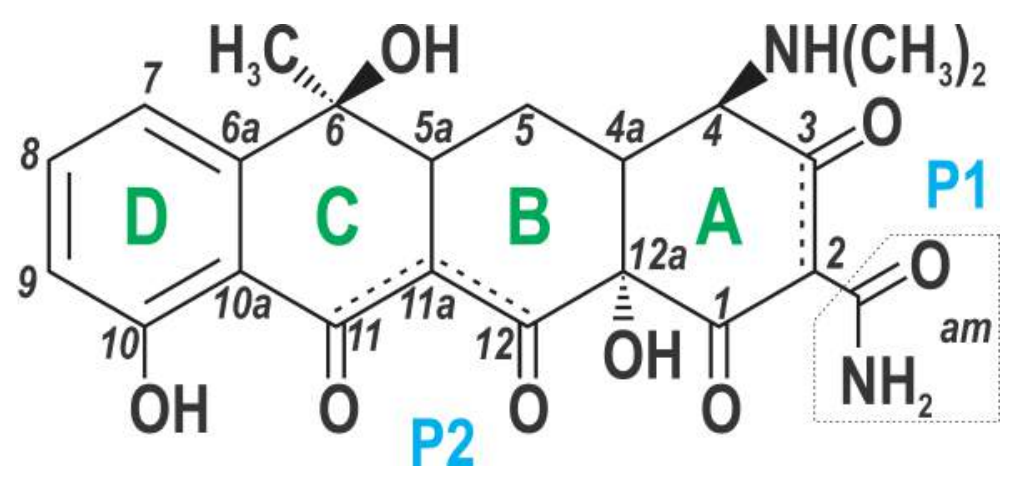

Figura 4.1: Estrutura da molécula $\mathrm{TC}^{-}$com as posições P1 e P2, onde o íon Mg pode se hospedar.

apenas com o ligante na forma $\mathrm{TC}^{-}$(ânion monovalente). As possíveis posições de hospedagem do íon $\mathrm{Mg}$ com a $\mathrm{TC}^{-}$são denominadas P1 e/ou P2. P1 está localizada entre os átomos de oxigênio $\mathrm{O}_{3} \mathrm{e}_{a m}$, ou seja, próximo ao anel $\mathrm{A}$ e ao grupo amida ${ }^{1}$. Já a posição P2 está localizada entre os átomos de oxigênio $\mathrm{O}_{11}$ e $\mathrm{O}_{12}$, portanto próximo aos anéis BC. Essas posições foram obtidas com várias simulações clássicas por MC com diferentes condições iniciais contendo apenas a molécula de TC o íon $\mathrm{Mg}$, onde apenas as posições P1 e P2 eram, ao final do processo, acessíveis ao íon. Estes resultados estão em boa concordância com dados experimentais e outras evidências estruturais $[103,104]$, onde há a indicação de que primeiro íon tende a ocupar a posição P2 formando o MgTC e o segundo íon tende a ocupar a posição P1 para formar $\mathrm{Mg}_{2} \mathrm{TC}$.

A primeira etapa para estudar espectro de absorção do complexo MgTC foi otimizar a geometria usando DFT com o funcional híbrido B3LYP e o conjunto de bases 6-31G(d). O solvente adotado foi novamente a água, e para o cálculo de otimização foi usada a aproximação PCM. Na tabela 4.1 comparamos a energia do complexo considerando as duas posições de acoplamento do íon. A diferença de energia entre as duas posições do íon poderia descartar a análise de determinada posição, caso o valor fosse muito alto indicando que tal posicionamento seria en-

\footnotetext{
${ }^{1}$ Consultar a figura 3.1 para a nomenclatura dos átomos da TC.
} 
ergeticamente desfavorável. Para ficar mais claro, uma análise populacional deve ser efetuada. Sendo um sistema formado por apenas duas espécies, $[A]+[B]=1$, podemos definir a população de cada espécie em função de $K$

$$
K=\frac{[B]}{[A]} ; \quad \text { População A }:[A]=\frac{1}{K+1} ; \quad \text { População } B:[B]=\frac{K}{K+1} .
$$

Cada espécie possui uma energia associada, e podemos definir pesos para cada uma delas em função do peso de Bolztmann, onde

$$
K=\exp \left(\frac{-\Delta E_{B-A}}{R T}\right)=\exp \left(\frac{-\left(E_{B}-E_{A}\right)}{R T}\right) .
$$

Considerando a temperatura ambiente igual a $25^{\circ} \mathrm{C}$, o produto da constante de Bolztmann e temperatura apresenta o valor de $0,593 \mathrm{kcal} / \mathrm{mol}$. Se a diferença de energia entre duas espécies for maior que $2 \mathrm{kcal} / \mathrm{mol}$, a análise populacional indica que apenas a espécie de menor energia estará presente no sistema. Caso o valor seja menor que $2 \mathrm{kcal} / \mathrm{mol}$, podemos estipular a população de cada espécie.

Tabela 4.1: Comparativo entre as energias das espécies estudadas do complexo MgTC obtidas com B3LYP/6-31G(d) usando o PCM para descrever o solvente e considerando as duas posições P1 e P2 para o íon. A unidade usada na segunda e terceira coluna é o hartree $\left(E_{h}\right)$ e na quarta coluna temos

\begin{tabular}{|c|c|c|c|}
\hline Método & MgTC:P1 $\left(E_{h}\right)$ & $\operatorname{MgTC}: \mathrm{P} 2\left(E_{h}\right)$ & $\mathrm{P} 2$ - P1 (kcal/mol)) \\
\hline Otimização com $\mathrm{TC}^{-}$rígida & $-1763,569427$ & $-1763,573152$ & $-2,337$ \\
\hline Otimização com $\mathrm{TC}^{-}$flexível & $-1763,584614$ & $-1763,581191$ & $-2,148$ \\
\hline $\mathrm{TC}^{-}$flexível + correções vibracionais & $-1763,201364$ & $-1763,200019$ & 0,844 \\
\hline
\end{tabular}
a diferença energética entre a posição P2 e P1 $\left(1 E_{h}=627,509 \mathrm{kcal} / \mathrm{mol}\right)$.

Na tabela 4.1, as duas primeiras linhas mostram a energia final após a otimização de geometria em duas situações, deixando a TC rígida na primeira linha e com todo o sistema flexível na segunda linha. Em ambos os casos, a diferença de energia foi favorável ao posicionamento do íon em P2, com valores acima de $2 \mathrm{kcal} / \mathrm{mol} \mathrm{em}$ cada caso. Entretanto, ao adicionar as correções vibracionais com a TC flexível, a diferença passa a ser $0,84 \mathrm{kcal} / \mathrm{mol}$ a favor da posição P1, invertendo a espécie mais 
estável. Devemos lembrar que esta análise leva em conta apenas o complexo MgTC desprezando as flutuações impostas pelo ambiente líquido. Dessa forma, vamos comparar ambas as estruturas e verificar o efeito do posicionamento do íon $\mathrm{Mg}^{2+}$ para o espectro vibracional e de absorção eletrônica.

A partir das geometrias dos complexos $\mathrm{MgTC}$ e $\mathrm{Mg}_{2} \mathrm{TC}$ obtidas com o modelo de solvente PCM é possível analisar as mudanças no espectro infravermelho, podendo resultar em deslocamentos ou mudanças de intensidades dos picos de acordo com o posicionamento do íon $\mathrm{Mg}^{2+}$, posições P1 e P2 na figura 4.2. O primeiro caso é o estiramento $\mathrm{OH}_{10}$ com o íon na posição P1 aonde o espectro IR apresenta um pico intenso $(1236 \varepsilon)$ posicionado em $3152 \mathrm{~cm}^{-1}$. Ao tratar o íon na posição P2, este pico diminui de intensidade pela metade $(603 \varepsilon)$ sendo reposicionado para $3383 \mathrm{~cm}^{-1}$, se deslocando $231 \mathrm{~cm}^{-1}$. No caso do $\mathrm{Mg}_{2} \mathrm{TC}$, a posição do pico se torna a mesma apresentada pelo íon em P2. Este estiramento é na direção da posição P2, e a ausência do Mg em P2 deixa o pico do espectro bastante intenso, devido à liberdade do movimento dos átomos próximos. Deslocamento semelhante é também observado no espectro vibracional para o estiramento do conjunto $\mathrm{NH}_{d m}$, que no complexo MgTC com o íon na posição P1 é localizado em $3152 \mathrm{~cm}^{-1}$ com intensidade de $790 \varepsilon$. Tanto para o complexo $\mathrm{MgTC}$ quanto $\mathrm{Mg}_{2} \mathrm{TC}$, essa vibração sofre um deslocamento para 3269 cm$^{-1}$ e queda da intensidade (438 ع) devido à presença do íon Mg em P2. Novamente, este estiramento também ocorre na direção da posição do íon $\mathrm{Mg} \mathrm{em}$ P2.

Outro grupo deslocado é o movimento de estiramento das cetonas $\mathrm{O}_{1}, \mathrm{O}_{a m}, \mathrm{O}_{3}$ associado à deformação angular simétrica (tesoura) do grupo $\left(\mathrm{NH}_{2}\right)_{a m}$. Com o íon na posição P2, essa vibração está localizada no espectro em $1729 \mathrm{~cm}^{-1}$ com intensidade média $(849 \varepsilon$ ), mas com o íon na posição P1 ocorre um deslocamento para 1647 $\mathrm{cm}^{-1}$, transformando num pico de alta intensidade $(1647 \varepsilon)$. Para o complexo $\mathrm{Mg}_{2} \mathrm{TC}$ temos o mesmo efeito, com o pico em $1653 \mathrm{~cm}^{-1}$ e alta intensidade $(1620 \varepsilon)$. 


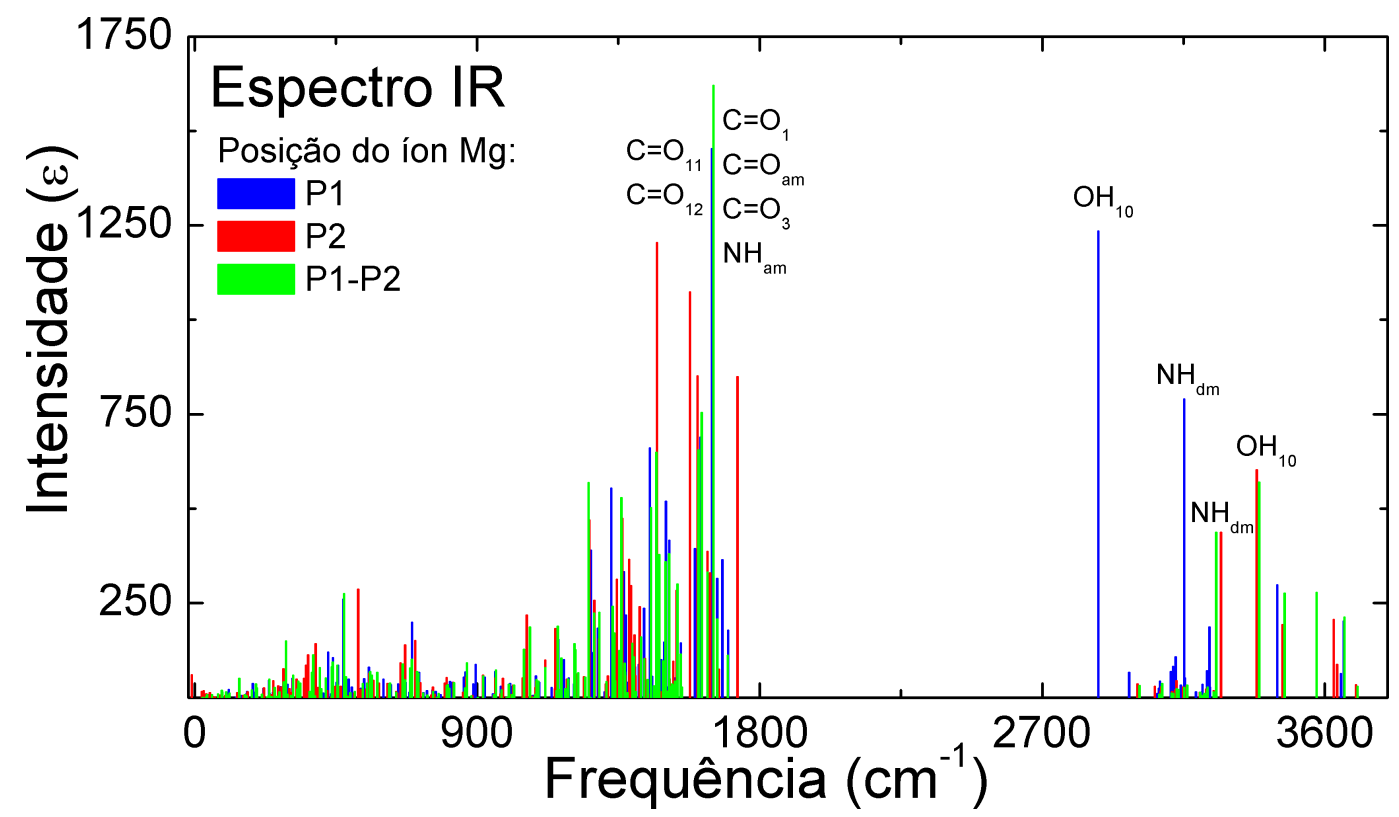

Figura 4.2: Espectro infravermelho obtido com um cálculo B3LYP/6-31G(d) em água usando o PCM onde podemos comparar os deslocamentos e mudanças de intensidades das vibrações para os complexos MgTC e $\mathrm{Mg}_{2} \mathrm{TC}$ com o íon nas posições P1 e P2.

Neste caso, o estiramento das ligações $\mathrm{C}_{a m}=\mathrm{O}_{a m}$ e $\mathrm{C}_{3}=\mathrm{O}_{3}$ está na direção do íon $\mathrm{Mg}$ em P1, e diferente do caso anterior, a presença do íon aumenta a intensidade deste pico, deslocando-o na direção contrária.

Diversas mudanças são observadas no espectro vibracional em função do posicionamento do íon $\mathrm{Mg}$, com frequências vibracionais positivas indicando que as otimizações de geometria foram bem sucedidas. O próximo passo é aplicar um modelo de descrição do íon e do solvente para obter o espectro de absorção dos complexos MgTC e $\mathrm{Mg}_{2} \mathrm{TC}$. Experimentalmente, tabela 1.3 e ref. [32], o primeiro íon se acopla a TC deslocando a primeira banda em $5 \mathrm{~nm}$ e o segundo íon aumenta a intensidade de uma terceira banda em $240 \mathrm{~nm}$. O desafio é observar tais mudanças no espectro teórico, permitindo estimar a ordem de agregação do íon $\mathrm{Mg}^{2+}$ na TC. 


\subsection{Espectro de Absorção com PCM}

Vamos iniciar a análise do espectro de absorção do complexo formado pelo íon e a TC a partir da estrutura obtida com o PCM. Este modelo permitirá obter os efeitos da presença do íon explícito de uma forma bem simples pois o solvente é tratado como um meio homogêneo, aproximado por uma constante dielétrica. Os espectros obtidos estão expostos nas figuras 4.3, 4.4, 4.5 com os dados para comparação teórico/experimental nas tabelas 4.2, 4.3 e 4.4.

No primeiro caso analisado, complexo MgTC com o íon na posição P1, obtivemos uma boa descrição qualitativa do espectro de absorção quando comparamos os dados experimentais e teóricos, figura 4.3 e tabela 4.2. Uma transição bem fraca é encontrada acima de $425,0 \mathrm{~nm}$, alterando um pouco a forma do espectro. A primeira banda do espectro teórico está localizada em 340,0 nm, distante de -35,2 $\mathrm{nm}$ da mesma banda experimental. A transição mais intensa, nessa banda, possui uma leve transferência de carga para os átomos $\mathrm{C}_{6 a}$ e $\mathrm{C}_{9}$ do anel $\mathrm{D}$ e grupos ácidos ligados ao anel $\mathrm{A}(\mathrm{H} \rightarrow \mathrm{L}+1)$, partindo dos anéis $\mathrm{CB}$.

A banda experimental em 270,1 nm é representada no modelo teórico por uma banda com o máximo em 255,1 nm, formada por diversas transições. Na mais intensa há um remanejamento das cargas na região do anel A. Outra redistribuição nos anéis DCB ocorre na banda teórica em 226,6 nm, representada no espectro experimental por um ombro em 252,9 nm.

Destas transições mais intensas, nenhum dos orbitais envolvem o íon de $\mathrm{Mg}$. Isso pode indicar que o íon na posição $\mathrm{P} 1$ influencia pouco no espectro de absorção, apontando para forma do espectro semelhante ao caso da $\mathrm{TC}^{-}$com PCM, figura 3.5. De acordo com os dados experimentais, a banda na região de $350 \mathrm{~nm}$ é deslocada $5 \mathrm{~nm}$ pela presença do íon e neste modelo o deslocamento teve o valor igual a 3,8 nm porém na direção contrária. O PCM apresentou uma diferença de 15,0 a 35,2 

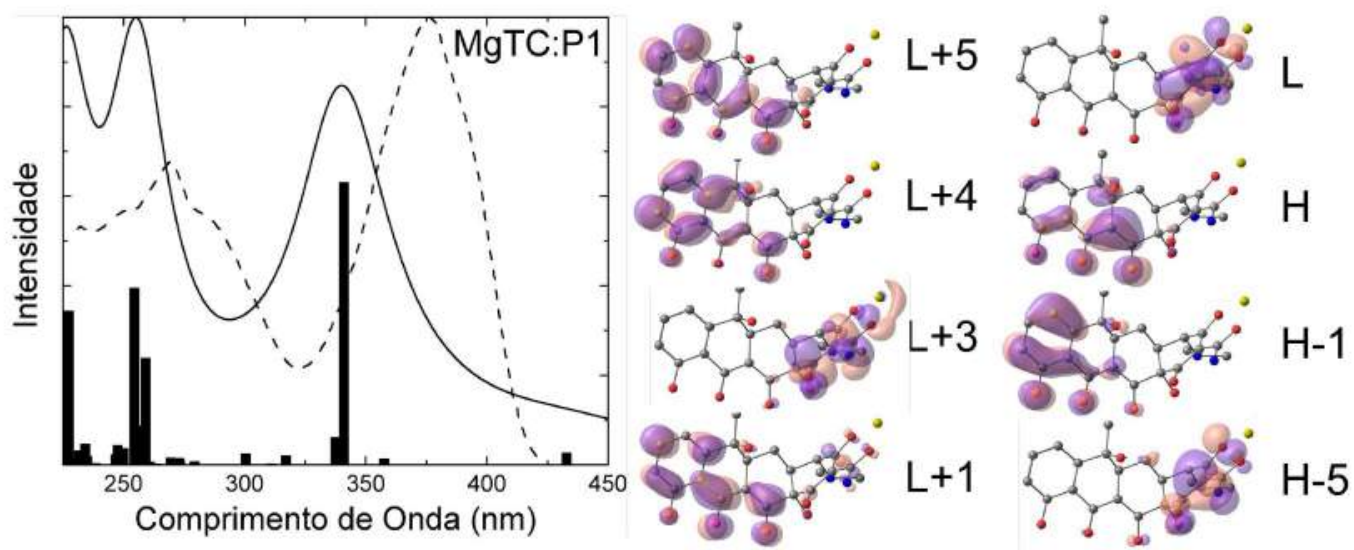

Figura 4.3: Espectro de absorção eletrônica do complexo MgTC com o íon na posição P1 usando o PCM para descrever o solvente (linha contínua) comparada com o resultado experimental (linha tracejada, ref. [30]) e os orbitais envolvidos nas transições mais intensas.

Tabela 4.2: Comparativo entre os máximos do espectro de absorção experimental [30] e teórico com as contribuições de cada orbital envolvido do complexo MgTC com o íon na posição P1 usando o PCM para descrever o solvente. $\mathrm{O}$ * indica a posição do ombro e entre parênteses está a intensidade normalizada.

\begin{tabular}{|c|c|c|c|c|c|}
\hline \multicolumn{2}{|c|}{ Máximo } & \multirow{2}{*}{ Ordem } & \multirow{2}{*}{$\begin{array}{l}\text { Energia } \\
(\mathrm{eV} / \mathrm{nm})\end{array}$} & \multirow{2}{*}{$\begin{array}{l}\text { Força do } \\
\text { Oscilador }\end{array}$} & \multirow{2}{*}{ Composição } \\
\hline Exp. (nm) & Teór. (nm) & & & & \\
\hline 375,2 & $340,0(0,85)$ & 3 & $3,64 / 340,9$ & 0,3154 & $\mathrm{H} \rightarrow \mathrm{L}+1(77 \%)$ \\
\hline \multirow[t]{2}{*}{270,1} & $255,1(1,00)$ & 16 & $4,79 / 259,1$ & 0,1195 & $\mathrm{H} \rightarrow \mathrm{L}+4(53 \%)$ \\
\hline & & 19 & $4,87 / 254,4$ & 0,1977 & $\mathrm{H}-5 \rightarrow \mathrm{L}(73 \%)$ \\
\hline \multirow[t]{3}{*}{$* 252,9$} & $226,4(0,98)$ & 28 & $5,45 / 227,3$ & 0,1716 & $\mathrm{H} \rightarrow \mathrm{L}+5(45 \%)$ \\
\hline & & & & & $\mathrm{H}-5 \rightarrow \mathrm{L}+3(21 \%)$ \\
\hline & & 32 & $5,56 / 222,9$ & 0,0779 & $\mathrm{H}-5 \rightarrow \mathrm{L}+3(46 \%)$ \\
\hline
\end{tabular}

nm quando comparamos os máximos das bandas teórica e experimental, sendo que a banda teórica em 255,1 nm possui intensidade semelhante à banda em 226,4 nm, contrariando o espectro experimental.

No segundo caso analisado, figura 4.3 e tabela 4.2, temos o complexo MgTC com o íon na posição P2. Uma transição em 323,4 nm interfere drasticamente na forma da primeira banda do espectro de absorção, com transferência de carga do 

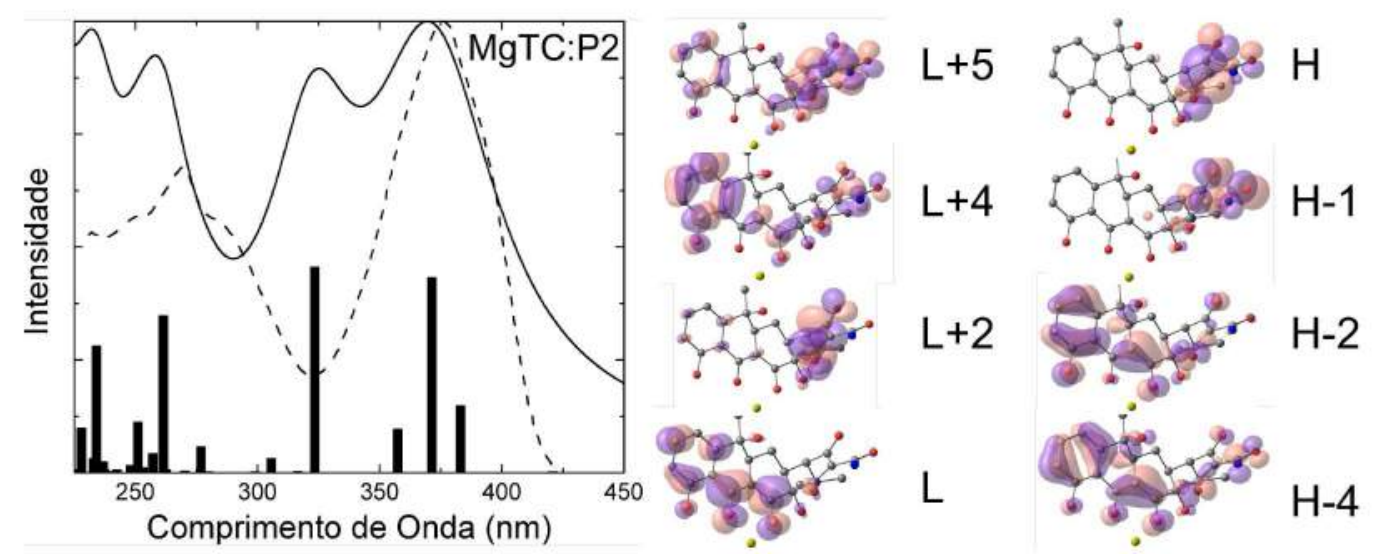

Figura 4.4: Espectro de absorção eletrônica do complexo MgTC com o íon na posição P2 usando o PCM para descrever o solvente (linha contínua) comparada com o resultado experimental (linha tracejada, ref. [30]) e os orbitais envolvidos nas transições mais intensas.

Tabela 4.3: Comparativo entre os máximos do espectro de absorção experimental [30] e teórico com as contribuições de cada orbital envolvido do complexo MgTC com o íon na posição P2 usando o PCM para descrever o solvente.

\begin{tabular}{|c|c|c|c|c|c|}
\hline \multicolumn{2}{|c|}{ Máximo } & \multirow{2}{*}{ Ordem } & \multirow{2}{*}{$\begin{array}{l}\text { Energia } \\
(\mathrm{eV} / \mathrm{nm})\end{array}$} & \multirow{2}{*}{$\begin{array}{l}\text { Força do } \\
\text { Oscilador }\end{array}$} & \multirow{2}{*}{ Composição } \\
\hline Exp. (nm) & Teór. (nm) & & & & \\
\hline \multirow[t]{2}{*}{375,2} & $369,5(1,00)$ & 2 & $3,24 / 383,1$ & 0,0744 & $\mathrm{H}-1 \rightarrow \mathrm{L}(85 \%)$ \\
\hline & & 3 & $3,34 / 371,4$ & 0,2166 & $\mathrm{H}-2 \rightarrow \mathrm{L}(75 \%)$ \\
\hline $\mathrm{n} / \mathrm{d}$ & $325,2(0,90)$ & 5 & $3,83 / 323,4$ & 0,2278 & $\mathrm{H}-4 \rightarrow \mathrm{L}(92 \%)$ \\
\hline 270,1 & $258,1(0,92)$ & 15 & $4,74 / 261,4$ & 0,1740 & $\mathrm{H} \rightarrow \mathrm{L}+2(82 \%)$ \\
\hline \multirow[t]{2}{*}{$* 252,9$} & $232,1(0,98)$ & 27 & $5,30 / 234,0$ & 0,1407 & $\mathrm{H} \rightarrow \mathrm{L}+5(32 \%)$ \\
\hline & & & & & $\mathrm{H} \rightarrow \mathrm{L}+4(28 \%)$ \\
\hline
\end{tabular}

anel A para os anéis DCB. Essa transferência de carga também ocorre no pico da primeira banda, com máximo em 369,5 nm e defasado do resultado experimental em apenas 5,7 nm. Além disso, há uma transição acima de $450 \mathrm{~nm}$ interferindo na forma da primeira banda, contribuindo para o alargamento da banda.

Para a região do espectro de energia maior, banda experimental em 270,1 nm e banda teórico em 258,1 nm, observamos que na transição mais intensa ocorre 
leve transferência de carga do anel A para o anel D. Neste caso, a banda abaixo de 250,0 nm apresenta intensidade maior do que a banda teórica em 258,1 nm, mesmo não apresentando transições mais intensas. Este efeito não está de acordo com o resultado experimental, da mesma forma do complexo MgTC com o íon em P1. Abaixo de $250 \mathrm{~nm}$ há transferência de carga do anel A para o anel D. Comparando com a forma $\mathrm{TC}^{-}$em água usando o PCM, o máximo da primeira banda foi obtido em 343,8 nm e de acordo com este modelo sofre um deslocamento de 25,7 nm, muito acima do deslocamento experimental que é igual a 5,0 nm.

Ao tratar a presença de dois íons $\mathrm{Mg}$, complexo $\mathrm{Mg}_{2} \mathrm{TC}$, conforme a figura 4.5 e tabela 4.4, o espectro apresenta novamente a primeira banda bastante larga. O máximo dessa banda está localizado em 368,6 nm, com sutil transferência de carga dos anéis DCB para o anel A. A mesma dinâmica de carga é obtida no ombro localizado em $337,8 \mathrm{~nm}$, devido à duas transições intensas. Novamente, a primeira banda apresenta a posição do máximo próximo ao resultado experimental, com diferença de apenas 6,2 nm. A segunda banda está localizada em 253,7 nm, perto também do máximo da banda experimental, igual a 269,7 nm, onde ocorre uma redistribuição de carga no anel $\mathrm{A}$.

Usando a aproximação PCM, observamos o deslocamento da primeira banda do complexo $\mathrm{Mg}_{2}$ TC igual a 24,8 nm, novamente muito acima do valor experimental que é igual a $5 \mathrm{~nm}$. Experimentalmente, surge um terceiro pico de alta intensidade e com máximo em 246,1 nm. Esta mudança foi reportada pelo resultado teórico com um pico na região em 223,4 nm, apresentando transferência de carga para o íon Mg. Porém não há uma correspondência entre as intensidades das bandas teóricas e experimentais abaixo de $300 \mathrm{~nm}$. Além disso, a banda abaixo de $250 \mathrm{~nm}$ já estava presente nos complexos MgTC anteriormente descritos, inclusive na forma $\mathrm{TC}^{-} \mathrm{em}$ água usando o mesmo modelo.

No geral, podemos afirmar que o uso do PCM para descrever o solvente apre- 

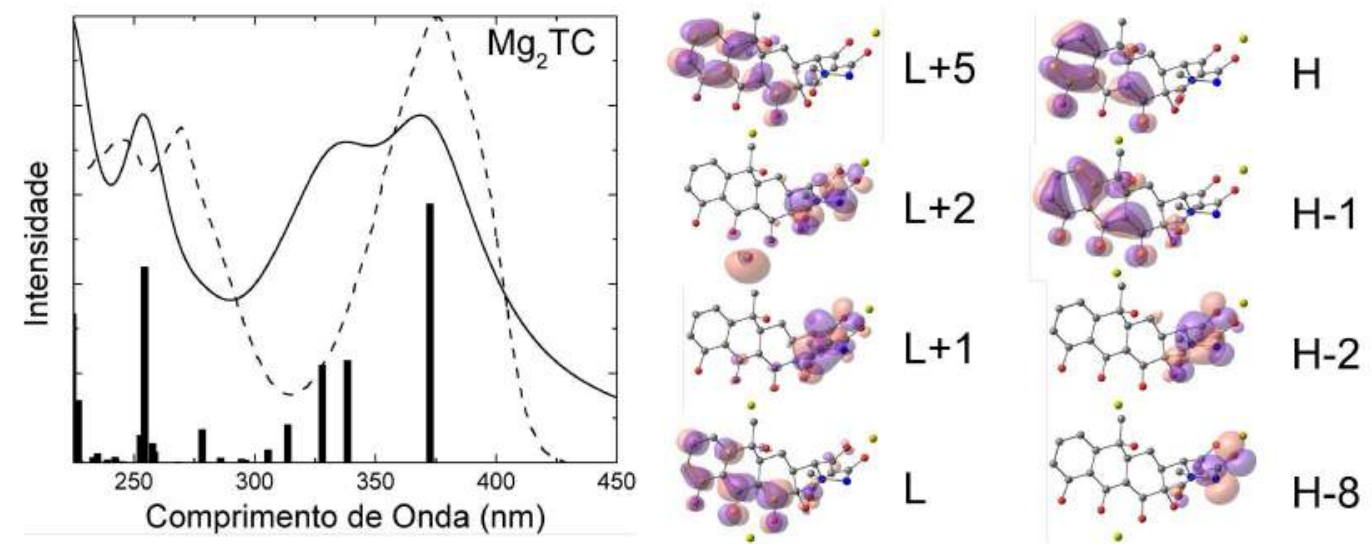

Figura 4.5: Espectro de absorção eletrônica do complexo $\mathrm{Mg}_{2} \mathrm{TC}$ com os íons nas posições P1 e P2 usando o PCM para descrever o solvente (linha contínua) comparada com o resultado experimental (linha tracejada, ref. [30]) e os orbitais envolvidos nas transições mais intensas.

Tabela 4.4: Comparativo entre os máximos do espectro de absorção experimental [30] e teórico com as contribuições de cada orbital envolvido do complexo $\mathrm{Mg}_{2} \mathrm{TC}$ com os íons nas posiç̃̃es P1 e P2 usando o PCM para descrever o solvente.

\begin{tabular}{|c|c|c|c|c|c|}
\hline \multicolumn{2}{|c|}{ Máximo } & \multirow{2}{*}{ Ordem } & \multirow{2}{*}{$\begin{array}{l}\text { Energia } \\
(\mathrm{eV} / \mathrm{nm})\end{array}$} & \multirow{2}{*}{$\begin{array}{l}\text { Força do } \\
\text { Oscilador }\end{array}$} & \multirow{2}{*}{ Composição } \\
\hline Exp. (nm) & Teór. (nm) & & & & \\
\hline 374,8 & $368,6(0,78)$ & 1 & $3,33 / 372,6$ & 0,2899 & $\mathrm{H} \rightarrow \mathrm{L}(95 \%)$ \\
\hline \multirow[t]{2}{*}{$\mathrm{n} / \mathrm{d}$} & $337,8(0,72)$ & 2 & $3,66 / 338,4$ & 0,1144 & $\mathrm{H}-1 \rightarrow \mathrm{L}(69 \%)$ \\
\hline & & 3 & $3,78 / 328,0$ & 0,1092 & $\mathrm{H} \rightarrow \mathrm{L}+1(66 \%)$ \\
\hline 269,7 & $253,7(0,78)$ & 14 & $4,88 / 254,3$ & 0,2191 & $\mathrm{H}-2 \rightarrow \mathrm{L}+1(76 \%)$ \\
\hline \multirow[t]{2}{*}{246,1} & $223,4(1,00)$ & 29 & $5,52 / 224,5$ & 0,1669 & $\mathrm{H}-2 \rightarrow \mathrm{L}+2(42 \%)$ \\
\hline & & & & & $\mathrm{H}-8 \rightarrow \mathrm{L}+1(26 \%)$ \\
\hline
\end{tabular}

sentou um espectro de absorção qualitativamente próximo aos dados experimentais, apesar das anomalias do espectro acima de $400 \mathrm{~nm}$ e deformações pela largura da primeira banda, principalmente com o íon na posição P2. Houve falha na descrição do deslocamento da primeira banda na presença do íon $\mathrm{Mg}$, com deslocamentos bem acima dos dados experimentais. Eletronicamente, o íon só participa para transições com energia elevada, abaixo de $250 \mathrm{~nm}$, mas a sua presença interfere nos 
orbitais em volta. A transferência de carga na primeira banda é bem sutil, com leve transferência de carga dos anéis DCB para o anel A, invertida no caso MgTC com o íon em P2. O próximo passo consiste em adicionar as flutuações do líquido a partir da simulação clássica.

\subsection{Simulação Clássica}

Novamente, vamos aplicar a metodologia envolvendo a simulação clássica para os complexos da TC com o íon $\mathrm{Mg}$, pois acreditamos que trabalhar com o solvente discretizado apresenta uma melhor descrição da interação soluto e solvente, quando comparada ao PCM. Esperamos que os efeitos térmicos inerentes à fase líquida sejam tratados de forma mais realista por inclusão do solvente explicitamente. Esta simulação seguiu os mesmos passos das simulações clássicas realizadas no capítulo anterior. Para a molécula $\mathrm{TC}^{-}$, a geometria é a mesma utilizada na simulação da $\mathrm{TC}^{-}$em água, além das cargas obtidas pelo cálculo CHELPg. A quantidade de moléculas de água não foi alterada, nem os valores de temperatura e pressão. Ao final, o espectro de absorção foi obtido novamente com os dois modelos: ASEC e solvente parcialmente explícito.

O potencial usado para a interação $\mathrm{Mg}^{2+}$ com os outros átomos foi obtido por Aqvist e colaboradores [105], que também pode ser escrito em função do potencial de Lennard-Jones mais Coulomb. A carga do íon usada durante a simulação foi igual

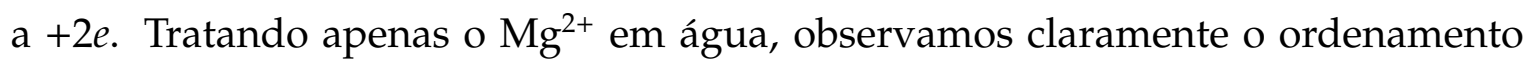
do solvente em torno do íon, com 6 moléculas de água na primeira camada de solvatação: isso indica que o grau de coordenação do íon é igual a 6. A função de distribuição radial em torno do íon mostra que, na primeira camada de solvatação, a distância média entre o íon Mg e o oxigênio da água é igual a 2,0 Å, enquanto entre o íon e o hidrogênio da água é igual a 2,7 Å. Estes resultados estão em excelente 
concordância com dados experimentais [106]

Para a simulação clássica, foram realizadas duas termalizações antes de obter os valores médios. Na primeira termalização, a TC e o íon foram mantidos com suas posições relativas fixas, para o melhor posicionamento do solvente em torno de ambos. Na segunda termalização, esse vínculo ligando a TC e o Mg foi retirado, dando liberdade ao complexo: caso a posição do íon não fosse favorável, ele poderia se afastar do ligante e assim o complexo não seria formado.

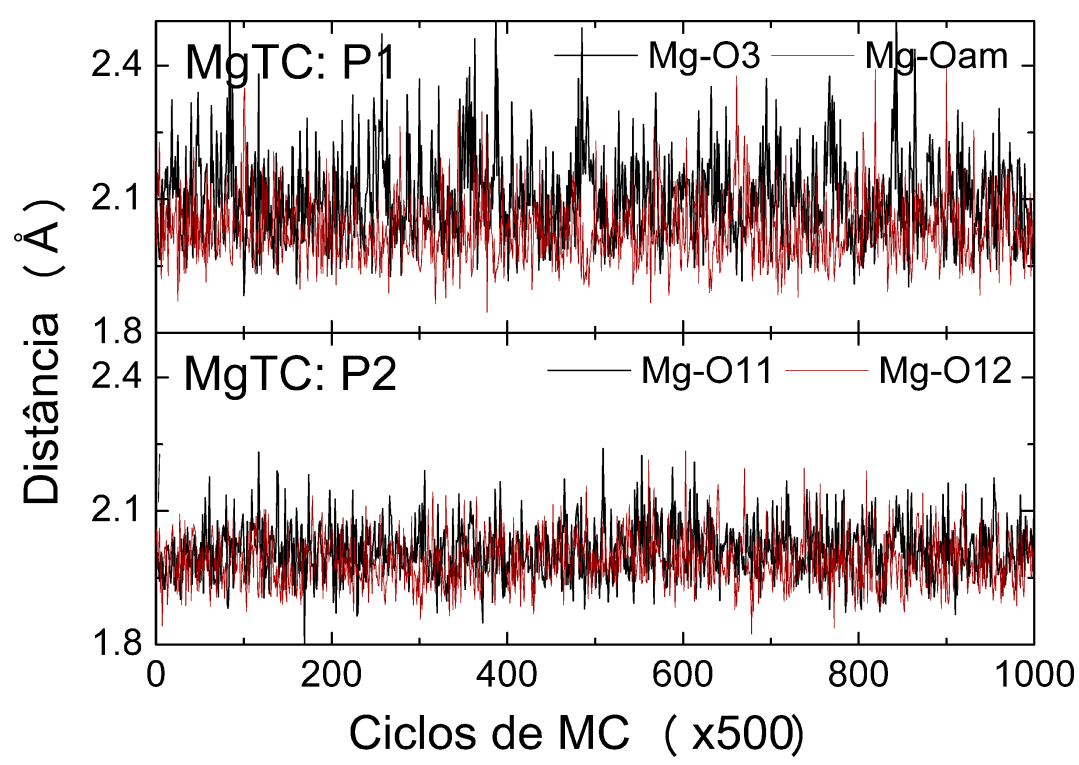

Figura 4.6: Distância do $\mathrm{Mg}^{2+}$ para o par de oxigênios $\mathrm{O}_{3}-\mathrm{O}_{a m}$ (posição P1) e do $\mathrm{Mg}^{2+}$ para o par de oxigênios $\mathrm{O}_{11}-\mathrm{O}_{12}$ (posição P2) em Å durante a simulação clássica dos complexos MgTC.

Como as posições P1 e P2 são próximas aos pares de átomos de oxigênio da TC, surge a dúvida se durante a simulação clássica o íon utilizará estes dois átomos da TC para a formação do ordenamento, de valor igual a seis como foi observado na simulação do íon em água. Podemos verificar o comportamento do íon durante a simulação clássica: as figuras 4.6 e 4.7 demonstram as distâncias, em $\AA$, do $\mathrm{Mg}^{2+}$ para os pares de oxigênios da TC: $\mathrm{O}_{3}-\mathrm{O}_{a m}$, em torno na posição P1 e $\mathrm{O}_{11}-\mathrm{O}_{12}$, próximo da posição P2.

Ambas as posições se mostraram estáveis durante a simulação clássica para 


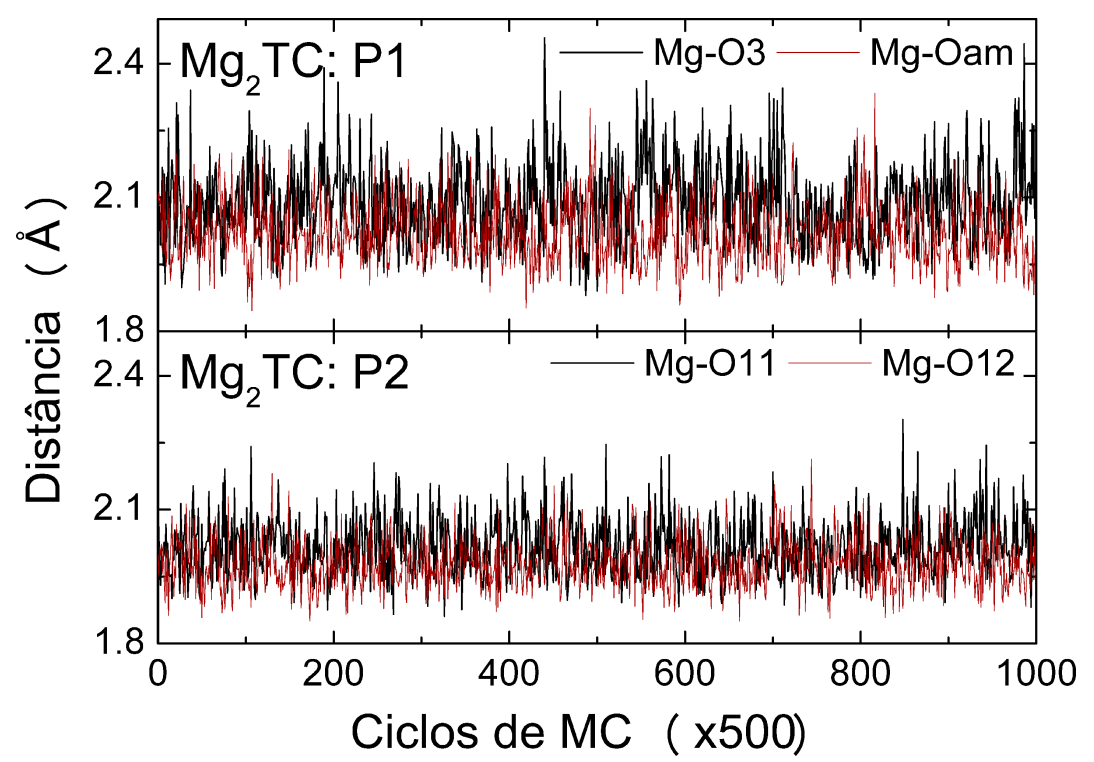

Figura 4.7: Distância do $\mathrm{Mg}^{2+}$ para o par de oxigênios $\mathrm{O}_{3}-\mathrm{O}_{a m}$ (posição P1) e do $\mathrm{Mg}^{2+}$ para o par de oxigênios $\mathrm{O}_{11}-\mathrm{O}_{12}$ (posição P2) em Å durante a simulação clássica do complexo $\mathrm{Mg}_{2} \mathrm{TC}$.

os dois complexos: $\mathrm{MgTC}$ e $\mathrm{Mg}_{2} \mathrm{TC}$. Este resultado indica que para manter o grau de coordenação igual a 6, o íon Mg se acopla a dois átomos de oxigênio da TC e mais quatro moléculas de água. De fato, as distâncias não são iguais, inclusive as flutuações parecem ser maiores com o íon na posição P1. Sendo assim vamos recorrer aos valores médios expostos na tabela 4.5, comparando com os dados obtidos com o PCM.

Os valores médios, a parir da fase de equilíbrio da simulação clássica, indicam que o íon $\mathrm{Mg}$ na posição P1 está mais próximo do oxigênio $\mathrm{O}_{a m}$ do que o $\mathrm{O}_{3}$, com uma diferença de $0,07 \AA$, enquanto que na posição P2 essa diferença fica entre 0,02 e 0,04 $\AA$ a favor do oxigênio $\mathrm{O}_{12}$, conforme a tabela 4.5. Esta grande distância do íon com o oxigênio $\mathrm{O}_{3}$ aparece também nos valores de desvio padrão, que é o maior valor obtido pelas simulações. Neste ponto é interessante comparar os valores de distância obtidos com o PCM. Todas as distâncias obtidas com PCM foram menores do que os valores apresentados na simulação clássica, com a maior diferença de 0,143 Å para o oxigênio $\mathrm{O}_{3}$, no complexo MgTC. 
Tabela 4.5: Comparativo entre as distâncias médias em Å do íon com específicos átomos de oxigênio da molécula TC, confrontanto os valores da simulação clássica e da estrutura otimizada com PCM.

\begin{tabular}{c|cccc}
\hline \hline & \multicolumn{4}{|c}{ Simulação Clássica } \\
\hline Complexo & $\mathrm{O}_{a m}$ & $\mathrm{O}_{3}$ & $\mathrm{O}_{11}$ & $\mathrm{O}_{12}$ \\
\hline $\mathrm{MgTC}$ & $2,032 \pm 0,077$ & $2,103 \pm 0,100$ & $2,010 \pm 0,062$ & $1,988 \pm 0,060$ \\
$\mathrm{Mg}_{2} \mathrm{TC}$ & $2,021 \pm 0,072$ & $2,087 \pm 0,090$ & $2,017 \pm 0,065$ & $1,978 \pm 0,056$ \\
\hline \hline & \multicolumn{5}{|c}{$\mathrm{PCM}$} \\
\hline Complexo & $\mathrm{O}_{a m}$ & $\mathrm{O}_{3}$ & $\mathrm{O}_{11}$ & $\mathrm{O}_{12}$ \\
\hline $\mathrm{MgTC}$ & 1,940 & 1,960 & 1,958 & 1,942 \\
$\mathrm{Mg}_{2} \mathrm{TC}$ & 1,939 & 1,971 & 1,964 & 1,953 \\
\hline \hline
\end{tabular}

\subsection{Resultados com o Modelo ASEC}

No modelo ASEC seguimos a mesma sequência descrita no capítulo anterior: uma configuração média é submetida a um cálculo TDDFT tendo os átomos da TC tratados na forma explícita, submetida a um campo eletrostático médio do íon e do solvente obtido pela sobreposição de 100 configurações energeticamente descorrelacionadas. A carga do íon é igual a $+2 e$, enquanto que as cargas dos átomos da molécula de água são obtidas do modelo SPC/E. As figuras 4.8, 4.9 e 4.10 mostram o espectro de absorção e os orbitais envolvidos nas transições mais intensas, com informações adicionais nas tabelas $4.6,4.7$ e 4.8 .

O primeiro caso analisado com o modelo ASEC é o complexo MgTC com o íon em P1, presente na figura 4.8 e tabela 4.6. O espectro é qualitativamente bem descrito pelo modelo. A primeira banda, que possui o máximo teórico em $329,3 \mathrm{~nm}$ e o máximo experimental em $375,2 \mathrm{~nm}$, mostra uma diferença de $-45,9$ $\mathrm{nm}$, concordância inferior ao PCM, onde a distância entre as primeiras bandas é igual a $-35,2 \mathrm{~nm}$. Nessa banda há uma transição muito intensa, $\mathrm{H} \rightarrow \mathrm{L}+1$, que 


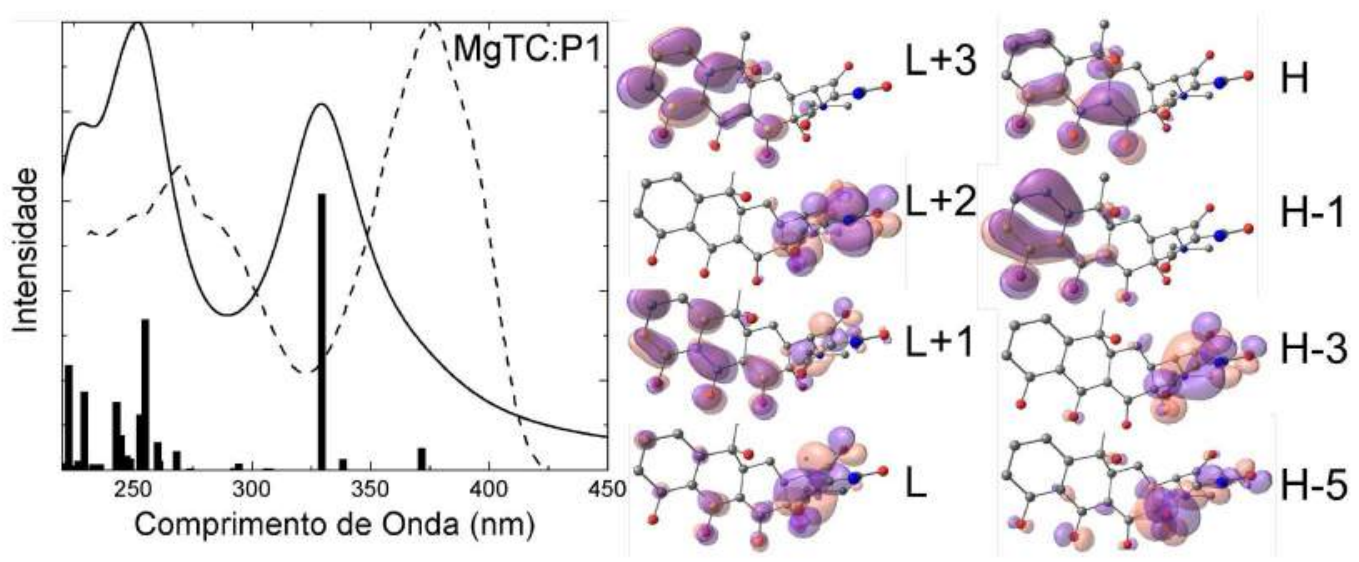

Figura 4.8: Espectro de absorção eletrônica do complexo MgTC com o íon na posição P1 usando o modelo ASEC para descrever o solvente (linha contínua) comparada com o resultado experimental (linha tracejada, ref. [30]) e os orbitais envolvidos nas transições mais intensas ( $L+4$ semelhante à $\mathrm{L}+3)$.

Tabela 4.6: Comparativo entre os máximos do espectro de absorção experimental [30] e teórico com as contribuições de cada orbital envolvido do complexo MgTC com o íon na posição P1 usando o modelo ASEC para descrever o solvente.

\begin{tabular}{|c|c|c|c|c|c|}
\hline \multicolumn{2}{|c|}{ Máximo } & \multirow{2}{*}{ Ordem } & \multirow{2}{*}{$\begin{array}{l}\text { Energia } \\
(\mathrm{eV} / \mathrm{nm})\end{array}$} & \multirow{2}{*}{$\begin{array}{l}\text { Força do } \\
\text { Oscilador }\end{array}$} & \multirow{2}{*}{ Composição } \\
\hline Exp. (nm) & Teór. (nm) & & & & \\
\hline 375,2 & $329,3(0,82)$ & 3 & $3,77 / 329,3$ & 0,3078 & $\mathrm{H} \rightarrow \mathrm{L}+1(85 \%)$ \\
\hline \multirow[t]{4}{*}{270,1} & $251,8(1,00)$ & 13 & $4,86 / 254,9$ & 0,1684 & $\mathrm{H}-3 \rightarrow \mathrm{L}+1(33 \%)$ \\
\hline & & & & & $\mathrm{H}-3 \rightarrow \mathrm{L}(29 \%)$ \\
\hline & & 19 & $5,10 / 242,9$ & 0,0757 & $\mathrm{H}-3 \rightarrow \mathrm{L}+2(53 \%)$ \\
\hline & & & & & $\mathrm{H}-2 \rightarrow \mathrm{L}+2(21 \%)$ \\
\hline \multirow[t]{4}{*}{$* 252,9$} & $232,9(0,81)$ & 22 & $5,41 / 229,4$ & 0,0872 & $\mathrm{H}-5 \rightarrow \mathrm{L}+2(53 \%)$ \\
\hline & & & & & $\mathrm{H}-3 \rightarrow \mathrm{L}+2(25 \%)$ \\
\hline & & 26 & $5,57 / 222,7$ & 0,1169 & $\mathrm{H}-1 \rightarrow \mathrm{L}+3(46 \%)$ \\
\hline & & & & & $\mathrm{H} \rightarrow \mathrm{L}+4(29 \%)$ \\
\hline
\end{tabular}

acarreta a transferência de carga dos anéis DCB para o anel A. Confrontando com o sistema $\mathrm{TC}^{-}$em água usando o modelo ASEC, o deslocamento da primeira banda pela presença do íon é igual a $4,5 \mathrm{~nm}$, na direção contrária ao comportamento 
experimental, resultado similar ao obtido pelo PCM.

Uma segunda banda é encontrada com o máximo em 251,8 nm, com a transição mais intensa envolvendo um deslocamento de carga do anel A para os anéis DCB. Experimentalmente, esta banda é encontrada em 270,1 nm e assim este modelo apresenta uma diferença de $-18,3 \mathrm{~nm}$. Um ombro bastante pronunciado foi encontrado em 232,9 nm, que acreditamos representar o ombro experimental em 252,9 nm e envolve redistribuição de carga nas regiões cromóforas. A diferença do máximo da segunda banda para a $\mathrm{TC}^{-}$usando o modelo ASEC para este resultado é igual $-3,2 \mathrm{~nm}$.

Com o íon na posição P2 no modelo ASEC, não foi observado transições acima de $350 \mathrm{~nm}$ conforme a figura 4.9 e a tabela 4.7. A primeira banda está a $-38,5 \mathrm{~nm}$ da mesma banda no espectro experimental, e da mesma forma que o caso anterior, piorando os valores do máximo com relação ao PCM. Porém, este pico mostra um deslocamento, comparado com o sistema $\mathrm{TC}^{-}$em água usando o mesmo modelo, igual a 2,9 nm, em boa concordância com o resultado experimental de $5 \mathrm{~nm}$. A banda é formada basicamente por uma transição intensa com transferência de carga do anel A para os anéis DCB.

Abaixo de 300 nm, há algumas mudanças em relação ao caso anterior. A segunda banda, com máximo em 256,4 nm, já não é tão intensa sendo formada por uma transição de intensidade média com leve transferência de carga dos anéis DCB para o anel A e seus grupos ácidos. Comparada com a $\mathrm{TC}^{-}$, o máximo desloca 1,4 nm. O ombro dessa banda em P1 assume agora o papel de uma nova banda, com máximo em 232,6 nm, de intensidade semelhante à segunda banda. Ela se relaciona com ombro experimental em 252,9 nm e nesta região, há transferência de carga dos anéis DCB para o anel A.

Da mesma forma apresentada pelo PCM, a primeira banda do espectro de absorção do complexo $\mathrm{Mg}_{2} \mathrm{TC}$, figura 4.10 e tabela 4.8 possui duas transições in- 


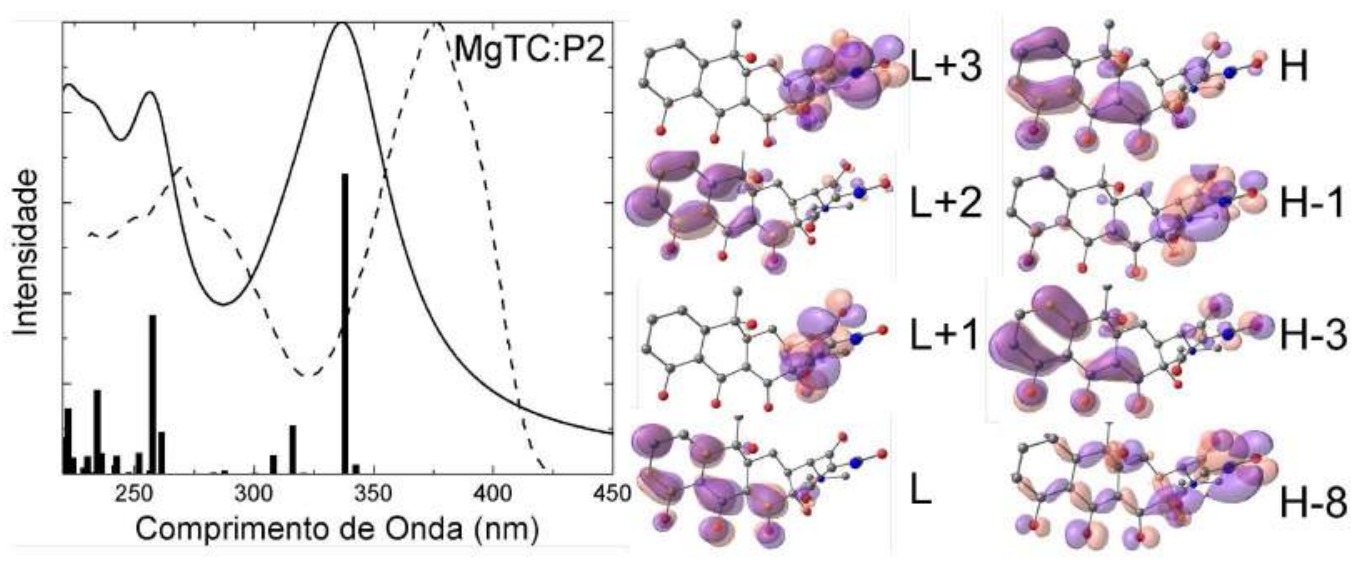

Figura 4.9: Espectro de absorção eletrônica do complexo MgTC com o íon na posição P2 usando o modelo ASEC para descrever o solvente (linha contínua) comparada com o resultado experimental (linha tracejada, ref. [30]) e os orbitais envolvidos nas transições mais intensas.

Tabela 4.7: Comparativo entre os máximos do espectro de absorção experimental e teórico com as contribuições de cada orbital envolvido do complexo MgTC com o íon na posição P2 usando o modelo ASEC para descrever o solvente.

\begin{tabular}{cccccc}
\hline \hline \multicolumn{2}{c}{ Máximo } & Ordem & $\begin{array}{c}\text { Energia } \\
(\mathrm{eV} / \mathrm{nm})\end{array}$ & $\begin{array}{c}\text { Força do } \\
\text { Oscilador }\end{array}$ & Composição \\
\hline Exp. (nm) & Teór. (nm) & & $3,67 / 338,1$ & 0,33 & $\begin{array}{c}\mathrm{H} \rightarrow \mathrm{L}(65 \%) \\
\mathrm{H}-1 \rightarrow \mathrm{L}(25 \%)\end{array}$ \\
\hline 375,2 & $336,7(1,00)$ & 2 & & & $\mathrm{H}-1 \rightarrow \mathrm{L}+1(71 \%)$ \\
\hline 270,1 & $256,4(0,84)$ & 11 & $4,81 / 257,7$ & 0,18 & $\mathrm{H}-1 \rightarrow \mathrm{L}+3(35 \%)$ \\
\hline$* 252,9$ & $* 22,6(0,86)$ & 19 & $5,28 / 234,5$ & 0,09 & $\mathrm{H} \rightarrow \mathrm{L}+3(25 \%)$ \\
& & & & & $\mathrm{H}-3 \rightarrow \mathrm{L}+2(30 \%)$ \\
& & 24 & $5,58 / 222,3$ & 0,07 & $\mathrm{H}-8 \rightarrow \mathrm{L}+1(23 \%)$ \\
\hline \hline
\end{tabular}

tensas, alargando essa banda. Essas transições demonstram transferência de carga direcionada ao anel A. O máximo dessa banda está localizado em 338,9 nm, distante de $-35,9 \mathrm{~nm}$ do resultado experimental. Para recordar, com PCM o máximo desta banda ficou localizado em 368,6 nm. O máximo desta banda está deslocando impressionantes 5,1 nm da $\mathrm{TC}^{-}$, em excelente concordância com o resultado 
experimental.
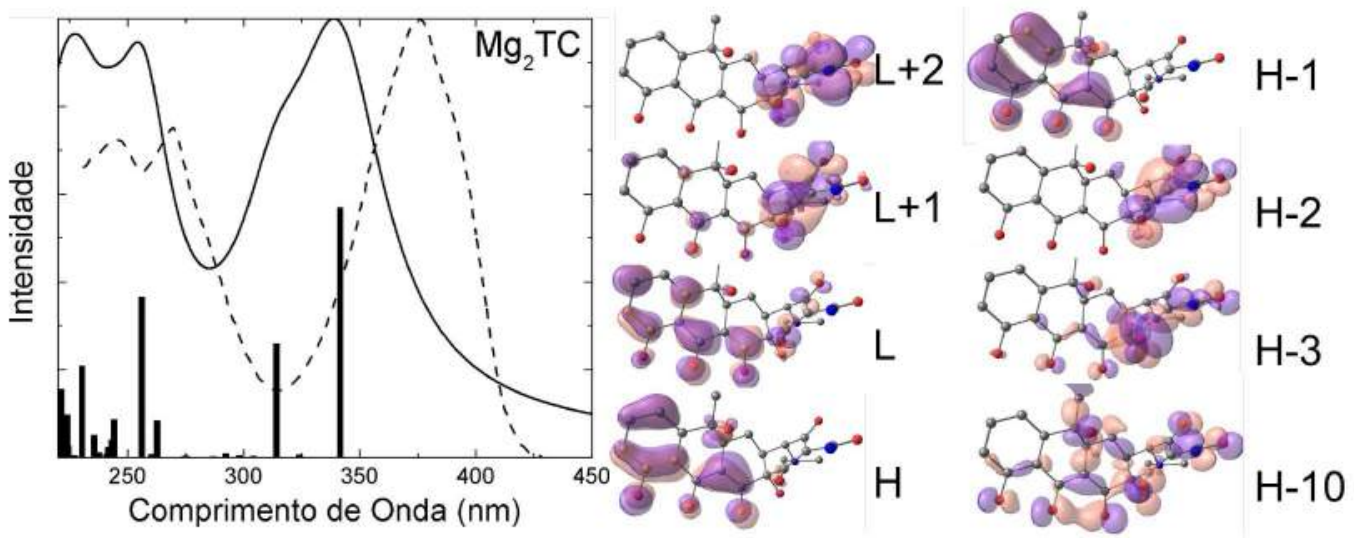

Figura 4.10: Espectro de absorção eletrônica do complexo $\mathrm{Mg}_{2} \mathrm{TC}$ com o íon nas posições $\mathrm{P} 1 \mathrm{e}$ P2 usando o modelo ASEC para descrever o solvente (linha contínua) comparada com o resultado experimental (linha tracejada, ref. [30]) e os orbitais envolvidos nas transições mais intensas (L+3 semelhante à $\mathrm{L}$ ).

Tabela 4.8: Comparativo entre os máximos do espectro de absorção experimental e teórico com as contribuições de cada orbital envolvido do complexo $\mathrm{Mg}_{2} \mathrm{TC}$ com os íons nas posições P1 e P2 usando o modelo ASEC para descrever o solvente.

\begin{tabular}{|c|c|c|c|c|c|}
\hline \multicolumn{2}{|c|}{ Máximo } & \multirow{2}{*}{ Ordem } & \multirow{2}{*}{$\begin{array}{l}\text { Energia } \\
(\mathrm{eV} / \mathrm{nm})\end{array}$} & \multirow{2}{*}{$\begin{array}{l}\text { Força do } \\
\text { Oscilador }\end{array}$} & \multirow{2}{*}{ Composição } \\
\hline Exp. (nm) & Teór. (nm) & & & & \\
\hline \multirow[t]{3}{*}{374,8} & $338,9(1,00)$ & 1 & $3,63 / 341,6$ & 0,2849 & $\mathrm{H} \rightarrow \mathrm{L}(90 \%)$ \\
\hline & & 3 & $3,95 / 314,1$ & 0,1295 & $\mathrm{H}-1 \rightarrow \mathrm{L}(57 \%)$ \\
\hline & & & & & $\mathrm{H} \rightarrow \mathrm{L}+1(29 \%)$ \\
\hline 269,7 & $254,3(0,95)$ & 12 & $4,84 / 256,1$ & 0,1830 & $\mathrm{H}-2 \rightarrow \mathrm{L}+1(84 \%)$ \\
\hline \multirow[t]{4}{*}{246,1} & $227,4(0,96)$ & 20 & $5,38 / 230,4$ & 0,1046 & $\mathrm{H}-3 \rightarrow \mathrm{L}+2(49 \%)$ \\
\hline & & & & & $\mathrm{H}-2 \rightarrow \mathrm{L}+2(30 \%)$ \\
\hline & & 24 & $5,60 / 221,3$ & 0,0776 & $\mathrm{H}-10 \rightarrow \mathrm{L}(31 \%)$ \\
\hline & & & & & $\mathrm{H}-1 \rightarrow \mathrm{L}+3(27 \%)$ \\
\hline
\end{tabular}

As duas bandas de intensidades próximas são formadas abaixo de $275 \mathrm{~nm}$. Estas bandas são observadas no experimento com os máximos em 269,7 nm e 246,1 
$\mathrm{nm}$, enquanto que o modelo teórico apresenta os valores dos máximos iguais a $254,3 \mathrm{~nm}$ e 227,4 nm, respectivamente. A diferença entre os valores experimentais e teóricos nesta região está abaixo de $20 \mathrm{~nm}$. Nestas transições ocorre redistribuiç̧ão de carga nas duas regiões cromóforas. Este resultado é muito interessante pois experimentalmente, a adição do segundo íon Mg cria uma banda intensa em 246,1 nm.

O modelo ASEC deslocou as bandas do espectro de absorção para maiores valores de energia, resultando numa piora na descrição do espectro quando comparado com PCM. Entretanto, os resultados para o deslocamento devido à presença do íon são bem animadores, concordando com os valores experimentais. A intensidade e a forma das bandas apresentaram boa correspondência com o espectro experimental e não foram encontradas transições acima de $400 \mathrm{~nm}$, que deformavam o espectro pelo PCM.

A transferência de carga segue o mesmo padrão exibido pelo PCM e o fato do íon ser tratado apenas como carga pontual já lhe torna suficiente na descrição dos efeitos da presença do $\mathrm{Mg}^{2+}$. Revisando os deslocamentos, este modelo indica que a primeira posição assumida pelo íon é a P2, gerando o deslocamento da primeira banda de 2,9 nm. A influência do íon em P1 é a intensidade da banda abaixo de 250 $\mathrm{nm}$, tornando tão perceptível quanto mostrado no resultado experimental.

\subsection{Resultados com o Modelo de Solvente Parcialmente Explícito}

A adição de átomos explícitos em volta da TC torna o nosso cálculo mais realista e pesado: ao invés de apenas uma configuração submetida ao cálculo TDDFT, agora é necessário calcular 100 configurações estatisticamente descorrelacionadas, incluindo íon e parte do solvente explicitamente. O espectro é obtido a patir da 
convolução das transições eletrônicas de todas essas configurações selecionadas. Os íons $\mathrm{Mg}$ e as 14 moléculas de água foram tratadas na forma explícita, enquanto que o restante do solvente, 736 moléculas de água, foram tratados como cargas pontuais. O número de águas explícitas é superior ao da primeira camada de solvatação para a simulação da $\mathrm{TC}^{-}$, figura 3.9. Este número se mantém nos complexos estudados, sendo que cada íon possui 4 moléculas de água na vizinhança. Esse número se soma aos átomos oxigênio da TC, próximos a posição de acoplamento, fechando o grau de coordenação em 6. Para cada configuração, usamos o funcional B3LYP com a base 6-31G(d) para os átomos da TC e os íons $\mathrm{Mg}^{2+}$, enquanto que na água usamos a base 6-31G.

Ao tratar parte do solvente e o íon Mg em P1 explicitamente, figura 4.11 e tabela 4.9, obtemos um resultado muito próximo ao modelo ASEC. O máximo da primeira banda está localizado em $335,8 \mathrm{~nm}, 6,5 \mathrm{~nm}$ a mais que o modelo ASEC e 39,4 nm a menos que o resultado experimental. Para lembrar, a posição do máximo com o PCM foi de $340,0 \mathrm{~nm}$. Essa banda é basicamente formada por transições do tipo $\mathrm{H} \rightarrow \mathrm{L}, \mathrm{H} \rightarrow \mathrm{L}+1$ e $\mathrm{H}-1 \rightarrow \mathrm{L}$, que contribuem para o alargamento da banda e numa configuração relevante indica transferência de carga dos anéis DCB para o anel A. Devemos lembrar que a presença do solvente e íon explícito pode alterar a ordem dos orbitais, dificultando a visualização do efeito de transferência de carga.

A segunda banda, de máximo em 260,5 nm, está distante do resultado experimental por $-10,4 \mathrm{~nm}$, melhor do que o valor apresentado pelos modelos ASEC e PCM. Essa banda também é formada por diferentes transições, em especial H-1 $\rightarrow$ $\mathrm{L}+1$ e H-2 $\rightarrow \mathrm{L}+1$, envolvendo redistribuição de carga nas duas regiões cromóforas. Tal banda apresenta um sutil ombro à esquerda, na região de $230 \mathrm{~nm}$, que acreditamos estar relacionado a um ombro em 252,9 nm na banda experimental. Transições intensas do ombro mostram transferência de carga do anel A para os anéis DCB. Conforme visto nos orbitais da configuração relevante, figura 4.11, nenhuma das 
transições mais intensas envolvem orbitais em torno do íon Mg na posição P1.
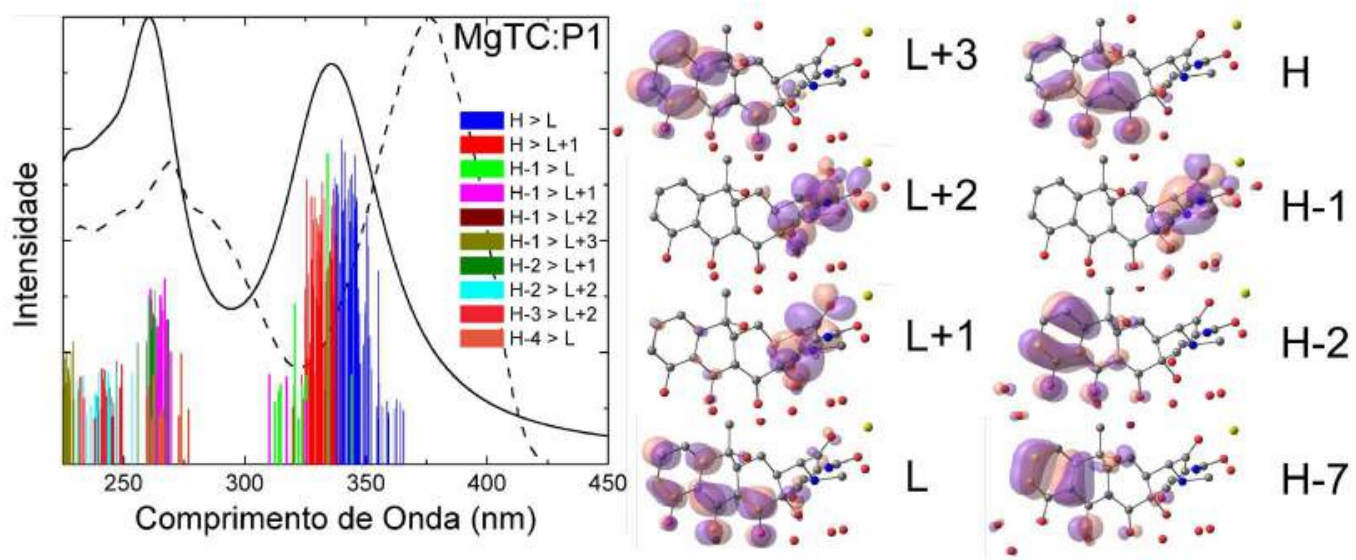

Figura 4.11: Espectro de absorção eletrônica do complexo MgTC com o íon na posição P1 usando o modelo de solvente parcialmente explícito (linha contínua) comparada com o resultado experimental (linha tracejada, ref. [30]) descrevendo a composição das transições, além dos orbitais envolvidos nas transições mais intensas de uma configuração relevante.

Tabela 4.9: Comparativo entre os máximos do espectro de absorção experimental [30] e teórico com as contribuições de cada orbital envolvido de uma configuração relevante do complexo $\mathrm{MgTC}$ com o íon na posição P1 usando o modelo de solvente parcialmente explícito.

\begin{tabular}{|c|c|c|c|c|c|}
\hline \multicolumn{2}{|c|}{ Máximo } & \multirow{2}{*}{ Ordem } & \multirow{2}{*}{$\begin{array}{l}\text { Energia } \\
(\mathrm{eV} / \mathrm{nm})\end{array}$} & \multirow{2}{*}{$\begin{array}{l}\text { Força do } \\
\text { Oscilador }\end{array}$} & \multirow{2}{*}{ Composição } \\
\hline Exp. (nm) & Teór. (nm) & & & & \\
\hline 375,2 & $335,8(0,90)$ & 1 & $3,71 / 334,0$ & 0,2988 & $\mathrm{H} \rightarrow \mathrm{L}(86 \%)$ \\
\hline \multirow[t]{4}{*}{270,1} & $260,5(1,00)$ & 10 & $4,69 / 264,1$ & 0,1543 & $\mathrm{H}-1 \rightarrow \mathrm{L}+1(68 \%)$ \\
\hline & & 14 & $4,84 / 256,1$ & 0,0725 & $\mathrm{H}-7 \rightarrow \mathrm{L}(26 \%)$ \\
\hline & & 17 & $5,04 / 246,1$ & 0,0851 & $\mathrm{H} \rightarrow \mathrm{L}+3(49 \%)$ \\
\hline & & 18 & $5,06 / 244,9$ & 0,0747 & $\mathrm{H}-1 \rightarrow \mathrm{L}+2(74 \%)$ \\
\hline
\end{tabular}

Comparando os espectros experimentais da $\mathrm{MgTC} \mathrm{TC}^{-}$, há um deslocamento apenas na primeira banda de $5 \mathrm{~nm}$. Neste modelo, o valor do deslocamento da primeira banda é igual a 1,2 nm, enquanto na segunda banda é igual a $-5,4 \mathrm{~nm}$, contrariando os dados experimentais.

Para o complexo MgTC com o íon na posição P2 usando o modelo explícito, 

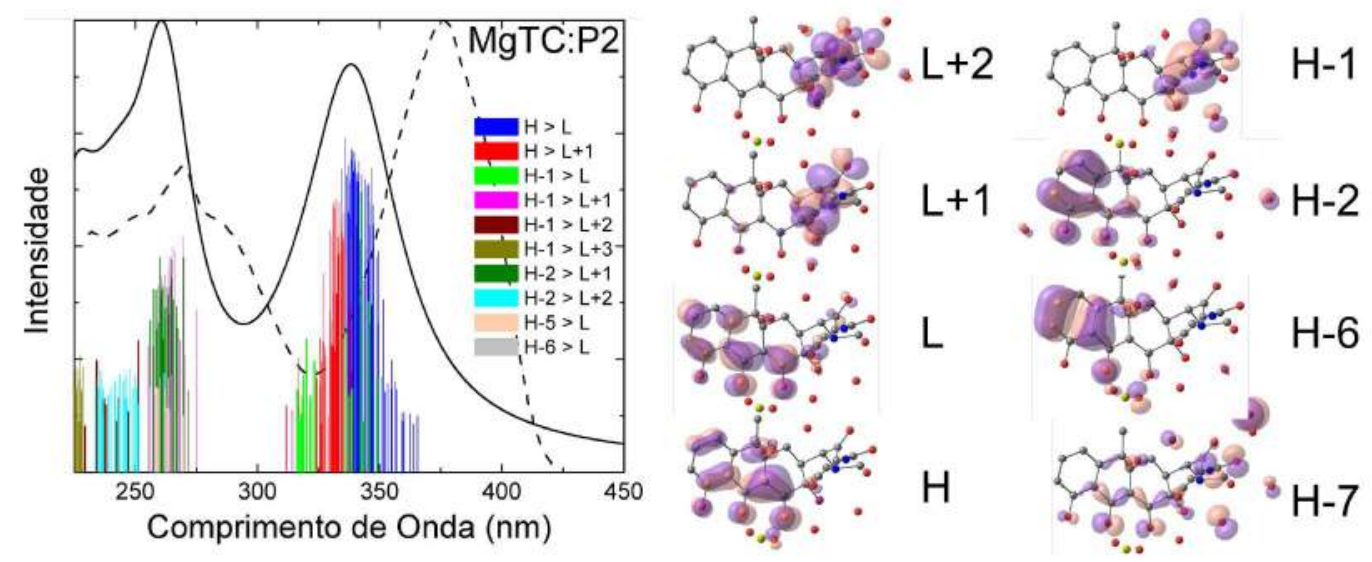

Figura 4.12: Espectro de absorção eletrônica do complexo MgTC com o íon na posição P2 usando o modelo de solvente parcialmente explícito (linha contínua) comparada com o resultado experimental (linha tracejada, ref. [30]), além dos orbitais envolvidos nas transições mais intensas de uma configuração relevante ( $\mathrm{L}+3$ semelhante ao $\mathrm{L})$.

Tabela 4.10: Comparativo entre os máximos do espectro de absorção experimental [30] e teórico com as contribuições de cada orbital envolvido de uma configuração relevante do complexo MgTC com o íon na posição P2 usando o modelo de solvente parcialmente explícito.

\begin{tabular}{|c|c|c|c|c|c|}
\hline \multicolumn{2}{|c|}{ Máximo } & \multirow{2}{*}{ Ordem } & \multirow{2}{*}{$\begin{array}{l}\text { Energia } \\
(\mathrm{eV} / \mathrm{nm})\end{array}$} & \multirow{2}{*}{$\begin{array}{l}\text { Força do } \\
\text { Oscilador }\end{array}$} & \multirow{2}{*}{ Composição } \\
\hline Exp. (nm) & Teór. (nm) & & & & \\
\hline 375,2 & $338,3(0,90)$ & 1 & $3,67 / 337,5$ & 0,3248 & $\mathrm{H} \rightarrow \mathrm{L}(94 \%)$ \\
\hline \multirow[t]{4}{*}{270,1} & $260,6(1,00)$ & 13 & $4,62 / 268,3$ & 0,1462 & $\mathrm{H}-1 \rightarrow \mathrm{L}+1(57 \%)$ \\
\hline & & 14 & $4,73 / 261,9$ & 0,0948 & $\mathrm{H}-6 \rightarrow \mathrm{L}(77 \%)$ \\
\hline & & 24 & $5,11 / 242,4$ & 0,0696 & $\mathrm{H}-1 \rightarrow \mathrm{L}+2(39 \%)$ \\
\hline & & & & & $\mathrm{H}-7 \rightarrow \mathrm{L}+1(23 \%)$ \\
\hline$* 252,9$ & $228,4(0,72)$ & 38 & $5,52 / 224,7$ & 0,0980 & $\mathrm{H}-2 \rightarrow \mathrm{L}+3(57 \%)$ \\
\hline
\end{tabular}

figura 4.12 e tabela 4.10, obtemos um resultado muito parecido com o íon na posição P1. O máximo da primeira banda está localizado em $338,3 \mathrm{~nm}$, enquanto no caso anterior foi igual a $335,8 \mathrm{~nm}$. Nessa banda, várias transições contribuem para seu alargamento, $\mathrm{H} \rightarrow \mathrm{L}, \mathrm{H} \rightarrow \mathrm{L}+1$ e $\mathrm{H}-1 \rightarrow \mathrm{L}$, onde também temos a transferência de carga dos anéis DCB para o anel A. A segunda banda tem o máximo em 260,6 $\mathrm{nm}$, próximo ao caso anterior. Nessa banda, as transições mais intensas na região 
do pico geram uma redistribuição de cargas pela TC. Uma mudança é que agora, o ombro da segunda banda ficou mais evidente: localizado em 228,4 nm, é formado por diversas transições com redistribuição de carga. Acreditamos que esse ombro teórico é a representação do ombro experimental em 252,9 nm. Novamente, nenhuma das transições mais intensas envolvem orbitais do íon $\mathrm{Mg}$ na posição P2, mas sua presença interfere nos orbitais dos átomos vizinhos. O deslocamento entre os máximos das bandas do $\mathrm{MgTC}$ e $\mathrm{TC}^{-}$apresenta 3,7 $\mathrm{nm}$ para a primeira banda e 2,2 nm para a segunda banda, em boa concordância com os dados experimentais.

Usando o modelo explícito para o $\mathrm{Mg}_{2} \mathrm{TC}$, figura 4.13 e tabela 4.11, observamos que o espectro apresenta forma semelhante aos casos anteriores. A primeira banda possui seu máximo em 337,5 nm, distante do resultado experimental de $-37,3 \mathrm{~nm}$. Novamente, essa banda é formada por transições do tipo $\mathrm{H} \rightarrow \mathrm{L}, \mathrm{H} \rightarrow \mathrm{L}+1$ e $\mathrm{H}-1 \rightarrow$ $\mathrm{L}$, onde ocorre uma transferência de carga dos anéis DCB para o anel A na região de maior energia da banda. Na segunda banda, com o máximo em 261,2 nm, há a formação de um ombro em 228,1 nm. Nestes dois pontos, ocorre redistribuição da carga nas regiões cromóforas, além de uma leve transferência de carga entre tais regiões. Comparando com a banda experimental, o máximo da segunda banda está afastado 8,5 nm enquanto que o ombro está afastado 18,0 nm para a banda experimental em 246,1 $\mathrm{nm}$.

Diferente do PCM, as transições mais intensas não apresentaram orbitais em torno dos íons. O deslocamento entre os máximos das bandas do $\mathrm{Mg}_{2} \mathrm{TC}$ e $\mathrm{TC}^{-}$ apresenta 2,9 $\mathrm{nm}$ para a primeira banda e 2,8 $\mathrm{nm}$ para a segunda banda, em boa concordância com o resultado experimental: $5 \mathrm{~nm}$ para a primeira banda e nulo para a segunda banda. No espectro experimental, ocorre o surgimento de uma banda em 246,1 nm, com intensidade compatível com a segunda banda em 269,7 nm. Acreditamos que o ombro da segunda banda está relacionado com o pico experimental, mas as diversas transições obtidas pelas 100 configurações submetidas ao cálculo 

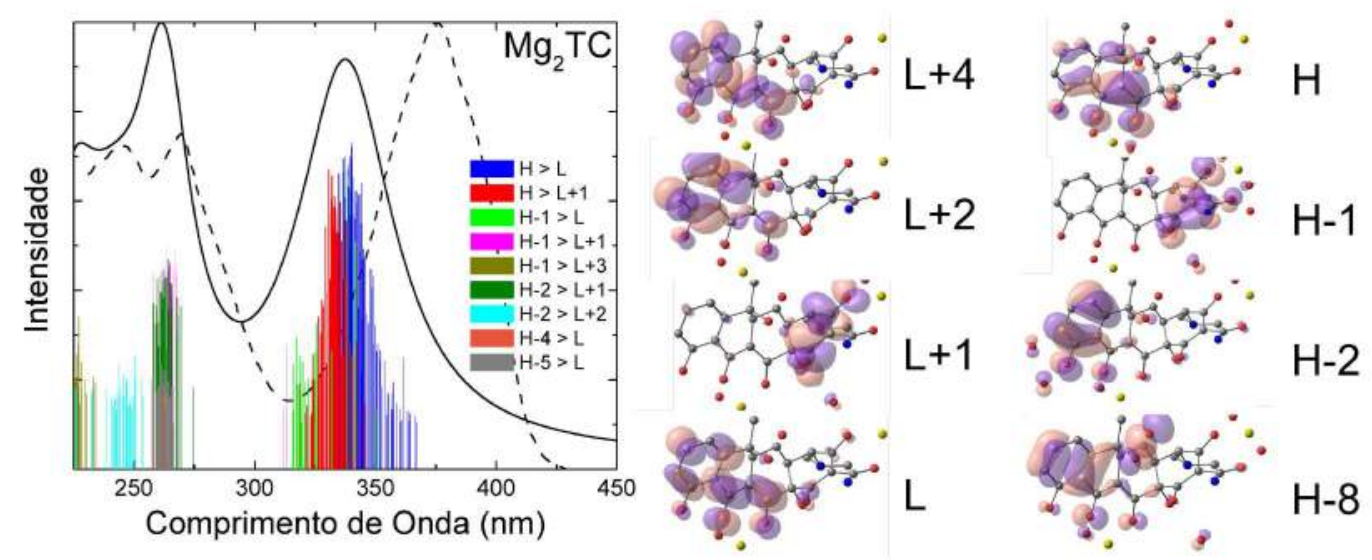

Figura 4.13: Espectro de absorção eletrônica do complexo $\mathrm{Mg}_{2} \mathrm{TC}$ com o íon na posição P1 e P2 usando o modelo de solvente parcialmente explícito (linha contínua) comparada com o resultado experimental (linha tracejada, ref. [30]), além dos orbitais envolvidos nas transições mais intensas de uma configuração relevante.

Tabela 4.11: Comparativo entre os máximos do espectro de absorção experimental [30] e teórico com as contribuições de cada orbital envolvido de uma configuração relevante do complexo $\mathrm{Mg}_{2} \mathrm{TC}$ com os íons nas posições P1 e P2 usando o modelo de solvente parcialmente explícito.

\begin{tabular}{|c|c|c|c|c|c|}
\hline \multicolumn{2}{|c|}{ Máximo } & \multirow{2}{*}{ Ordem } & \multirow{2}{*}{$\begin{array}{l}\text { Energia } \\
(\mathrm{eV} / \mathrm{nm})\end{array}$} & \multirow{2}{*}{$\begin{array}{l}\text { Força do } \\
\text { Oscilador }\end{array}$} & \multirow{2}{*}{ Composição } \\
\hline Exp. (nm) & Teór. (nm) & & & & \\
\hline 374,8 & $337,5(0,92)$ & 1 & $3,66 / 338,5$ & 0,3062 & $\mathrm{H} \rightarrow \mathrm{L}(95 \%)$ \\
\hline \multirow[t]{3}{*}{269,7} & $261,2(1,00)$ & 11 & $4,63 / 267,6$ & 0,2319 & $\mathrm{H}-1 \rightarrow \mathrm{L}+1(84 \%)$ \\
\hline & & 13 & $4,76 / 260,5$ & 0,0921 & $\mathrm{H}-8 \rightarrow \mathrm{L}(53 \%)$ \\
\hline & & & & & $\mathrm{H} \rightarrow \mathrm{L}+2(25 \%)$ \\
\hline \multirow[t]{2}{*}{246,1} & $228,1(0,73)$ & 34 & $5,54 / 224,0$ & 0,0880 & $\mathrm{H} \rightarrow \mathrm{L}+4(40 \%)$ \\
\hline & & & & & $\mathrm{H}-2 \rightarrow \mathrm{L}+2(31 \%)$ \\
\hline
\end{tabular}

TDDFT omitem a banda. Isso ocorre porque o número de transições foi padronizado para 50 em todos os cálculos efetuados nesta tese, para cada configuração. Com apenas a TC na forma explícita, estas 50 transições são suficientes para descrever até $200 \mathrm{~nm}$. Nos complexos estudados, parte destas transições são calculadas para o solvente e o íon, pois estes foram tratados explicitamente. Estas transições estão espalhadas em todo o espectro, dificultando a descrever a banda abaixo de $250 \mathrm{~nm}$. 
Em geral, usando o modelo de solvente parcialmente explícito conseguimos uma boa descrição qualitativa do espectro. As mudanças impostas no espectro pela presença de um ou dois íons também foram bem descritas neste modelo, corroborando a ideia de que o íon ocupa primeiramente a posição P2, que causa o deslocamento da primeira banda e a presença do segundo íon aumenta a intensidade das transições abaixo de $250 \mathrm{~nm}$. Devemos relembrar que os valores energéticos para cada posição do íon obtidas com PCM indicou que a posição P2 apresenta a menor energia. As intensidades das bandas foram melhor descritas pelo modelo ASEC, enquanto houve uma pequena melhora nas posições dos máximos com o modelo explícito. Ainda assim, ambos os modelos apresentam bandas muito afastadas dos valores experimentais.

Tabela 4.12: Comparativo dos deslocamentos em nm do máximo da primeira banda do espectro de absorção eletrônica teórica e experimental partindo da forma $\mathrm{TC}^{-}$para a $\mathrm{TC}^{3-}$ ou a presença do íon Eu nas três diferentes posições.

\begin{tabular}{cccc}
\hline & $\mathrm{TC}^{-} \rightarrow \mathrm{MgTC}: \mathrm{P} 1$ & $\mathrm{TC}^{-} \rightarrow \mathrm{MgTC}: \mathrm{P} 2$ & $\mathrm{TC}^{-} \rightarrow \mathrm{Mg}_{2} \mathrm{TC}$ \\
\hline Experimento [32] & 5,0 & & 5,0 \\
Experimento [30] & 5,8 & & 5,5 \\
PCM - TC Rígida & $-3,8$ & 25,7 & 24,8 \\
Modelo ASEC & $-4,5$ & 2,9 & 5,1 \\
Modelo Explícito & 1,2 & 3,7 & 2,8 \\
\hline \hline
\end{tabular}

Na tabela 4.12, apresentamos os deslocamentos apenas para a primeira banda, comparando os resultados experimentais e os modelos teóricos. A presença do íon em P1 causa um deslocamento pequeno ou no sentido contrário, e o PCM falha em descrever as mudanças no espectro. Já os resultados com os métodos derivados do S-QM/MM descrevem corretamente o efeito do íon nos complexos. Um ponto interessante ao comparar ambos os modelos é que o resultado é independente do tratamento o íon explicitamente ou como carga pontual, indicando que o ambiente 
e em especial o efeito eletrostático têm grande influência nas mudanças do espectro. Tal efeito foi evidenciado pela geometria da TC, mantida rígida durante todos os cálculos de espectro. Sem a alteração da geometria do soluto, o íon altera o posicionamento das moléculas de solvente em torno da TC que por sua vez causam o deslocamentos do máximo da banda. Como transições da primeira banda envolve a região cromófora dos anéis DCB, mudanças do posicionamento do solvente nessa região modificam a energia de transição. Da mesma forma, transições abaixo de $250 \mathrm{~nm}$ envolve outra região cromófora, em torno do anel A. Com o íon em P1, essas transições aumentam de intensidade, conforme o modelo ASEC demonstrou. Quanto ao efeito de transferência de carga para o complexo MgTC, observamos uma leve transferência na direção do posicionamento do íon, para as transições mais intensas na primeira banda. E transferências envolvendo as duas regiões cromóforas apresentaram baixa ocorrência, associadas a transições de baixa intensidade. 


\section{Capítulo 5}

\section{Espectro de Absorção do Complexo EuTC em Água}

Neste capítulo, vamos finalizar o estudo da TC com a adição do íon Eu. Para isso, vamos comparar os espectros de absorção teóricos com o espectro experimental do complexo EuTC, usando vários modelos para tratar o solvente, seguindo o procedimento adotado no capítulo anterior. Conforme informado na introdução, o EuTC funciona como uma sonda biológica e uma de suas aplicações recentes consistem em estimar a concentração de colesterol ruim no sangue humano. $\mathrm{O}$ complexo possui carga nula e, como o íon Eu apresenta emissão na região de 600 $\mathrm{nm}$ deve estar configurado com carga $+3 e$, forçando a molécula TC a atuar na forma ânion trivalente. Além disso, a forma $\left(\mathrm{Eu}^{3+} \mathrm{TC}^{3-}\right)^{0}=$ EuTC é mais fácil de ser encontrado para $\mathrm{pH}$ acima de 7,5. Para esse mesmo valor de $\mathrm{pH}$, a forma de maior incidência da TC em água é a ânion monovalente, $\mathrm{TC}^{-}$. De modo que, analisaremos, dentro de um mesmo modelo, as mudanças pela presença do íon comparando os espectros dos sistemas EuTC e TC ${ }^{-}$em solução aquosa. Cabe ressaltar, conforme apresentado no capítulo de introdução, a presença do íon Eu gera um deslocamento de $25 \mathrm{~nm}$ na primeira banda de absorção da TC [21,25]. 


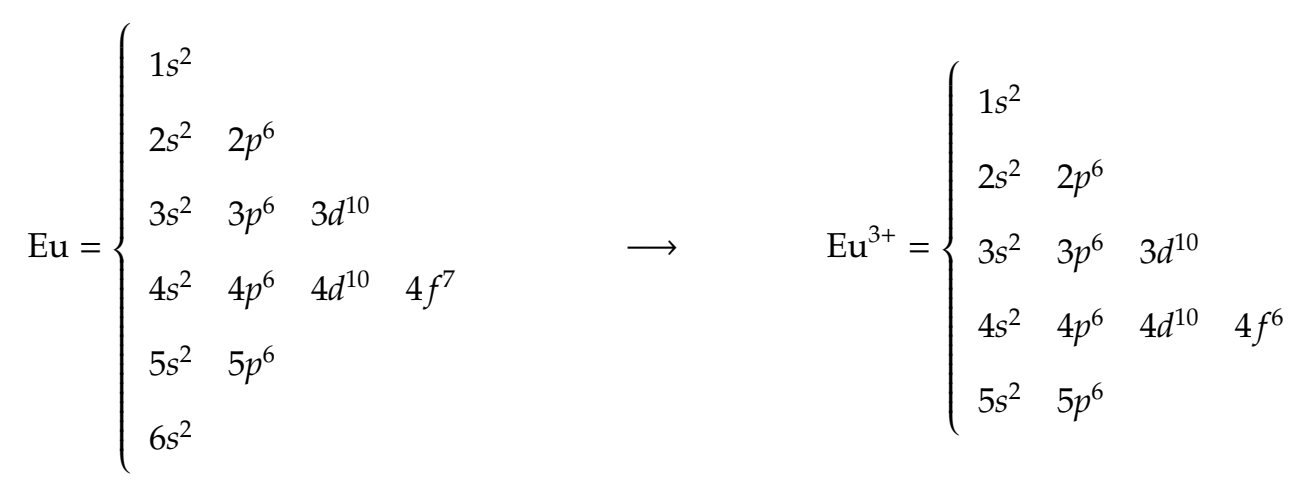

De acordo como o diagrama acima, o átomo de Eu possui o orbital $4 f \mathrm{com}$ sete elétrons onde cada um ocupa um número quântico magnético ou número quântico terciário. Entretanto, para a formação do íon estudado, o Eu perde três elétrons, acabando com o orbital $6 s^{2}$ e deixando o orbital $4 f$ com um número quântico magnético não ocupado: este orbital permite até 14 elétrons, mas o íon permanece ocupado com apenas 6 elétrons. Além disso, os orbitais $5 s^{2}$ e $5 p^{6}$ blindam o orbital $4 f$, de onde ocorre as emissões na região de $600 \mathrm{~nm}(5 d \rightarrow 4 f)$, conforme o diagrama de Jablonski na figura 1.3: a blindagem mantém a banda de emissão do Eu estreita com longo tempo de vida, pois o ambiente pouco interfere em tais transições, gerando desdobramentos dos níveis energéticos e nas intensidades [107,108].

Ainda não está claro a posição de hospedagem do íon na TC. Evidências experimentais indicam que seu posicionamento muda de acordo com o $\mathrm{pH}$ [20]: localizado entre os átomos ${ }^{1} \mathrm{O}_{a m}$ e $\mathrm{O}_{3}$ para $\mathrm{pH}$ igual a 2,0 e entre os átomos $\mathrm{O}_{12}$ e $\mathrm{O}_{11}$ para $\mathrm{pH}$ igual a 8,6, mas este resultado foi aplicado para o íon $\mathrm{Gd}^{3+}$ [109]. Ao realizar simulação clássica contendo apenas íon $\mathrm{Eu}^{3+}$ e a molécula de $\mathrm{TC}^{3-}$, três posições de acoplamento foram encontradas conforme a figura 5.1: as posições P1 e P2, que já foram discutidas no capítulo do complexo MgTC, e a posição P3, próximo aos oxigênios $\mathrm{O}_{10}$ e $\mathrm{O}_{11}$. Esta última posição só é acessível porque ao sair da forma $\mathrm{TC}^{-}$para a forma $\mathrm{TC}^{3-}$ ocorre duas desprotonações: a primeira pelo $\mathrm{H}_{d m} \mathrm{e}$

\footnotetext{
${ }^{1}$ Consultar a figura 3.1 para a nomenclatura dos átomos da TC.
} 
a segunda pelo $\mathrm{H}_{10}$. No primeiro momento, realizaremos a comparação da energia relacionada a cada complexo para estimar qual possui maior incidência, ou seja, cálculo de concentração de cada espécie. Depois vamos analisar a diferenças no espectro de absorção eletrônica com TDDFT para os diferentes posicionamentos do íon com os modelos já usados PCM, ASEC e solvente explícito.

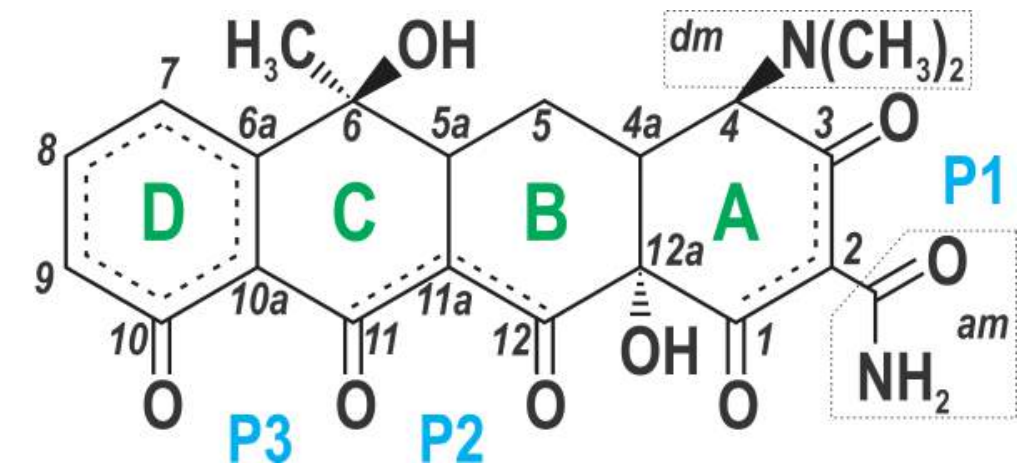

Figura 5.1: Estrutura da molécula $\mathrm{TC}^{3-}$ com as posições P1, P2 e P3 onde o consideramos que o íon $\mathrm{Eu}^{3+}$ pode se hospedar.

\subsection{Resultados com PCM}

A primeira etapa foi realizada usando o PCM para representar a água. O EuTC teve a geometria optimizada usando o funcional híbrido B3LYP e a base 6-31G(d) para descrever os átomos da TC e a base ECP52MWB com potencial substituindo os elétrons do caroço para descrever o $\mathrm{Eu}^{3+}[78,79]$. A variação da energia entre os complexos é dada na tabela 5.1, e a menor energia é sempre para o complexo EuTC com o íon em P3.

Para facilitar a leitura da tabela 5.1, colocamos a energia total apenas no caso com o íon em P3 por ser a menor (em $E_{h}$ ). Nas outras duas posições apresentamos apenas a diferença de energia subtraíndo do valor em P3 (em kcal/mol). A menor diferença é igual 5,3 kcal/mol considerando as correções vibracionais e ocorre com o íon na posição P2, bem maior do que o valor encontrado para o complexo MgTC. 
Tabela 5.1: Comparativo energético entre as diferentes posições ocupadas do íon no complexo EuTC, obtidas com o funcional B3LYP e usando o PCM. Como o complexo com o íon em P3 possui sempre a menor energia, sua coluna mostra o valor da energia total em hartree $\left(E_{h}\right)$, enquanto que nos casos P1 e P2 apresentamos apenas a diferença para P3 em kcal $/ \mathrm{mol}\left(1 E_{h}=627,509 \mathrm{kcal} / \mathrm{mol}\right)$.

\begin{tabular}{cccc}
\hline & \multicolumn{3}{c}{ Energia do EuTC com o íon em : } \\
\hline Método & P1 $(\mathrm{kcal} / \mathrm{mol})$ & P2 $(\mathrm{kcal} / \mathrm{mol})$ & P3 $\left(E_{h}\right)$ \\
\hline TC Rígida & 29,8 & 11,1 & $-1597,773267$ \\
TC Flexível & 25,0 & 7,1 & $-1597,784328$ \\
TC Flexível + Correções Vibracionais & 23,4 & 5,3 & $-1597,431459$ \\
\hline \hline
\end{tabular}

Relembrando da análise populacional ${ }^{2}$, qualquer diferença acima de $2 \mathrm{kcal} / \mathrm{mol}$ já é suficiente para que apenas a espécie de menor energia esteja presente na solução. Seguindo esse resultado, apresentaremos os espectros de absorção apenas para o caso com o íon em P3, sempre comentando os resultados em outros posicionamentos do $\mathrm{Eu}^{3+}$ proporcionando um texto mais fluido.

Com o íon em P3, figura 5.2 e tabela 5.6, o espectro de absorção teórico mostra um comportamento bastante diferente do experimental, com a primeira banda deslocada para a direita do valor experimental, apresentando baixos valores de energia de transição. Em 459,5 nm, temos a transição mais intensa com transferência de carga dos anéis da TC para o íon. Essa banda é larga pela presença de várias transições na região e em 377,2 nm há a formação de um ombro. O deslocamento do máximo dessa banda está acima de $110 \mathrm{~nm}$, superestimando o valor experimental de $25 \mathrm{~nm}$. Relembrando que esse valor é diferença da posição da banda do complexo e do $\mathrm{TC}^{-}$usando o mesmo modelo teórico. Novamente o PCM falha em descrever o deslocamento pela presença do íon, fato que também ocorreu no complexo MgTC. Considerando outros posicionamentos do íon, observamos a mesma dificuldade em descrever o espectro, gerando um deslocamento de 29,2 nm com o íon em P1 e 103,5

\footnotetext{
${ }^{2}$ Considerando as mesmas condições termodinâmicas, em especial a temperatura. Para mais, ver seção 4 .
} 

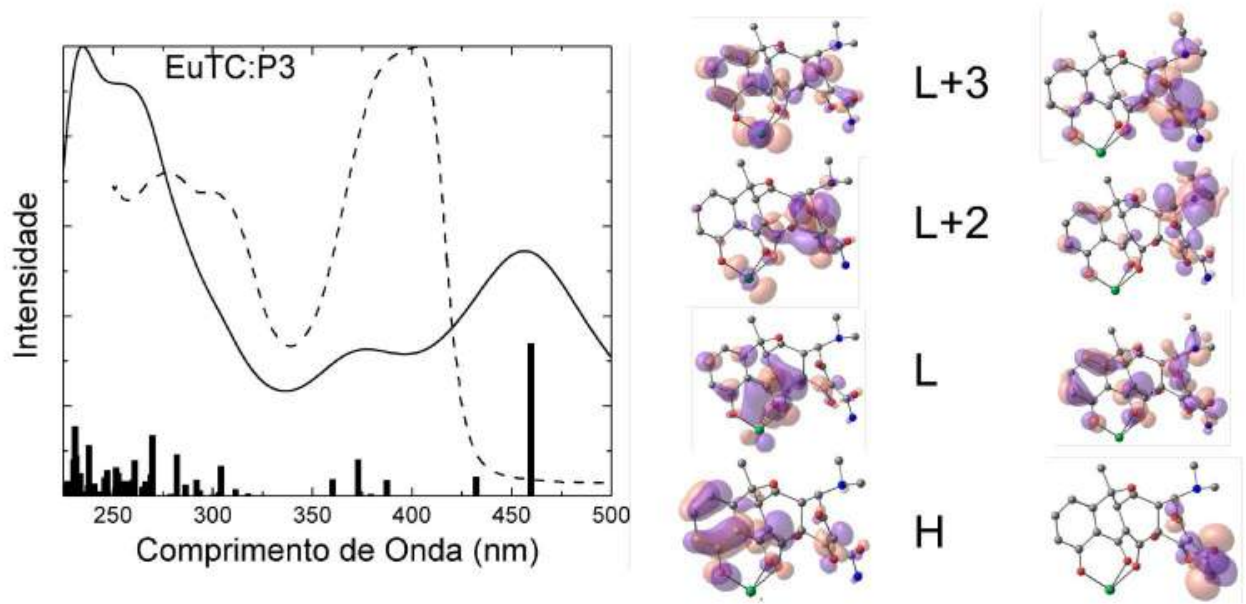

$\mathrm{H}-1$

$\mathrm{H}-2$

H-3

$\mathrm{H}-8$

Figura 5.2: Espectro de absorção eletrônica do complexo EuTC com a TC flexível e o íon na posição P3 usando o PCM para descrever o solvente comparado com o espectro experimental [25], além dos orbitais envolvidos nas transições mais intensas.

Tabela 5.2: Comparativo entre os máximos do espectro de absorção experimental [25] e teórico com as contribuições de cada orbital envolvido do complexo EuTC com a TC flexível e o íon na posição P3 usando o PCM para descrever o solvente.

\begin{tabular}{|c|c|c|c|c|c|}
\hline \multicolumn{2}{|c|}{ Máximo } & \multirow{2}{*}{ Ordem } & \multirow{2}{*}{$\begin{array}{l}\text { Energia } \\
(\mathrm{eV} / \mathrm{nm})\end{array}$} & \multirow{2}{*}{$\begin{array}{l}\text { Força do } \\
\text { Oscilador }\end{array}$} & \multirow{2}{*}{ Composição } \\
\hline Exp. (nm) & Teór. (nm) & & & & \\
\hline 395,0 & $456,4(0,54)$ & 1 & $2,70 / 459,5$ & 0,1696 & $\mathrm{H} \rightarrow \mathrm{L}(97 \%)$ \\
\hline \multirow[t]{4}{*}{276,9} & $234,7(1,00)$ & 17 & $4,60 / 269,7$ & 0,0670 & $\mathrm{H}-2 \rightarrow \mathrm{L}+2(31 \%)$ \\
\hline & & & & & $\mathrm{H}-1 \rightarrow \mathrm{L}+2(24 \%)$ \\
\hline & & 36 & $5,21 / 237,9$ & 0,0563 & $\mathrm{H}-3 \rightarrow \mathrm{L}+3(40 \%)$ \\
\hline & & 42 & $5,37 / 230,8$ & 0,0771 & $\mathrm{H}-8 \rightarrow \mathrm{L}+2(16 \%)$ \\
\hline
\end{tabular}

nm para o íon em P2. Devemos lembrar que as duas posições do íon estão associadas a altos valores de energia total do complexo. Em todos os casos analisados ocorre transferência de carga para o íon, com a segunda banda apresentando alta intensidade devido a grande quantidade de transições.

Observando o formato da molécula com os orbitais, figura 5.2, é possível constatar que a geometria otimizada causa grande deformação na TC. Os anéis 

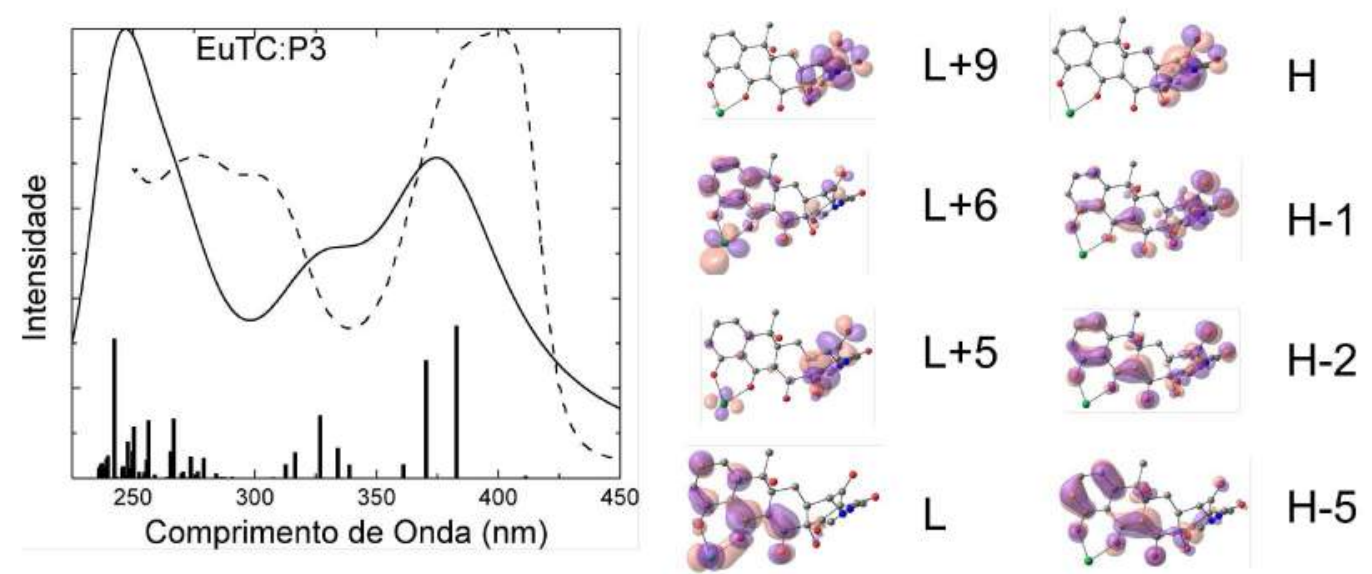

Figura 5.3: Espectro de absorção eletrônica do complexo EuTC com a TC rígida e o íon na posição P3 usando o PCM para descrever o solvente comparado com o espectro experimental [25], além dos orbitais envolvidos nas transições mais intensas.

Tabela 5.3: Comparativo entre os máximos do espectro de absorção experimental [25] e teórico com as contribuições de cada orbital envolvido do complexo EuTC com a TC rígida e o íon na posição P3 usando o PCM para descrever o solvente.

\begin{tabular}{|c|c|c|c|c|c|}
\hline \multicolumn{2}{|c|}{ Máximo } & \multirow{2}{*}{ Ordem } & \multirow{2}{*}{$\begin{array}{l}\text { Energia } \\
(\mathrm{eV} / \mathrm{nm})\end{array}$} & \multirow{2}{*}{$\begin{array}{l}\text { Força do } \\
\text { Oscilador }\end{array}$} & \multirow{2}{*}{ Composição } \\
\hline Exp. (nm) & Teór. (nm) & & & & \\
\hline \multirow[t]{3}{*}{395,0} & $374,7(0,71)$ & 2 & $3,24 / 382,8$ & 0,1691 & $\mathrm{H}-1 \rightarrow \mathrm{L}(56 \%)$ \\
\hline & & 3 & $3,35 / 370,3$ & 0,1309 & $\mathrm{H}-2 \rightarrow \mathrm{L}(66 \%)$ \\
\hline & & 7 & $3,79 / 326,9$ & 0,0697 & $\mathrm{H}-5 \rightarrow \mathrm{L}(65 \%)$ \\
\hline \multirow[t]{4}{*}{276,9} & $246,9(1,00)$ & 24 & $4,65 / 266,7$ & 0,0661 & $\mathrm{H} \rightarrow \mathrm{L}+5(48 \%)$ \\
\hline & & 28 & $4,84 / 256,3$ & 0,0640 & $\mathrm{H} \rightarrow \mathrm{L}+5(18 \%)$ \\
\hline & & 34 & $4,95 / 250,4$ & 0,0573 & $\mathrm{H} \rightarrow \mathrm{L}+6(55 \%)$ \\
\hline & & 43 & $5,12 / 242,4$ & 0,1548 & $\mathrm{H} \rightarrow \mathrm{L}+9(76 \%)$ \\
\hline
\end{tabular}

DCB são torcidos de tal forma que a posição P3 acaba adicionando o oxigênio $\mathrm{O}_{12}$ em sua coordenação. Como o PCM apresentou deformações no espectro do complexo MgTC e nas outras posições do íon $\mathrm{Eu}^{3+}$, limitaremos a flexibilidade da TC para diminuir o efeito da presença do íon. Consequentemente, vamos adotar a estrutura geométrica da forma $\mathrm{TC}^{3-}$, que já foi trabalhada na seção 3.1, e otimizar 
o posicionamento do íon nas posições P1, P2 e P3. Os valores das energias dos complexos não alteram significantemente conforme a tabela 5.1, mesmo adotando tal procedimento.

Tratando a TC rígida, figura 5.3 e tabela 5.3, observamos que o espectro de absorção apresenta o formato de duas bandas, qualitativamente próximo ao experimento. Nesta banda, várias transições intensas são observadas com transferência de carga do anel A para os anéis DCB e o Eu ${ }^{3+}$. O máximo está localizado em 374,7 nm, e comparando com a $\mathrm{TC}^{-}$em água com o mesmo modelo teórico podemos calcular o deslocamento pela presença do íon, que é igual a 30,9 nm, valor levemente acima do resultado experimental que é igual a 25,0 nm, mas ainda em boa concordância. Esta banda possui grande e apresenta um ombro em 325,0 nm, formado por transições de baixa intensidade onde a mais intensa apresenta a mesma dinâmica de transporte de carga do máximo da banda. Devemos observar que o resultado experimental também apresenta a banda larga, com largura maior do que $50 \mathrm{~nm}$ a meia altura.

Novamente, a segunda banda, abaixo de 300 nm, apresentou várias transições contribuindo para o alto valor da intensidade. Nessa região, a transferência de carga é direcionada para o íon $\mathrm{Eu}^{3+}$ e os anéis $\mathrm{DCB}$, com origem no anel $\mathrm{A}$. O máximo desta banda está localizado em $246,9 \mathrm{~nm}$, bem distante da banda experimental com máximo em 276,9 nm.

Mesmo adotando as restrições geométricas, encontramos dificuldades em obter o espectro para o íon em P2, com transições acima de $500 \mathrm{~nm}$. Devemos lembrar que a mesma falha ocorreu para o complexo $\mathrm{MgTC}$ com o $\mathrm{Mg}^{2+}$ também em P2. Para a posição P1, obtivemos um espectro semelhante ao $\mathrm{TC}^{3-}$, com o deslocamento igual a 28,0 nm na primeira banda. Ainda assim, transições de baixa intensidade foram encontradas acima de $450 \mathrm{~nm}$. Constatamos até agora a participação efetiva do íon em praticamente todas as transições intensas do complexo EuTC, diferente do complexo MgTC. O efeito de transferência de carga da primeira 
banda não segue a mesma direção ao comparar as duas possibilidades da rigidez da $\mathrm{TC}$, além da forma $\mathrm{TC}^{3-}$ em água. O próximo passo é aplicar a simulação clássica e obter o espectro com os dois outros modelos, ASEC e explícito, analisando as características de cada espectro.

\subsection{Simulação Clássica: Modelo ASEC e Explícito}

Usando os parâmetros do potencial do $\mathrm{Eu}^{3+}$ de acordo com van Veggel e colaboradores [110] e a carga do íon igual a $+3 e$, realizamos uma simulação clássica do $\mathrm{Eu}^{3+}$ em água nas mesmas condições termodinâmicas citadas nos capítulos anteriores. Novamente foi observado a formação de estruturas de coordenação do solvente em função do íon. A função de distribuição radial desta simulação mostrou que a primeira camada de solvatação é formada por nove moléculas de água, onde a distância média do $\mathrm{Eu}^{3+}-\mathrm{O}_{\text {água }}$ é igual a 2,45 ̊̊ enquanto a distância média $\mathrm{Eu}^{3+}-\mathrm{H}_{\text {água }}$ é igual 3,15 ̊̊. Estes resultados estão em boa concordância com os dados experimentais [111], e, comparado com o íon Mg, o grau de coordenação aumenta de 6 para 9.

Em seguida, realizamos a simulação clássica do complexo EuTC em água, trabalhando com o ligante na forma $\mathrm{TC}^{3-}$ rígida, a mesma usada na seção 3.3. Três simulações foram efetuadas, com o íon inicialmente próximo a cada uma das posições P1, P2 e P3, conforme a figura 5.1. As distâncias entre o íon e os átomos de oxigênio da TC se mantiveram constantes durante a simulação clássica na fase de equilíbrio, como podemos observar na tabela 5.4. Na mesma tabela, comparamos as distâncias obtidas pela média da simulação clássica e pelo PCM, sempre do $\mathrm{Eu}^{3+}$ para os pares de oxigênios da TC: $\left(\mathrm{O}_{3}-\mathrm{O}_{a m}\right)$ próximo da posição $\mathrm{P} 1,\left(\mathrm{O}_{11}-\mathrm{O}_{12}\right)$ próximo da posição $\mathrm{P} 2$ e $\left(\mathrm{O}_{10}-\mathrm{O}_{11}\right)$ próximo da posição P3. É neste parâmetro que encontramos também o maior desvio padrão, 0,141 Å. Observando os valores da 
tabela 5.4, o PCM permite que o íon fique mais próximo dos átomos de oxigênio da TC do que a simulação chegando a apresentar diferença de até 0,35 Å para o oxigênio $\mathrm{O}_{11}$ da posição P3. Este comportamento já havia sido observada no complexo MgTC, e o fato de deixar TC rígida na otimização do complexo acaba afastando o íon em quase todos os casos, menos no $\mathrm{O}_{10}$.

Tabela 5.4: Comparativo entre as distâncias médias em $\AA$ do íon $\mathrm{Eu}^{3+}$ com específicos átomos de oxigênio da molécula TC, comparando os valores da simulação clássica e da estrutura otimizada com PCM.

\begin{tabular}{c|cc|cc|cc}
\hline \hline & \multicolumn{2}{|c}{$\mathrm{P1}$} & \multicolumn{2}{c}{$\mathrm{P} 2$} & \multicolumn{2}{c}{$\mathrm{P3}$} \\
\hline Método/Átomos & $\mathrm{O}_{a m}$ & $\mathrm{O}_{3}$ & $\mathrm{O}_{11}$ & $\mathrm{O}_{12}$ & $\mathrm{O}_{10}$ & $\mathrm{O}_{11}$ \\
\hline Simulação & 2,535 & 2,513 & 2,424 & 2,486 & 2,358 & 2,563 \\
clássica & $\pm 0,105$ & $\pm 0,085$ & $\pm 0,061$ & $\pm 0,084$ & $\pm 0,050$ & $\pm 0,141$ \\
\hline PCM - TC flexível & 2,236 & 2,241 & 2,179 & 2,217 & 2,270 & 2,215 \\
PCM - TC rígida & 2,311 & 2,313 & 2,238 & 2,269 & 2,218 & 2,253 \\
\hline \hline
\end{tabular}

Realizamos o cálculo do espectro de absorção eletrônica com TDDFT para o íon em P3 usando o modelo ASEC, conforme a figuras 5.4 e tabela 5.5. Neste modelo, o íon e as moléculas do solvente foram tratados como cargas pontuais criando um envoltório eletrostático. O espectro assume uma forma muito próxima ao caso $\mathrm{TC}^{3-}$, tratada na seção 3.3, com pequenos deslocamentos proporcionados pela presença do íon e seu efeito afastando algumas moléculas do solvente. A primeira banda possui o máximo em 345,7 nm e o efeito de transferência de carga não está claro: a transição $\mathrm{H} \rightarrow$ L possui uma leve transferência de carga dos anéis DCB para o anel A, enquanto que a transição H-3 $\rightarrow$ L ocorre transferência do anel A para os anéis DCB. O deslocamento desta banda pela presença do íon é igual a 11,9 nm, metade do valor experimental ao comparar com a forma $\mathrm{TC}^{-}$com o mesmo modelo teórico. No PCM, transições na região de $325 \mathrm{~nm}$ eram intensas ao ponto de deformar a primeira banda. Tal efeito é muito sutil no modelo ASEC apesar, da presença das 
mesmas transições entre as duas bandas do espectro.
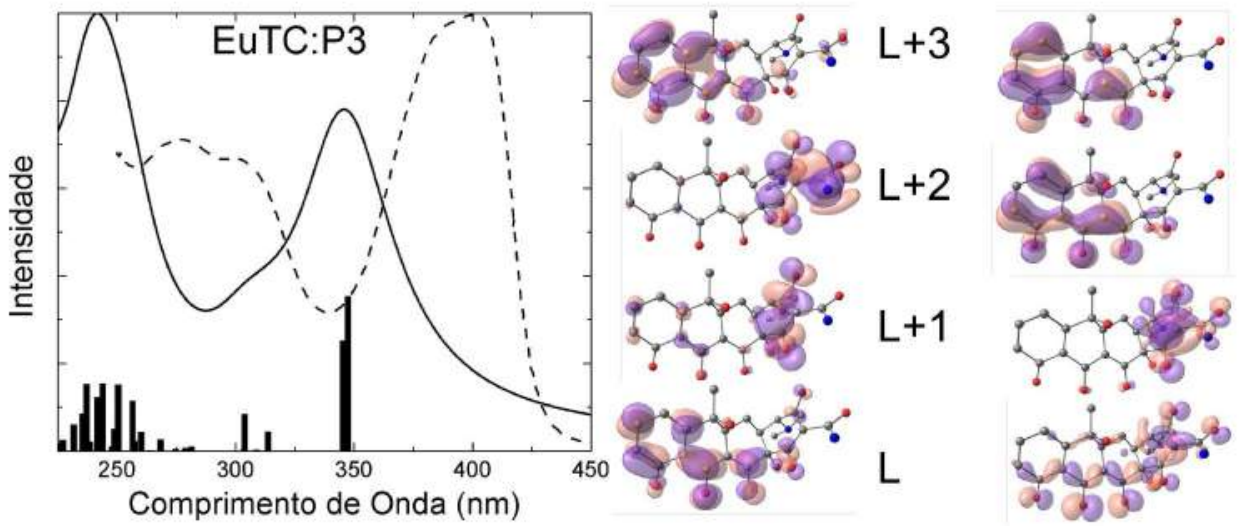

$\mathrm{H}$

$\mathrm{H}-1$

$\mathrm{H}-2$

$\mathrm{H}-3$

Figura 5.4: Espectro de absorção eletrônica do complexo EuTC com o íon na posição P3 usando o modelo ASEC para descrever o solvente comparado com o espectro experimental [25], além dos orbitais envolvidos nas transições mais intensas ( $\mathrm{H}-4$ semelhante ao $\mathrm{H}-3$ e $\mathrm{L}+4$ semelhante ao $\mathrm{L}+3$ ).

Tabela 5.5: Comparativo entre os máximos do espectro de absorção experimental [25] e teórico com as contribuições de cada orbital envolvido do complexo EuTC com o íon na posição P3 usando o modelo ASEC para descrever o solvente.

\begin{tabular}{|c|c|c|c|c|c|}
\hline \multicolumn{2}{|c|}{ Máximo } & \multirow{2}{*}{ Ordem } & \multirow{2}{*}{$\begin{array}{l}\text { Energia } \\
(\mathrm{eV} / \mathrm{nm})\end{array}$} & \multirow{2}{*}{$\begin{array}{l}\text { Força do } \\
\text { Oscilador }\end{array}$} & \multirow{2}{*}{ Composição } \\
\hline Exp. (nm) & Teór. (nm) & & & & \\
\hline \multirow[t]{4}{*}{395,0} & $345,7(0,78)$ & 1 & $3,57 / 347,5$ & 0,1768 & $\mathrm{H} \rightarrow \mathrm{L}(53 \%)$ \\
\hline & & & & & $\mathrm{H}-3 \rightarrow \mathrm{L}(32 \%)$ \\
\hline & & 2 & $3,59 / 345,2$ & 0,1262 & $\mathrm{H} \rightarrow \mathrm{L}(43 \%)$ \\
\hline & & & & & $\mathrm{H}-3 \rightarrow \mathrm{L}(34 \%)$ \\
\hline \multirow[t]{4}{*}{276,9} & $241,7(1,00)$ & 17 & $4,95 / 250,4$ & 0,0758 & $\mathrm{H}-4 \rightarrow \mathrm{L}+1(37 \%)$ \\
\hline & & 20 & $5,08 / 243,8$ & 0,0767 & $\mathrm{H}-2 \rightarrow \mathrm{L}+2(70 \%)$ \\
\hline & & 24 & $5,23 / 237,0$ & 0,0761 & $\mathrm{H}-1 \rightarrow \mathrm{L}+3(62 \%)$ \\
\hline & & 30 & $5,57 / 222,6$ & 0,0736 & $\mathrm{H} \rightarrow \mathrm{L}+4(44 \%)$ \\
\hline
\end{tabular}

A segunda banda possui o máximo em $241,7 \mathrm{~nm}$ e apresenta a intensidade alta devido a grande quantidade de transições. O máximo da banda experimental está localizado em $276,9 \mathrm{~nm}$, gerando uma diferença de $35,2 \mathrm{~nm}$ para a mesma banda 
experimental. Os efeitos de transferência de carga nas transições desta banda são desprezíveis nas transições mais intensas. Comparando com a forma $\mathrm{TC}^{3-}$ e usando o mesmo modelo teórico, a segunda banda desloca-se -3,5 nm. Comparando com a forma $\mathrm{TC}^{-}$, o deslocamento nesta banda é grande: $-13,3 \mathrm{~nm}$.

Com o íon nas outras posições, P1 e P2, o espectro mostra uma primeira banda de grande largura, pois transições na região de $300 \mathrm{~nm}$ modificam a forma do espectro. Nestes casos, podemos considerar o surgimento de outra banda, porém o resultado experimental não prevê tal efeito. O deslocamento do máximo da primeira banda foi superestimado com o íon na posição P2, com valor igual a 48,8 nm, enquanto que o íon na posição P1 apresenta deslocamento 13,8 nm. O próximo passo é analisar os resultados com o modelo de solvente parcialmente explícito, na tentativa de melhorar a descrição eletrônica em torno da TC.

Vamos considerar os átomos da TC, das 16 moléculas mais próximas de solvente e do Eu na forma explícita e 734 moléculas de água como cargas pontuais. Como o íon sempre está hospedado próximo de um par de átomos de oxigênio da TC e sendo nove o grau de coordenação do íon, sete moléculas de água sempre vão se posicionar próximas ao Eu para fechar a coordenação. As outras moléculas de águas são as mais próximas do soluto formando, na maioria dos casos, a ligação de hidrogênio. O espectro, que é a convolução de 100 configurações estatisticamente descorrelacionadas submetidas ao cálculo TDDFT, está exposto na figura e 5.5 e na tabela 5.6.

O espectro de absorção apresenta um formato bastante diferente ao adicionar átomos explícitos. A primeira banda acaba se dividindo em duas bandas de baixa intensidade, novamente devido ao aumento da força de oscilador das transições na região de $300 \mathrm{~nm}$. No primeiro pico é formado por transições do tipo $\mathrm{H} \rightarrow \mathrm{L}$ e H $\rightarrow \mathrm{L}+1$, acarretando na transferência de carga dos anéis DC para os anéis BA. O máximo deste pico está em $366.3 \mathrm{~nm}$, indicando que a presença do íon causa um 

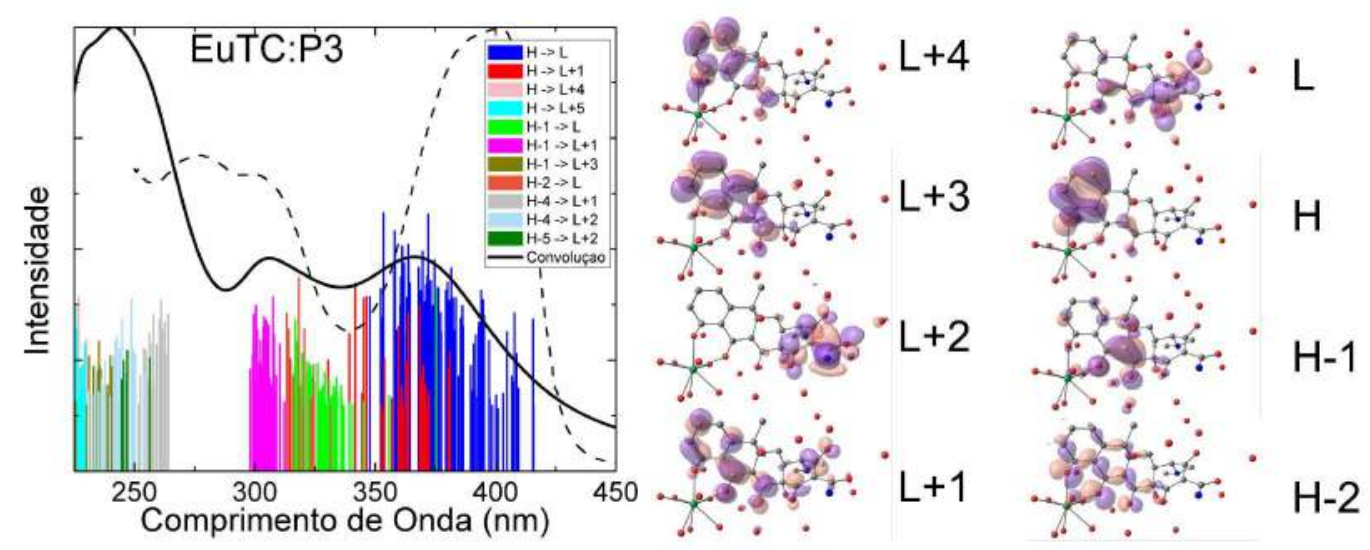

Figura 5.5: Espectro de absorção eletrônica do complexo EuTC com o íon na posição P3 usando o modelo de solvente parcialmente explícito comparado com o espectro experimental [25], além dos orbitais envolvidos nas transições mais intensas para uma configuração relevante.

Tabela 5.6: Comparativo entre os máximos do espectro de absorção experimental [25] e teórico com as contribuições de cada orbital envolvido do complexo EuTC com o íon na posição P3 usando o modelo de solvente parcialmente explícito.

\begin{tabular}{|c|c|c|c|c|c|}
\hline \multicolumn{2}{|c|}{ Máximo } & \multirow{2}{*}{ Ordem } & \multirow{2}{*}{$\begin{array}{l}\text { Energia } \\
(\mathrm{eV} / \mathrm{nm})\end{array}$} & \multirow{2}{*}{$\begin{array}{l}\text { Força do } \\
\text { Oscilador }\end{array}$} & \multirow{2}{*}{ Composição } \\
\hline Exp. (nm) & Teór. (nm) & & & & \\
\hline \multirow[t]{3}{*}{395,0} & $366,3(0,48)$ & 1 & $3,22 / 384,5$ & 0,0950 & $\mathrm{H} \rightarrow \mathrm{L}(46 \%)$ \\
\hline & & 3 & $3,51 / 353,4$ & 0,0608 & $\mathrm{H} \rightarrow \mathrm{L}+1(41 \%)$ \\
\hline & $306,0(0,48)$ & 8 & $4,09 / 303,3$ & 0,1056 & $\mathrm{H}-1 \rightarrow \mathrm{L}+1(37 \%)$ \\
\hline \multirow[t]{3}{*}{276,9} & $241,5(1,00)$ & 30 & $5,19 / 238,9$ & 0,0785 & $\mathrm{H}-1 \rightarrow \mathrm{L}+3(21 \%)$ \\
\hline & & 43 & $5,50 / 225,5$ & 0,0967 & $\mathrm{H} \rightarrow \mathrm{L}+4(18 \%)$ \\
\hline & & & & & $\mathrm{H}-2 \rightarrow \mathrm{L}+4(14 \%)$ \\
\hline
\end{tabular}

deslocamento de $31,7 \mathrm{~nm}$, acima do valor experimental de $25 \mathrm{~nm}$. O segundo pico, com máximo em $306,0 \mathrm{~nm}$, é formado basicamente por transições do tipo $\mathrm{H}-1 \rightarrow \mathrm{L}+1$ e H-1 $\rightarrow$ L, onde a carga se transfere do centro da TC para os anéis D e A. Não está claro se essas transições pertencem à primeira ou à segunda banda experimental. Abaixo de $300 \mathrm{~nm}$, é encontrada uma banda bastante intensa, contendo várias transições que apenas redistribuem a carga nas regiões cromóforas. 
A primeira banda com baixa intensidade e larga também é vista nos casos com o íon em P2 e P1. Em ambos os casos o deslocamento desta banda é igual a 21 $\mathrm{nm}$, em boa concordância com o experimento. Mas devemos lembrar que a energia associadas aos complexos EuTC com o íon em P1 ou P2 é muito maior do que com o íon em P3. Abaixo de $300 \mathrm{~nm}$, a banda apresenta o mesmo comportamento independente da posição do íon: muito intensa e com máximo entre 241 e 247 nm.

A princípio o complexo EuTC não apresenta um resultado animador quando comparado aos casos $\mathrm{MgTC}$ e $\mathrm{Mg}_{2} \mathrm{TC}$, pois a presença do íon não gerou apenas um deslocamento na banda. $\mathrm{O}$ espectro deixou de ser qualitativamente bem descrito pelos modelos teóricos e, em alguns casos, houve transições com energias bem abaixo do experimento, principalmente no PCM. Devemos lembrar que os resultados experimentais foram obtidos por grupos de pesquisa diferentes, mas o efeito reportado é o mesmo, deslocamento de $25 \mathrm{~nm}$ na primeira banda de absorção, o qual poucos modelos teóricos descreveram corretamente.

Tabela 5.7: Comparativo dos deslocamentos em $\mathrm{nm}$ do máximo da primeira banda do espectro de absorção eletrônica teórica e experimental partindo da forma $\mathrm{TC}^{-}$para a $\mathrm{TC}^{3-}$ ou a presença do íon Eu nas três diferentes posições.

\begin{tabular}{ccccc}
\hline \hline & $\mathrm{TC}^{-} \rightarrow \mathrm{TC}^{3-}$ & $\mathrm{TC}^{-} \rightarrow$ EuTC:P1 & $\mathrm{TC}^{-} \rightarrow$ EuTC:P2 & $\mathrm{TC}^{-} \rightarrow$ EuTC:P3 \\
\hline Experimento [21,25] & $\mathrm{n} / \mathrm{d}$ & 25 & 25 & 25 \\
PCM - TC Flexível & 30,5 & 29,2 & 103,5 & 112,7 \\
PCM - TC Rígida & 30,5 & 28,0 & 176,5 & 30,9 \\
Modelo ASEC & 23,2 & 13,8 & 48,8 & 11,9 \\
Modelo Explícito & 21,4 & 21,1 & 22,6 & 31,7 \\
\hline \hline
\end{tabular}

Podemos considerar que o deslocamento é composto por duas contribuições. A primeira é devido à mudança de geometria e desprotonação ao sair da forma $\mathrm{TC}^{-}$e se estabilizar na forma $\mathrm{TC}^{3-}$. A segunda contribuição provém da presença do íon $\mathrm{Eu}^{3+}$ próximo a $\mathrm{TC}^{3-}$. Os valores do deslocamentos da primeira banda estão 
expostos na tabela 5.7, comparando dados experimentais e modelo teóricos. Nessa tabela, observamos que todos os modelos teóricos apresentaram deslocamento devido à desprotonação compatível com o deslocamento experimental pela presença do íon. Devemos lembrar que a cada desprotonação, ocorre um deslocamento para o vermelho na primeira banda. Entretanto, não há o valor experimental deste deslocamento para a forma $\mathrm{TC}^{3-}$. Mas ao adicionar o íon teoricamente na forma $\mathrm{TC}^{3-}$, o resultado é distinto. Com o íon em P1, o valor do deslocamento diminuiu independente do modelo. Aplicando o PCM para o modelo da TC flexível obtivemos deslocamento exagerados para as posições P2 e P3. Com o modelo TC rgida, o deslocamento se torna melhor apenas com a posição P3. Para o modelo explícito com íon em P3, o deslocamento de 31,7 nm é formado por 21,4 nm somente da desprotonação e mudanças geométricas enquanto que a presença do íon contribui com 10,3 nm. Com o Eu ${ }^{3+}$ em P2, a presença do íon contribui em 1,2 nm. Já o modelo ASEC indica que a presença do íon desloca a primeira banda em 25,6 nm com o íon em P2 e -11,3 nm com o íon em P3.

Da mesma forma para os complexos $\mathrm{MgTC}$ e $\mathrm{Mg}_{2} \mathrm{TC}$, o orbital H está presente nos anéis DCB e está presente nas transições mais intensas da primeira banda do espectro de absorção. Então a presença o íon próximo a estes orbitais deve causar maior interferênia na primeira banda, como as posições P2 e P3, sendo esperando um deslocamento para o vermelho. Para a posição P1, afastada do orbtial $\mathrm{H}$, o efeito na primeira banda deve ser mínimo. Pelos resultados na tabela 5.7, o tratamento explícito do íon e solvente se torna fundamental para a descrição correta do deslocamento, enquanto que considerar apenas a contribuição eletrostática pode, em certos casos, fornecer uma descrição equivocada do espectro.

Observamos o afastamento entre as transições da primeira banda em muito casos, ocasionando também mudanças de intensidade. Entretanto, tal efeito já foi observado para a forma $\mathrm{TC}^{3-}$, sendo agravado com a presença do íon. Não foi pos- 
sível estimar corretamente a origem destas transições, nem relacionar com alguma banda experimental. Com a $\mathrm{TC}^{3-}$ em água, a primeira banda posuia a transferência parcial de carga dos anéis DC para o restante da TC. Tal comportamento foi novamente obtido com a presença do íon nos modelos ASEC e explícito. Não é possível descrever corretamente o posicionamento do íon Eu na TC pela mudança no espectro, diferente do que foi obtido do complexo MgTC. Entretanto, a diferença de energia entre os complexos é muito alta, indicando a preferência pela posição P3. 


\section{Capítulo 6}

\section{Conclusões}

Nesta tese estudamos os espectros de absorção da TC e dos complexos MgTC e EuTC. Entretanto, desprotonações/protonações ocorrem na TC em função do pH do solvente. Com as diferentes formas da TC, diversas posições de acoplamento dos íons poderiam ser analisadas, incluindo ainda diferentes razões entre o íon e o ligante, tornando a análise inviável. Após a obtenção da correta posição de desprotonação das diferentes formas da TC, calculamos o espectro de absorção eletrônica para cada uma destas moléculas, sempre comparando com os dados experimentais. Com o discernimento adquirido para os sistemas de TC em água, estudamos o efeito da presença do íon na formação de específicos complexos. Estas estruturas foram comparadas considerando as formas da TC e complexos mais intensos em função da condição do ambiente.

Para a obtenção do espectro de absorção usamos a TDDFT com o funcional híbrido B3LYP e a base 6-31G(d), com diferentes aproximações para descrever o solvente. O modelo mais simples foi o PCM, que considera o meio como um dielétrico contínuo. Outros modelos, como o puramente eletrostático ASEC ou incluindo explícitamente algumas moléculas de solvente, são baseados no S-QM/MM, necessitando de uma simulação clássica para gerar as configurações contendo soluto e solvente. Outros funcionais foram empregados além da mudança do tamanho da 
base, sem relevantes mudanças na posição das bandas do espectro.

De maneira geral, obtivemos uma boa descrição qualitativa do espectro de absorção dos vários sistemas estudados. Para as cinco formas da TC em água, todos os modelos de solvente representaram bem o espectro de absorção, com méritos para o PCM que forneceu os valores dos máximos das bandas próximo dos dados experimentais, principalmente para os sistemas $\mathrm{TC}^{-}$e $\mathrm{TC}^{2-}$. Porém cada forma da TC tem sua incidência máxima numa respectiva faixa de $\mathrm{pH}$, e os deslocamentos das bandas provocados pela mudança da acidez do solvente foram melhores descritos pelos modelos ASEC e solvente parcialmente explícito, em especial para o caso $\mathrm{TC}^{ \pm} \rightarrow \mathrm{TC}^{-}$que apresenta boa concordância com o resultado experimental.

Os espectros das formas da TC em água apresentaram um comportamento bastante comum: duas bandas bem definidas localizadas nas regiões de $350 \mathrm{~nm}$ e $260 \mathrm{~nm}$, sendo que cada espectro apresentou ombros e picos em locais específicos, com as bandas teóricas sempre se posicionando com energia maior do que as mesmas bandas experimentais. O aumento da quantidade de solvente explícito não implicou numa melhora na descrição do espectro como um todo. Ao colocar toda a primeira camada de solvatação, a mudança do espectro foi $4 \mathrm{~nm}$. Quanto à base, a adição de funções difusas ou o uso de outras famílias de bases melhorou o espectro de forma sutil, $7 \mathrm{~nm}$, apresentando um elevado custo computacional que dificulta o cálculo com um número grande de configurações para o S-QM/MM.

Observando as transições, verificamos a existência de duas regiões cromóforas onde os orbitais se associam: uma nos anéis DCB e outra no anel A com seus grupos atômicos. Transições envolvendo a total transferência de carga de uma região para outra possuem baixa frequência e estão associadas à força de oscilador fracas. Nas transições intensas da primeira banda, constatamos a sutil transferência de carga dos anéis $\mathrm{DBC}$ para o anel $\mathrm{A}$ nas formas $\mathrm{TC}^{+}, \mathrm{TC}^{-}$e $\mathrm{TC}^{3-}$, enquanto que na $\mathrm{TC}^{ \pm} \mathrm{a}$ direção é invertida e na $\mathrm{TC}^{2-}$ não apresenta transferência. Para as bandas de maior 
energia, há grande quantidade de transições intensas, dificultando uma análise mais apurada.

O bom resultado obtido pelo PCM para representar o espectro de absorção das formas da TC em água não se repetiu nos complexos MgTC e EuTC. Bandas muito deslocadas ou em regiões não previstas experimentalmente contribuíram para descrever a falha, além dos valores discrepantes dos deslocamentos pela presença do íon. Devemos lembrar que no PCM estamos trabalhando com apenas uma configuração onde o complexo possui geometria otimizada em solvente. Usando este modelo, observamos que a distância entre o íon e os átomos de oxigênio foi menor do que os valores da simulação clássica, que por sua vez são coerentes com experimentos de cristalografia.

Para os complexos com o íon $\mathrm{Mg}^{2+}$, tanto o modelo ASEC quanto o explícito mostraram o espectro de absorção coerente com o experimento, diferentes do PCM. Porém a posição das bandas no espectro teórico se tornou mais afastada das posições das bandas experimentais quando comparado ao modelo contínuo. Os deslocamentos pela presença do íon mostraram excelentes valores comparados aos dados experimentais nos casos MgTC com boa representação das intensidades. Para o íon em P1, o deslocamento é muito pequeno no explícito e na direção contrária no ASEC. Para o íon em P2, o valor do deslocamento se torna muito próximo ao experimento em ambos os modelos. No complexo $\mathrm{Mg}_{2} \mathrm{TC}$, o deslocamento da primeira banda se mantém, em excelente concordância com o experimento. Interessante notar que os modelos diferentes de tratar parte do solvente mostraram o mesmo resultado, indicando que a interação específica e eletrostática foram fundamentais para o cálculo do espectro.

Estes resultados corroboram alguns dados experimentais sobre a posição preferencial do acoplamento do íon na TC. Pelo deslocamento da primeira banda, acreditamos que o primeiro local a ser ocupado pelo $\mathrm{Mg}$ é a posição P2 para formar o 
MgTC e o segundo íon ocupa a posição P1 formando o $\mathrm{Mg}_{2} \mathrm{TC}$. Tal resultado mostra como o espectro de absorção funciona como caracterização do posicionamento do íon. Vale ressaltar que os orbitais envolvidos na transições mais intensas da primeira banda estão sob os anéis DCB, região próxima ao íon em P2.

Outra propriedade de caracterização é relacionada a uma terceira banda em 246,1 $\mathrm{nm}$, observada experimentalmente no complexo $\mathrm{Mg}_{2} \mathrm{TC}$ e de intensidade similar a segunda banda. Novamente, o modelo ASEC é capaz de descrever tal efeito do acoplamento dos dois íons. No caso do PCM, este pico estava presente em todas as análises, inclusive do sistema $\mathrm{TC}^{-}$. Para o modelo explicito, transições no solvente dificultam a análise na região abaixo de $250 \mathrm{~nm}$. Quanto aos orbitais, constatamos que no complexo MgTC há uma tendência a deslocar parte da carga na direção do íon. Este efeito é bem claro no modelo ASEC. No restante não observamos grandes mudanças nos orbitais envolvidos nos complexos com $\mathrm{Mg}^{2+}$, sendo que os orbitais deste íon não participam das transições mais intensas.

Com o íon Eu, a analise do complexo se tornou mais complicada. Pelo valor energético, apenas a posição P3 é adotada pelo sistema líquido, sendo que novamente o PCM aproximou o íon dos átomos da TC. O espectro perdeu a boa descrição qualitativa, obtida na TC e no complexo com o $\mathrm{Mg}^{2+}$. Transições na região de 300 $\mathrm{nm}$, que já estavam presentes na forma $\mathrm{TC}^{3-}$, aumentaram a intensidade gerando uma banda intermediária em vários casos analisados. Da mesma forma que o complexo MgTC, o espectro de absorção apresentou transições com energia menor que os valores experimentais usando o modelo PCM.

Experimentalmente, é observado um deslocamento $25 \mathrm{~nm}$ na primeira banda. Esse deslocamento é proveniente de dois efeitos: a desprotonação da $\mathrm{TC}^{-}$para $\mathrm{TC}^{3-}$ e a presença do íon. O primeiro efeito já causa um deslocamento entre 20 e $30 \mathrm{~nm}$, valor equiparável com o total efeito da presença do íon. Com o íon em P1, obtivemos a diminuição deste deslocamento, em concordância com o resultado para o $\mathrm{Mg}^{2+}$ 
também na posição P1. Energeticamente, a posição P3 é a mais favorável, mas a presença do íon em P2 gera um deslocamento superestimado pelo ASEC e muito próximo do dado experimental. Para a posição P3, o deslocamento obtido com ASEC é baixo, enquanto que o valor do explícito é um pouco acima do experimental. Estes resultados indicam que para descrever o espectro de absorção neste complexo é necessário considerar o íon e parte do solvente explicitamente. 


\section{Referências Bibliográficas}

[1] Canuto, S. (ed.) Solvation Effects on Molecules and Biomolecules. Computational Methods And Applications (Springer, Alemanha, 2008).

[2] Clementi, E. Evolution of computational chemistry, the "launch pad"to scientific computational models: The early days from a personal account, the present status from the TACC-2012 congress, and eventual future applications from the global simulation approach. AIP Conference Proceedings 1456, 5-54 (2012).

[3] Canuto, S. (ed.) Combining Quantum Mechanics and Molecular Mechanics.Some Recent Progresses in QM/MM Methods. Advances in Quantum Chemistry, v. 59 of Advances in Quantum Chemistry (Elsevier, 2010).

[4] Chopra, I. e Roberts, M. Tetracycline antibiotics: mode of action, applications, molecular biology, and epidemiology of bacterial resistance. Microbiology and molecular biology reviews : MMBR 65, 232-260 (2001).

[5] Duggar, B. M. Aureomycin: a product of the continuing search for new antibiotics. Annals of the New York Academy of Sciences 1241, 163-169 (2011).

[6] Demain, A. L. e Sanchez, S. Microbial drug discovery: 80 years of progress. The Journal of Antibiotics 62, 5-16 (2009).

[7] Wainwright, M. Miracle Cure: The Story of Penicillin and the Golden Age of Antiвiotics (Blackwell, 1990).

[8] Stephens, C. R., Conover, L. H., Hochstein, F. A., Regna, P. P., Pilgrim, F. J. e Brunings, K. J. Terramycin. VIII. Structure of Aureomycin and Terramycin. Journal of the American Chemical Society 74, 4976-4977 (1952).

[9] Oka, H., Ito, Y. e Matsumoto, H. Chromatographic analysis of tetracycline antibiotics in foods. Journal of Chromatography. A 882, 109-133 (2000).

[10] Griffin, M. O., Fricovsky, E., Ceballos, G. e Villarreal, F. Tetracyclines: a pleitropic family of compounds with promising therapeutic properties. Review of the literature. American Journal of Physiology. Cell Physiology 299, C539-C548 (2010). 
[11] Michalova, E., Novotna, P. e Schlegelova, J. Tetracyclines in veterinary medicine and bacterial resistance to them. A review. Veterinarni Medicina-UZPI 2004, 79-100 (2004).

[12] Chang, P.-H., Li, Z., Jiang, W.-T. e Jean, J.-S. Adsorption and intercalation of tetracycline by swelling clay minerals. Applied Clay Science 46, 27-36 (2009).

[13] Stryer, L. Biochemistry (Freeman, 1988), $3 \stackrel{a}{a}$ edn.

[14] Storer, A. e Cornish-bowden, A. Concentration of $\mathrm{MgATP}^{2-}$ snd other Ions in Solution. Calculation of True Concentrations of Species Present in Mixtures of Associating Ions. Biochemical Journal 159, 1-5 (1976).

[15] Smith, R., Thompson, L. e Maguire, M. Cloning and characterization of MgtE, a putative new class of $\mathrm{Mg}^{2+}$ transporter from Bacillus firmus $\mathrm{OF}_{4}$. Journal of Bacteriology 177, 1233-1238 (1995).

[16] Kaji, H., Suzuka, I. e Kaji, A. Binding of Specific Soluble Ribonucleic Acid to Ribosomes - Binding of Soluble Ribonucleic Acid to Template-30 S Subunits Complex. Journal of Biological Chemistry 241, 1251-1256 (1966).

[17] Tanaka, S., Igarashi, K. e Kaji, A. Studies on the Action of Tetracycline and Puromycin. Journal of Biological Chemistry 247, 45 (1972).

[18] Tritton, T. Ribosome-tetracycline interactions. Biochemistry 16, 4133-4138 (1977).

[19] Selvin, P. R. Principles and biophysical applications of lanthanide-based probes. Annual Review of Biophysics and Biomolecular Structure 31, 275-302 (2002).

[20] Hirschy, L. M., Dose, E. V. e Winefordner, J. D. Lanthanidesensitized of tetracyclines luminescence for the detection of Tetracyclines. Analytica Chimica Acta 147, 311-316 (1983).

[21] Liu, X.-j., Li, Y.-z. e Ci, Y.-x. Time-resolved fluorescence studies of the interaction of the $\mathrm{Eu}^{3+}$ complexes of tetracycline analogues with DNA. Analytica Chimica Acta 345, 213-217 (1997).

[22] Chen, J. e Selvin, P. R. Lifetime- and Color-Tailored Fluorophores in the Micro- to Millisecond Time Regime. Journal of the American Chemical Society 122, 657-660 (2000).

[23] Selvin, P. R. The renaissance of fluorescence resonance energy transfer. Nature Structural Biology 7, 730-734 (2000).

[24] Wu, M., Lin, Z. e Wolfbeis, O. S. Determination of the activity of catalase using a europium(III) tetracycline-derived fluorescent substrate. Analytical Biochemistry 320, 129-135 (2003).

[25] Courrol, L. C. e Samad, R. E. Applications of Europium Tetracycline Complex: A Review. Current Pharmaceutical Analysis 4, 238-248 (2008). 
[26] Hirsch, L., Geel, T. V. e Winefordner, J. Characteristics of the binding of europium (III) to tetracycline. Analytica Chimica Acta 166, 207-219 (1985).

[27] Boothe, J. H., Morton, J., Petisi, J. P., Wilkinson, R. G. e Williams, J. H. Tetracycline1. Journal of the American Chemical Society 75, 4621-4621 (1953).

[28] Conover, L. H., Moreland, W. T., English, A. R., Stephens, C. R. e Pilgrim, F. J. Terramycin. XI. Tetracycline. Journal of the American Chemical Society 75, 4622-4623 (1953).

[29] Takahashi, M., Altschmied, L. e Hillen, W. Kinetic and equilibrium characterization of the Tet repressor-tetracycline complex by fluorescence measurements: Evidence for divalent metal ion requirement and energy transfer. Journal of Molecular Biology 187, 341 - 348 (1986).

[30] Schneider, S., Schmitt, M. O., Brehm, G., Reiher, M., Matousek, P. e Towrie, M. Fluorescence kinetics of aqueous solutions of tetracycline and its complexes with $\mathrm{Mg}^{2+}$ and $\mathrm{Ca}^{2+}$. Photochemical \& Photobiological Sciences 2, 1107 (2003).

[31] Amat, A., Fantacci, S., Angelis, F., Carlotti, B. e Elisei, F. DFT/TDDFT investigation of the stepwise deprotonation in tetracycline: $\mathrm{pK}_{a}$ assignment and UV-vis spectroscopy. Theoretical Chemistry Accounts 131, 1218 (2012).

[32] Carlotti, B., Cesaretti, A. e Elisei, F. Complexes of tetracyclines with divalent metal cations investigated by stationary and femtosecond-pulsed techniques. Physical Chemistry Chemical Physics 14, 823-34 (2012).

[33] Georg, H. C. e Canuto, S. Electronic properties of water in liquid environment. A sequential QM/MM study using the free energy gradient method. The Journal of Physical Chemistry. B 116, 11247-54 (2012).

[34] Manzoni, V., Lyra, M., Gester, R., Coutinho, K. e Canuto, S. Study of the optical and magnetic properties of pyrimidine in water combining PCM and QM/MM methodologies. Physical Chemistry Chemical Physics 12, 14023-14033 (2010).

[35] Gester, R., Georg, H., Canuto, S., Cristina Caputo, M. e Provasi, P. NMR chemical shielding and spin-spin coupling constants of liquid $\mathrm{NH}_{3}$ : A systematic investigation using the sequential QM/MM method. Journal of Physical Chemistry A 113, 14936-14942 (2009).

[36] Bistafa, C. e Canuto, S. Solvent effects on the two lowest-lying singlet excited states of 5-fluorouracil. Theoretical Chemistry Accounts 132, 1-10 (2013).

[37] Jaramillo, P., Coutinho, K. e Canuto, S. Continuum, discrete, and explicit solvation models for describing the low-lying absorption spectrum of the pterin acid in aqueous environment. International Journal of Quantum Chemistry 110, 2371-2377 (2010).

[38] Silva, D. L., Coutinho, K. e Canuto, S. Electronic spectroscopy of biomolecules in solution: Fluorescein dianion in water. Molecular Physics 108, 3125-3130 (2010). 
[39] Allen, M. P. e Tildesley, D. J. Computer Simulation of Liquids (Oxford University Press, 1996), $1^{a}$ edn.

[40] Jensen, F. Introduction to Computational Chemistry (John Wiley \& Sons, 1999), $1^{a}$ edn.

[41] Levine, I. N. Quantum Chemistry (Prentice-Hall, 1991), $4^{a}$ edn.

[42] Morgon, N. H. e Coutinho, K. Métodos de Química Teórica e Modelagem Molecular (Livraria da Física, 2007), $1^{a} \stackrel{a}{\text { edn. }}$

[43] Vianna, D. J., Fazzio, A. e Canuto, S. Teoria Quântica de Moléculas e Sólidos (Editora Livraria da Física, 2004), 1ํㅡ edn. São Paulo.

[44] Laurent, A. D. e Jacquemin, D. TD-DFT benchmarks: A review. International Journal of Quantum Chemistry 113, 2019-2039 (2013).

[45] Tomasi, J., Mennucci, B. e Cammi, R. Quantum mechanical continuum solvation models. Chemical Reviews 105, 2999-3093 (2005).

[46] Tomasi, J. Thirty years of continuum solvation chemistry: A review, and prospects for the near future. Theoretical Chemistry Accounts 112, 184-203 (2004).

[47] Marques, M. A. L. e Gross, E. K. U. Time-dependent density functional theory. Annual review of physical chemistry 55, 427-55 (2004).

[48] Coutinho, K. e Canuto, S. DICE: A Monte Carlo program for molecular liquid simulation, University of Sao Paulo, v. 2.9, (2009).

[49] Salinas, S. R. A. Introdução À Física Estatística (Edusp, 2005), 2aㅡ edn.

[50] Coutinho, K. R. Modelo Discreto de Solvente. Solvatocromismo no Espectro de Absorção Molecular. Tese de doutoramento, Universidade de São Paulo (1997).

[51] Coutinho, K. e Canuto, S. The sequential Monte Carlo-quantum mechanics methodology. Application to the solvent effects in the Stokes shift of acetone in water. Journal of Molecular Structure: THEOCHEM 632, 235 - 246 (2003).

[52] Coutinho, K. e Canuto, S. Solvent effects in emission spectroscopy: A Monte Carlo quantum mechanics study of the $n \leftarrow \pi^{*}$ shift of formaldehyde in water. The Journal of Chemical Physics 113, 9132-9139 (2000).

[53] Jorgensen, W. L., Maxwell, D. S. e Tirado-Rives, J. Development and Testing of the OPLS All-Atom Force Field on Conformational Energetics and Properties of Organic Liquids. Journal of the American Chemical Society 118, 11225-11236 (1996).

[54] Jaramillo, P., Coutinho, K., Cabral, B. J. C. e Canuto, S. Ionization of chlorophyll- $\mathrm{c}_{2}$ in liquid methanol. Chemical Physics Letters 546, 67-73 (2012). 
[55] Jaramillo, P., Coutinho, K., Cabral, B. J. e Canuto, S. Explicit solvent effects on the visible absorption spectrum of a photosynthetic pigment: Chlorophyll- $\mathrm{c}_{2}$ in methanol. Chemical Physics Letters 516, 250-253 (2011).

[56] Manzoni, V., Lyra, M. L., Coutinho, K. e Canuto, S. Comparison of polarizable continuum model and quantum mechanics/molecular mechanics solute electronic polarization: study of the optical and magnetic properties of diazines in water. The Journal of Chemical Physics 135, 144103 (2011).

[57] Mateus, M. P., Galamba, N., Cabral, B. J. C., Coutinho, K. e Canuto, S. Electronic properties of a methane-water solution. Chemical Physics Letters 506, 183-189 (2011).

[58] Georg, H. C., Coutinho, K. e Canuto, S. Solvent effects on the UV-visible absorption spectrum of benzophenone in water: a combined Monte Carlo quantum mechanics study including solute polarization. The Journal of Chemical Physics 126, 034507 (2007).

[59] Coutinho, K., Oliveira, M. J. D. e Canuto, S. Sampling configurations in Monte Carlo simulations for quantum mechanical studies of solvent effects. International Journal of Quantum Chemistry 66, 249-253 (1998).

[60] Chatfield, C. The Analysis of Time Series. An Introduction (Chapman and Hall, London, 1984), $3^{a}$ edn.

[61] Leininger, M. L., Allen, W. D., Schaefer, H. F. e Sherrill, C. D. Is Möller-Plesset perturbation theory a convergent ab initio method? The Journal of Chemical Physics 112, 9213 (2000).

[62] Kitel, C. Introduction to Solid State Physics (John Wiley \& Sons, 1995), $7^{a} \stackrel{a}{e}$ edn.

[63] Slater, J. C. A simplification of the Hartree-Fock method. Physical Review 81, 385-390 (1951).

[64] Hohenberg, P. e Kohn, W. Inhomogeneous electron gas. Physical Review 136, B864B871 (1964).

[65] Perdew, J. P. e Yue, W. Accurate and simple density functional for the electronic exchange energy: Generalized gradient approximation. Physical Review B 33, 88008802 (1986).

[66] Becke, A. D. Density-functional exchange-energy approximation with correct asymptotic behavior. Physical Review A 38, 3098-3100 (1988).

[67] Vosko, S. H., Wilk, L. e Nusair, M. Accurate spin-dependent electron liquid correlation energies for local spin density calculations: a critical analysis. Canadian Journal of Physics 58, 1211 (1980).

[68] Perdew, J. P., Chevary, J. A., Vosko, S. H., Jackson, K. A., Pederson, M. R., Singh, D. J. e Fiolhais, C. Atoms, molecules, solids, and surfaces: Applications of the generalized 
gradient approximation for exchange and correlation. Physical Review B 46, 6671-6687 (1992).

[69] Miehlich, B., Savin, A., Stoll, H. e Preuss, H. Results obtained with the correlation energy density functionals of becke and Lee, Yang and Parr. Chemical Physics Letters 157, 200-206 (1989).

[70] Lee, C., Yang, W. e Parr, R. G. Development of the Colle-Salvetti correlation-energy formula into a functional of the electron density. Physical Review B 37, 785-789 (1988).

[71] Runge, E. e Gross, E. K. U. Density-Functional Theory for Time-Dependent Systems. Physical Review Letters 52, 997 (1984).

[72] Bauernschmitt, R. e Ahlrichs, R. Treatment of electronic excitations within the adiabatic approximation of time dependent density functional theory. Chemical Physics Letters 256, 454-464 (1996).

[73] Runge, E. e Gross, E. K. U. Density-Functional Theory for Time-Dependent Systems. Physical Review Letters 52, 997-1000 (1984).

[74] Marques, M. A. L. e Gross, E. K. U. Time-dependent density functional theory. Annual Review of Physical Chemistry 55, 427-455 (2004).

[75] Binning Jr., R. C. e Curtiss, L. A. Compact contracted basis sets for third-row atoms: Ga-Kr. Journal of Computational Chemistry 11, 1206 - 1216 (2004).

[76] Rassolov, V. A., Pople, J. A., Ratner, M. A. e Windus, T. L. 6-31G* basis set for atoms K through Zn. Journal of Chemical Physics 109, 1223-1229 (1998).

[77] Rassolov, V. A., Ratner, M. A., Pople, J. A., Redfern, P. C. e Curtiss, L. A. 6-31G* basis set for third-row atoms. Journal of Computational Chemistry 22, 976-984 (2001).

[78] Dolg, M. e Cao, X. Relativistic pseudopotentials: their development and scope of applications. Chemical Reviews 112, 403-480 (2012).

[79] Dolg, M., Stoll, H. e Preuss, H. Energy-adjusted ab initio pseudopotentials for the rare earth elements. The Journal of Chemical Physics 90, 1730 (1989).

[80] Frisch, M. J., Trucks, G. W., Schlegel, H. B., Scuseria, G. E., Robb, M. A., Cheeseman, J. R., Scalmani, G., Barone, V., Mennucci, B., Petersson, G. A., Nakatsuji, H., Caricato, M., Li, X., Hratchian, H. P., Izmaylov, A. F., Bloino, J., Zheng, G., Sonnenberg, J. L., Hada, M., Ehara, M., Toyota, K., Fukuda, R., Hasegawa, J., Ishida, M., Nakajima, T., Honda, Y., Kitao, O., Nakai, H., Vreven, T., Montgomery, J. A., Jr., Peralta, J. E., Ogliaro, F., Bearpark, M., Heyd, J. J., Brothers, E., Kudin, K. N., Staroverov, V. N., Kobayashi, R., Normand, J., Raghavachari, K., Rendell, A., Burant, J. C., Iyengar, S. S., Tomasi, J., Cossi, M., Rega, N., Millam, J. M., Klene, M., Knox, J. E., Cross, J. B., Bakken, V., Adamo, C., Jaramillo, J., Gomperts, R., Stratmann, R. E., Yazyev, O., Austin, A. J., Cammi, R., Pomelli, C., Ochterski, J. W., Martin, R. L., Morokuma, K., Zakrzewski, 
V. G., Voth, G. A., Salvador, P., Dannenberg, J. J., Dapprich, S., Daniels, A. D., Farkas, O., Foresman, J. B., Ortiz, J. V., Cioslowski, J. e Fox, D. J. Gaussian 09 Revision A.1. Gaussian Inc. Wallingford CT 2009.

[81] Kirkwood, J. G. Theory of Solutions of Molecules Containing Widely Separated Charges with Special Application to Zwitterions. The Journal of Chemical Physics 2, 351 (1934).

[82] Onsager, L. Electric Moments of Molecules in Liquids. Journal of the American Chemical Society 58, 1486-1493 (1936).

[83] Rinaldi, D. e Rivail, J.-L. Polarisabilites moléculaires et effet diélectrique de milieu à l'état liquide. Étude théorique de la molécule d'eau et de ses diméres. Theoretica Chimica Acta 32, 57-70 (1973).

[84] Tomasi, J., Cammi, R., Mennucci, B., Cappelli, C. e Corni, S. Molecular properties in solution described with a continuum solvation model. Physical Chemistry Chemical Physics 4, 5697-5712 (2002).

[85] Tomasi, J., Cammi, R. e Mennucci, B. Medium effects on the properties of chemical systems: An overview of recent formulations in the polarizable continuum model (PCM). International Journal of Quantum Chemistry 75, 783-803 (1999).

[86] Canuto, S. e Coutinho, K. From Hydrogen Bond to Bulk: Solvation Analysis of the $n \leftarrow \pi^{*}$ Transition of Formaldehyde in Water. International Journal of Quantum Chemistry 77, 192-198 (2000).

[87] Chirlian, L. E. e Francl, M. M. Atomic charges derived from electrostatic potentials: A detailed study. Journal of Computational Chemistry 8, 894-905 (1987).

[88] Breneman, C. M. e Wiberg, K. B. Determining atom-centered monopoles from molecular electrostatic potentials. The need for high sampling density in formamide conformational analysis. Journal of Computational Chemistry 11, 361-373 (1990).

[89] Martin, F. e Zipse, H. Charge distribution in the water molecule - A comparison of methods. Journal of Computational Chemistry 26, 97-105 (2005).

[90] Coutinho, K., Georg, H., Fonseca, T., Ludwig, V. e Canuto, S. An efficient statistically converged average configuration for solvent effects. Chemical Physics Letters 437, 148152 (2007).

[91] Heinemann, F. W., Leypold, C. F., Roman, C. R., Schmitt, M. O. e Schneider, S. XRay Crystallography of Tetracycline, Doxycycline and Sancycline. Journal of Chemical Crystallography 43, 213-222 (2013).

[92] Stezowski, J. J. e John, J. Chemical-structural properties of tetracycline derivatives. 1. Molecular structure and conformation of the free base derivatives. Journal of the American Chemical Society 98, 6012-8 (1976). 
[93] Leypold, C. F., Reiher, M., Brehm, G., Schmitt, M. O., Schneider, S., Matousek, P. e Towrie, M. Tetracycline and derivatives assignment of IR and Raman spectra via DFT calculations. Physical Chemistry Chemical Physics 5, 1149-1157 (2003).

[94] Jin, L., Amaya-Mazo, X., Apel, M. E., Sankisa, S. S., Johnson, E., Zbyszynska, M. a. e Han, A. $\mathrm{Ca}^{2+}$ and $\mathrm{Mg}^{2+}$ bind tetracycline with distinct stoichiometries and linked deprotonation. Biophysical Chemistry 128, 185-196 (2007).

[95] de Paula, F. C., Carvalho, S., Duarte, H. A., Paniago, E. B., Mangrich, A. S. e PereiraMaia, E. C. A physicochemical study of the tetracycline coordination to oxovanadium(IV). Journal of Inorganic Biochemistry 76, 221-230 (1999).

[96] Duarte, H. A., Carvalho, S., Paniago, E. B. e Simas, A. M. Importance of tautomers in the chemical behavior of tetracyclines. Journal of Pharmaceutical Sciences 88, 111-120 (1999).

[97] Othersen, O. G., Beierlein, F., Lanig, H. e Clark, T. Conformations and Tautomers of Tetracycline. The Journal of Physical Chemistry B 107, 13743-13749 (2003).

[98] Barreto, R. C., Coutinho, K., Georg, H. C. e Canuto, S. Combined Monte Carlo and quantum mechanics study of the solvatochromism of phenol in water. The origin of the blue shift of the lowest $\pi-\pi^{*}$ Transition. Physical Chemistry Chemical Physics 11, 1388-1396 (2009).

[99] Jaramillo, P., Coutinho, K. e Canuto, S. Solvent effects in chemical processes. waterassisted proton transfer reaction of pterin in aqueous environment. Journal of Physical Chemistry A 113, 12485-12495 (2009).

[100] Kongsted, J., Mennucci, B., Coutinho, K. e Canuto, S. Solvent effects on the electronic absorption spectrum of camphor using continuum, discrete or explicit approaches. Chemical Physics Letters 484, 185-191 (2010).

[101] Zerner, M. C. ZINDO, A Semi-empirical Program Package (2000). University of Florida, Gainsesville, FL 32611.

[102] Neese, F. The ORCA program system. Wiley Interdisciplinary Reviews: Computational Molecular Science 2, 73-78 (2012).

[103] Aleksandrov, A. e Simonson, T. Molecular Dynamics Simulations of the 30S Ribosomal Subunit Reveal a Preferred Tetracycline Binding Site. Journal of the American Chemical Society 19, 1114-1115 (2008).

[104] De Almeida, W. B., Dos Santos, H. F. e Zerner, M. C. A theoretical study of the interaction of anhydrotetracycline with Al(III). Journal of Pharmaceutical Sciences 87, 1101-8 (1998).

[105] Aaqvist, J. Ion-water interaction potentials derived from free energy perturbation simulations. Journal of Physical Chemistry 94, 8021-8024 (1990). 
[106] Aleksandrov, A., Proft, J., Hinrichs, W. e Simonson, T. Protonation patterns in tetracycline:tet repressor recognition: simulations and experiments. Chembiochem: a European journal of chemical biology 8, 675-685 (2007).

[107] Sabbatini, N., Guardigli, M., Manet, I., Ungaro, R., Casnati, A., Ziessel, R., Ulrich, G., Asfari, Z. e Lehn, J.-M. Lanthanide complexes of encapsulating ligands: Luminescent devices at the molecular level. Pure and Applied Chemistry 67, 135-140 (1995).

[108] Maas, H., Currao, A. e Calzaferri, G. Encapsulated lanthanides as luminescent materials. Angewandte Chemie (International ed. in English) 41, 2495-2497 (2002).

[109] Celotti, M. e Fazakerley, G. V. Conformation of various tetracycline species determined with the aid of a nuclear magnetic resonance relaxation probe. Journal of the Chemical Society, Perkin Transactions 2 1319-1322 (1977).

[110] van Veggel, F. C. J. M. e Reinhoudt, D. N. New, Accurate Lennard-Jones Parameters for Trivalent Lanthanide Ions, Tested on [18]Crown-6. Chemistry - A European Journal 5, 90-95 (1999).

[111] Gaillard, C., Billard, I., Chaumont, A., Mekki, S., Ouadi, A., Denecke, M. a., Moutiers, G. e Wipff, G. Europium(III) and its halides in anhydrous room-temperature imidazolium-based ionic liquids: a combined TRES, EXAFS, and molecular dynamics study. Inorganic Chemistry 44, 8355-8367 (2005). 